\title{
Evaluation of the Organisation and Delivery of Patient Centred Acute Nursing Care
}

Paula Ormandy

Carol Haigh

Jackie Solomon

Report 13

February 2006

Salford Centre for Nursing, Midwifery and Collaborative Research

\section{Bolton Hospitals N/W}

NHS Trust

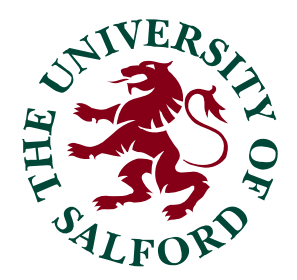


Salford Centre for Nursing, Midwifery and Collaborative Research

The Salford Centre for Nursing, Midwifery and Collaborative Research (SCNMCR) is a research centre within the Institute of Health and Social Care Research, at the University of Salford. The SCNMCR undertakes collaborative health services research to evaluate and develop nursing and midwifery practice and education.

\section{Web site address:}

http://www.research.salford.ac.uk/scnmer/SCNMCR/

\section{(C) University of Salford}

All rights reserved. No part of this publication may be reproduced in a retrieval system, or transmitted, in any form or by any means, electronic, mechanical, photocopying, recording and /or otherwise, without the prior written permission of the authors. 


\section{Evaluation of the Organisation and \\ Delivery of Patient Centred Acute \\ Nursing Care}

Report 13

February 2006

Research Team

Paula Ormandy (Research Fellow) *

Dr Carol Haigh (Senior Lecturer Research) *

*Salford Centre for Nursing, Midwifery and Collaborative

Research, Institute of Health and Social Care Research,

University of Salford

Jackie Solomon (Deputy Director of Nursing) Bolton Hospitals NHS Trust 


\section{CONTENTS}

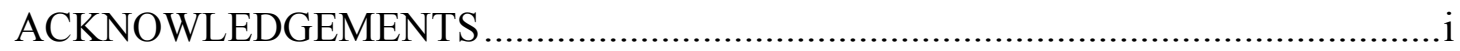

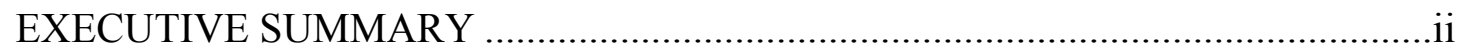

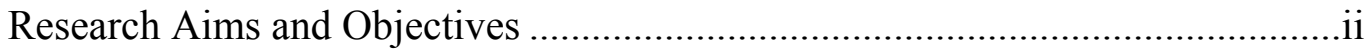

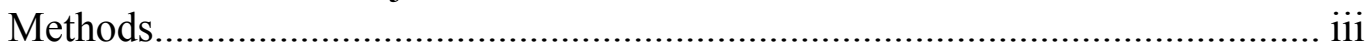

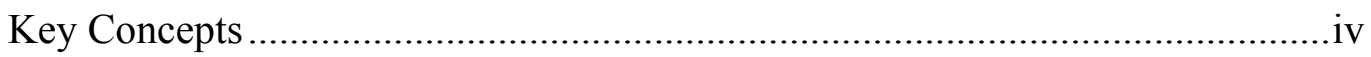

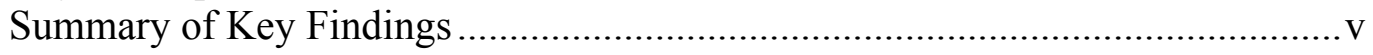

Strengths and Limitations ..................................................................... viii

Conclusions and Key Messages ....................................................................

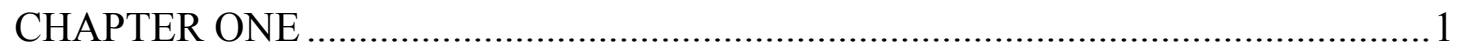

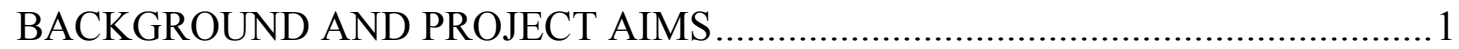

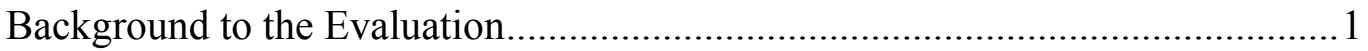

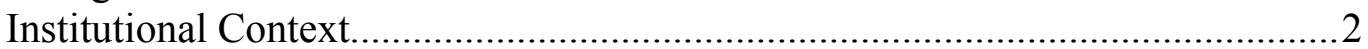

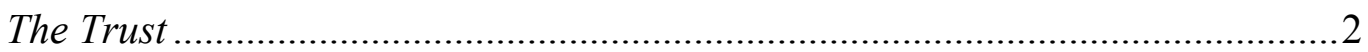

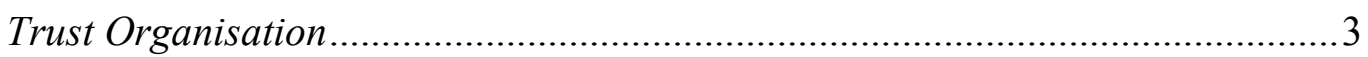

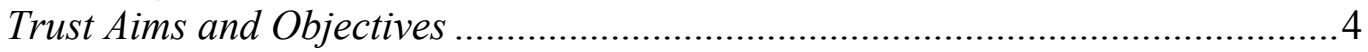

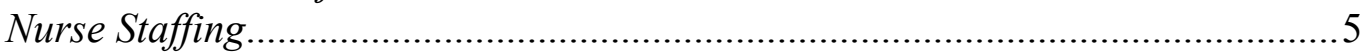

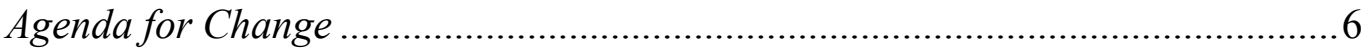

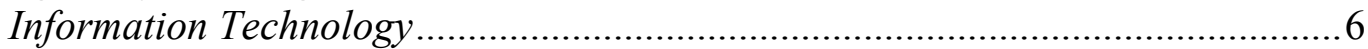

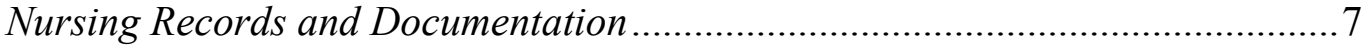

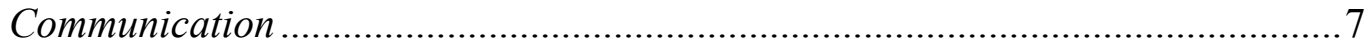

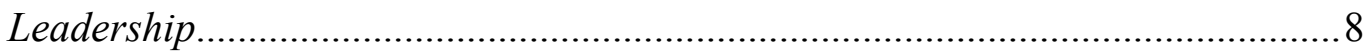

Why Evaluate the Delivery and Organisation of Nursing Care? ......................... 8

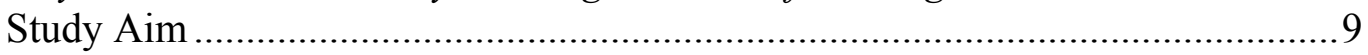

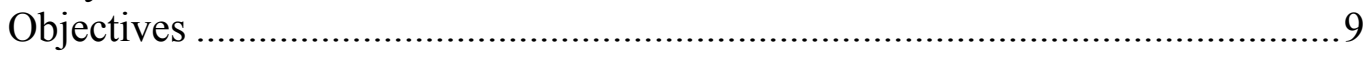

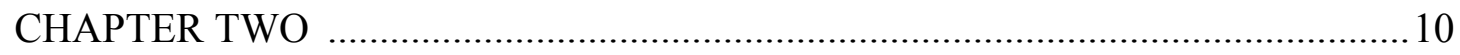

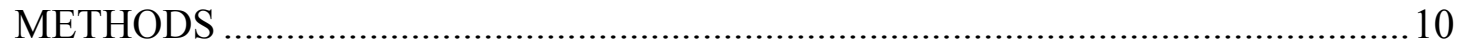

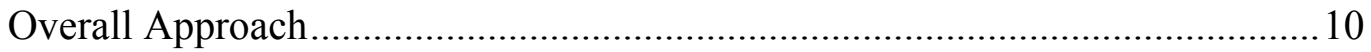

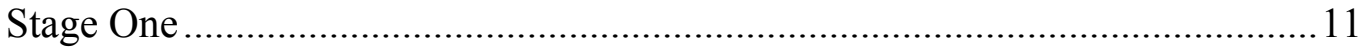

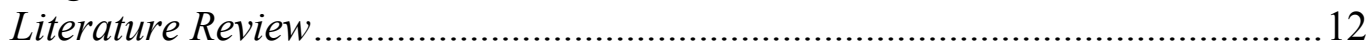

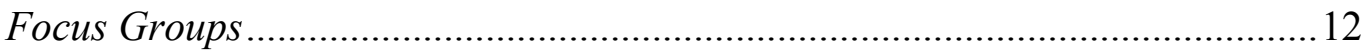

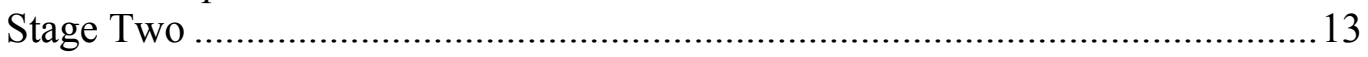

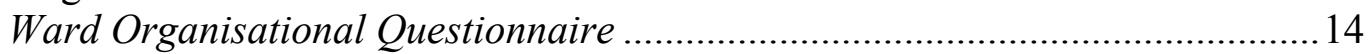

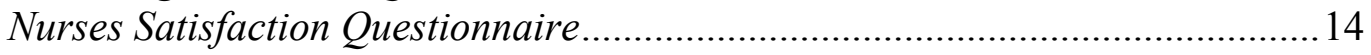

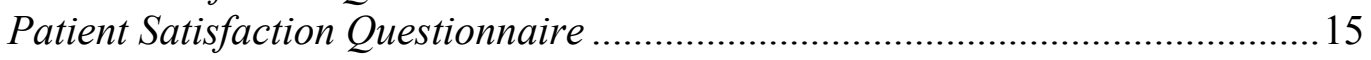

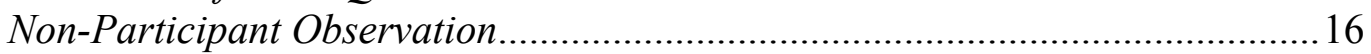

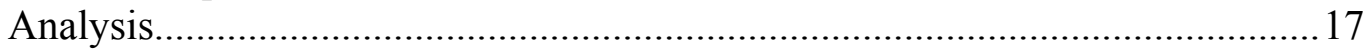

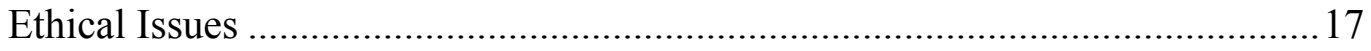

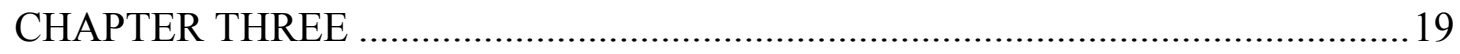

STAGE ONE - FINDINGS AND ROOT DEFINITION........................................ 19

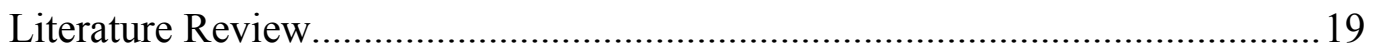




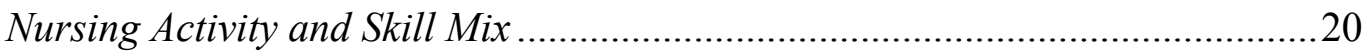

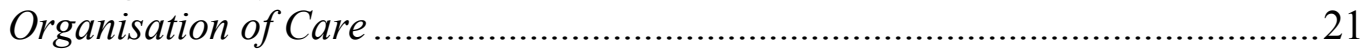

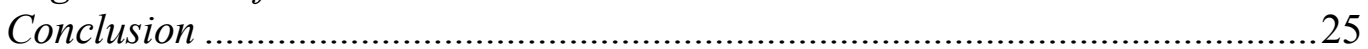

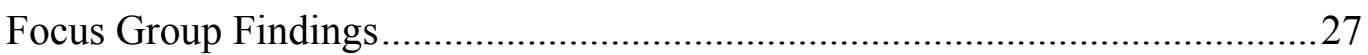

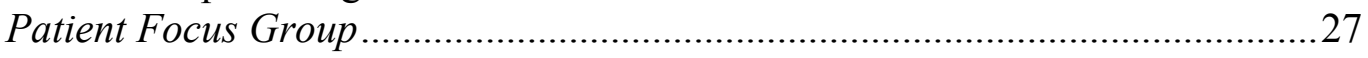

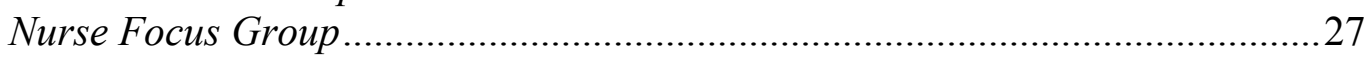

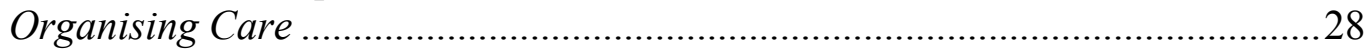

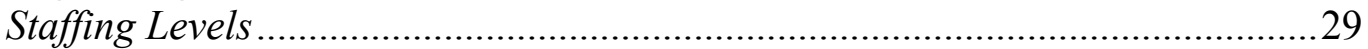

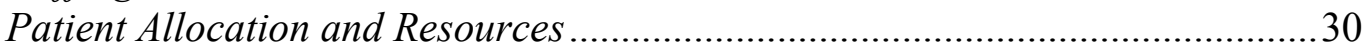

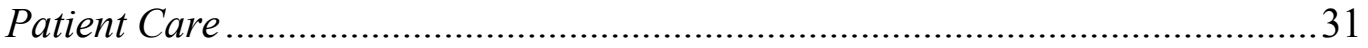

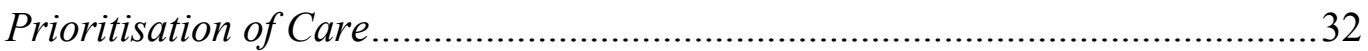

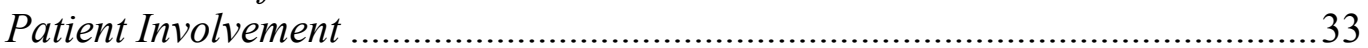

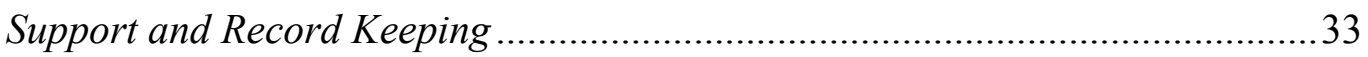

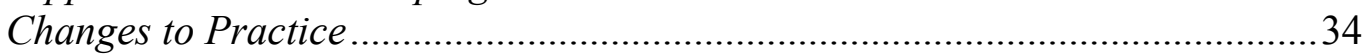

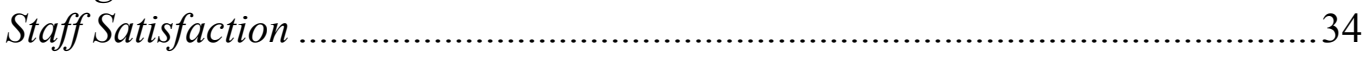

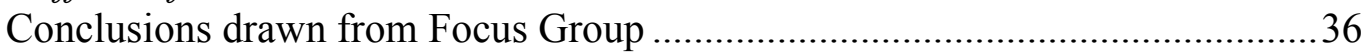

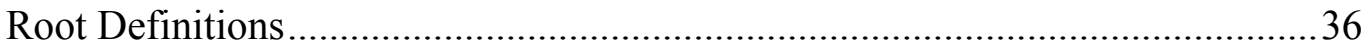

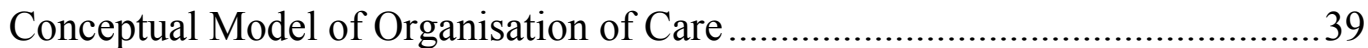

Understanding the Rich Picture ......................................................................... 40

Summary of Findings from Stage One ............................................................... 42

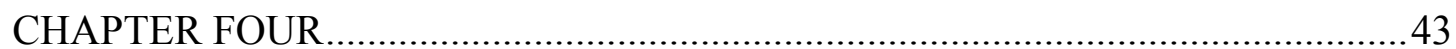

STAGE TWO - NURSES PERCEPTIONS OF PATIENT CARE ............................43

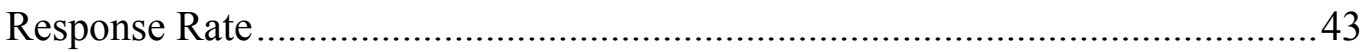

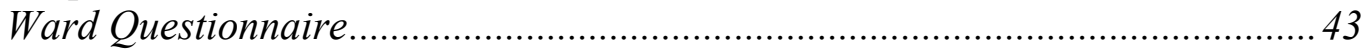

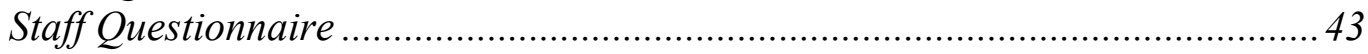

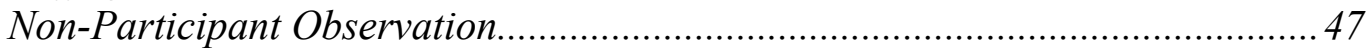

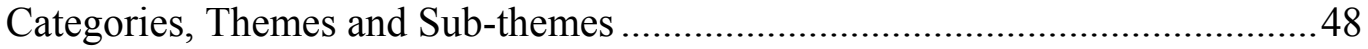

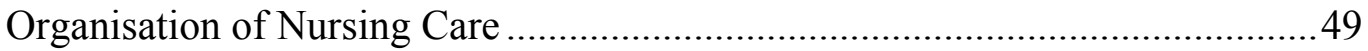

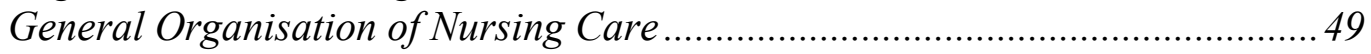

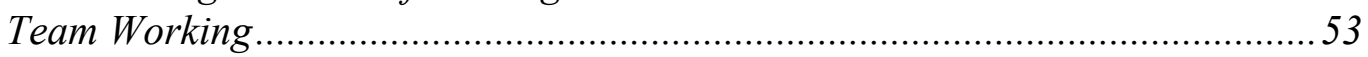

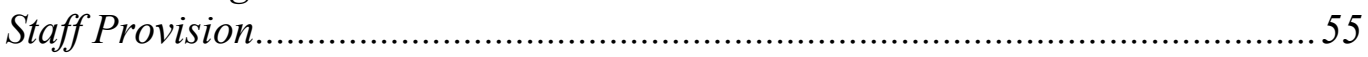

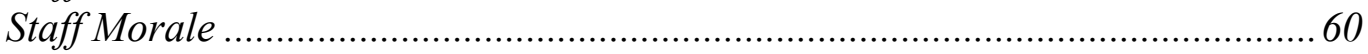

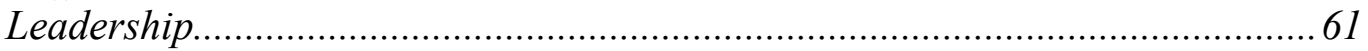

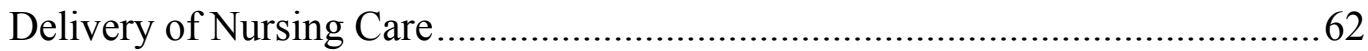

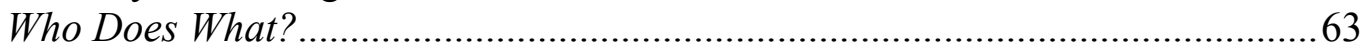

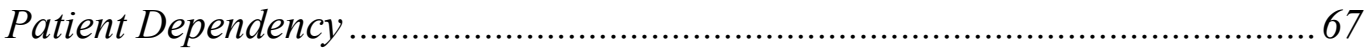

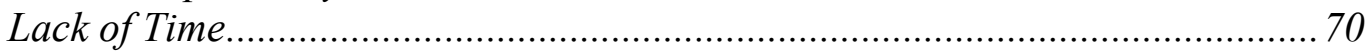

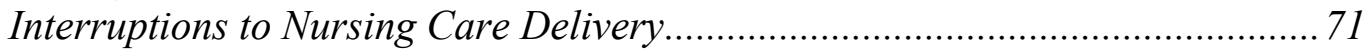

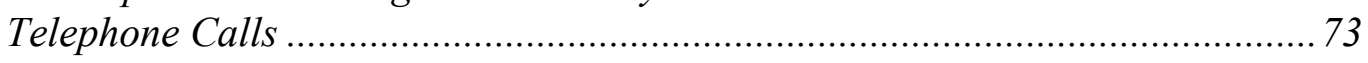

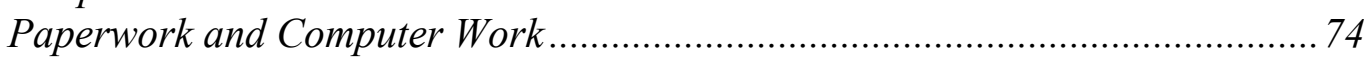

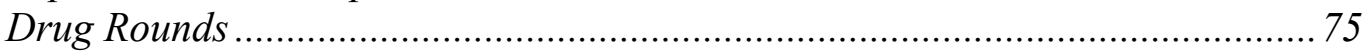

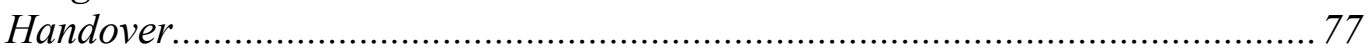

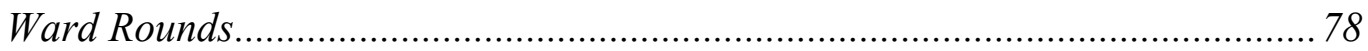

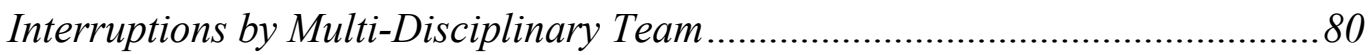




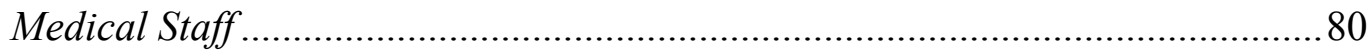

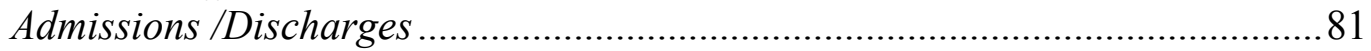

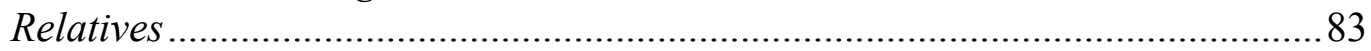

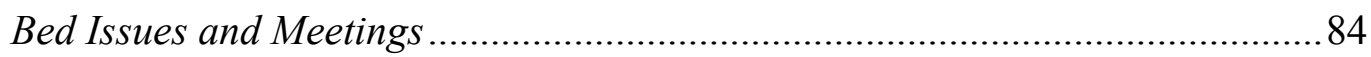

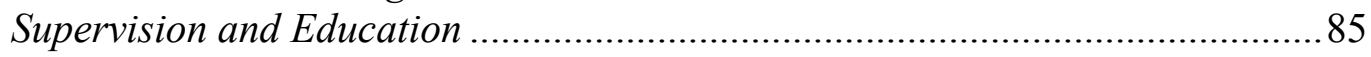

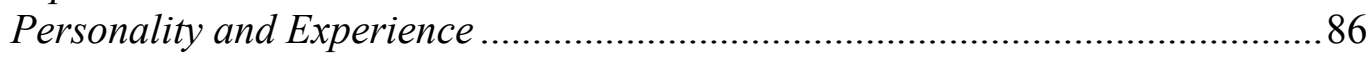

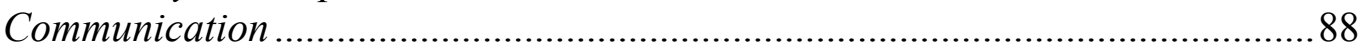

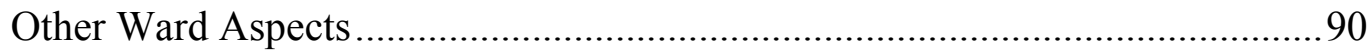

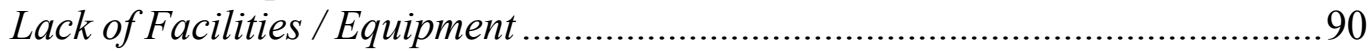

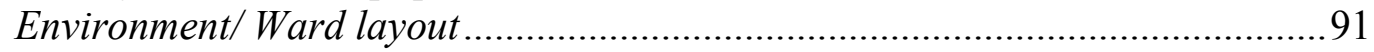

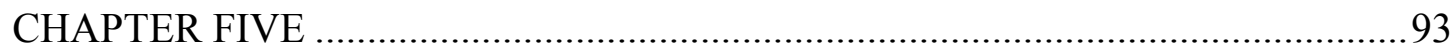

STAGE TWO - PATIENTS PERSPECTIVE OF NURSING CARE.........................93

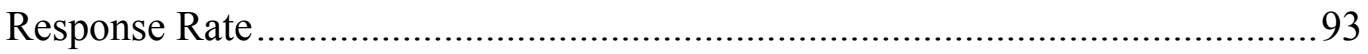

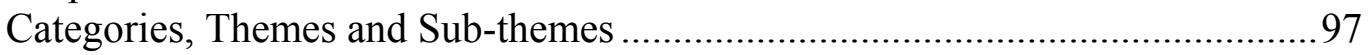

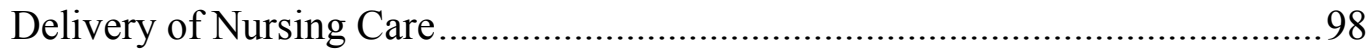

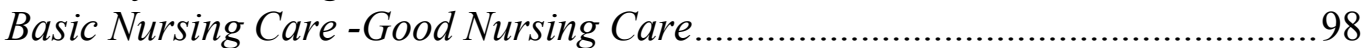

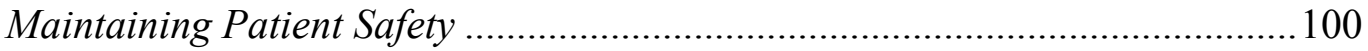

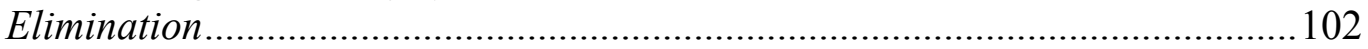

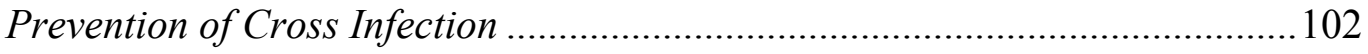

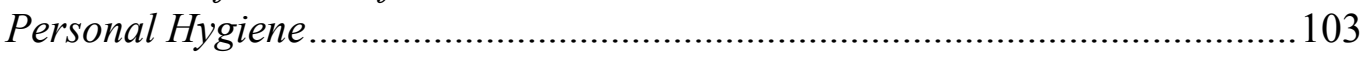

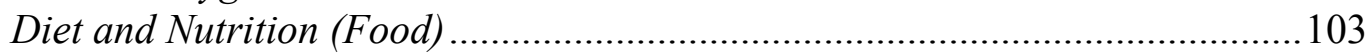

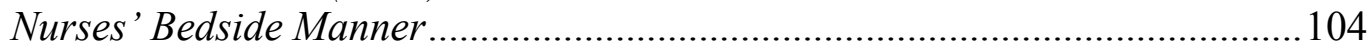

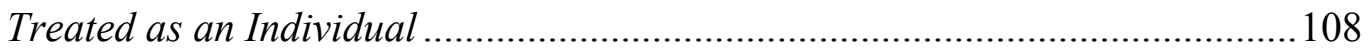

Time Taken to Care Versus Waiting for Care ................................................. 109

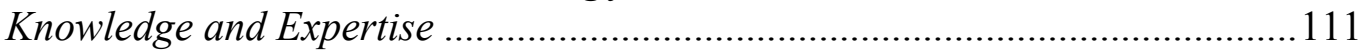

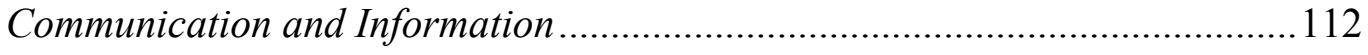

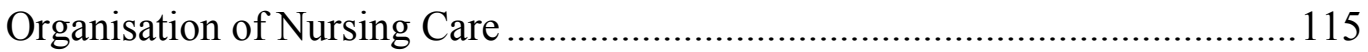

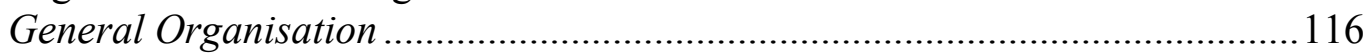

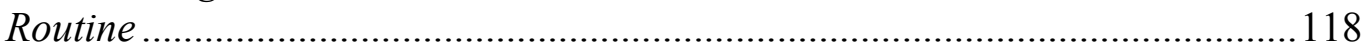

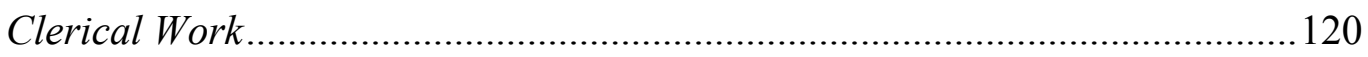

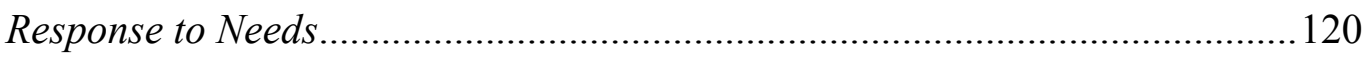

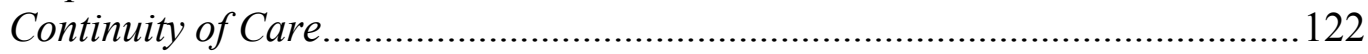

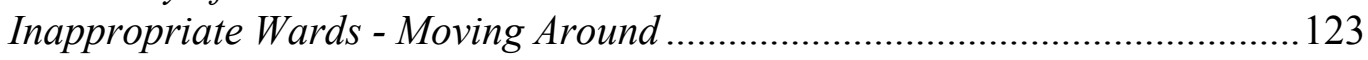

Staffing Levels, Skill Mix and Workload......................................................... 124

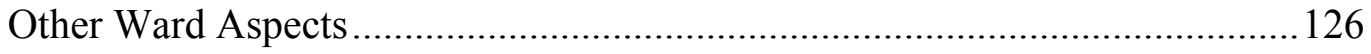

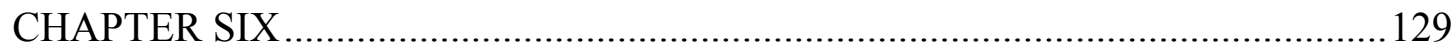

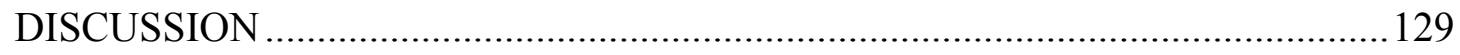

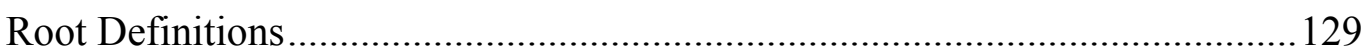

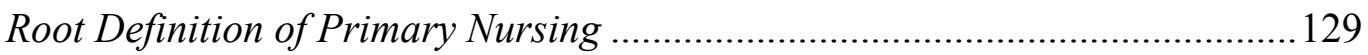

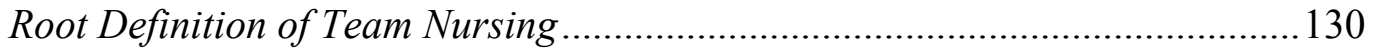

Root Definition of Task Allocation (Functional Nursing) ...............................130 


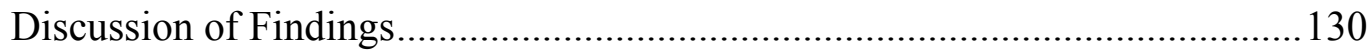

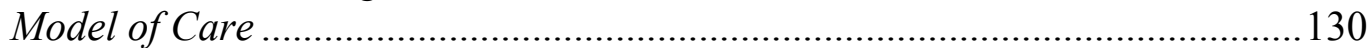

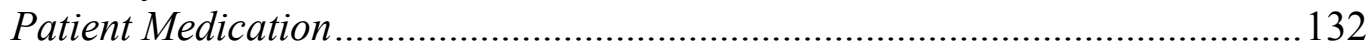

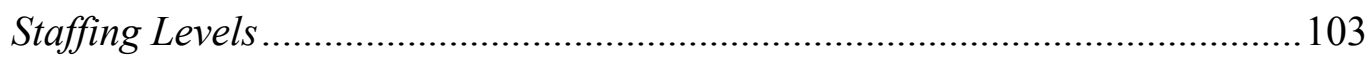

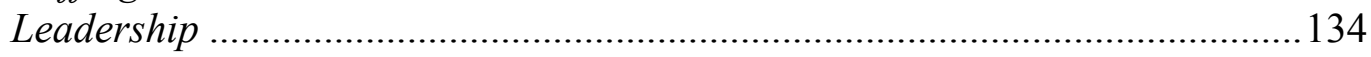

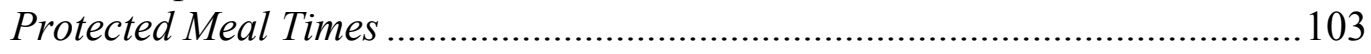

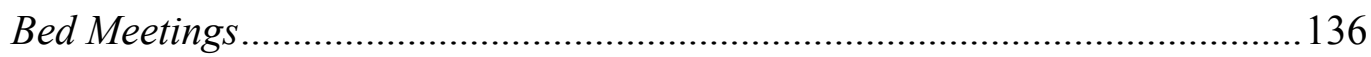

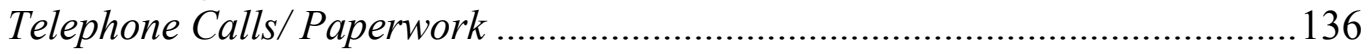

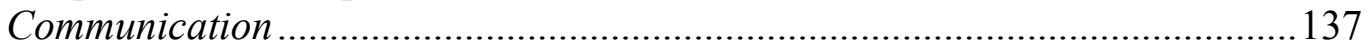

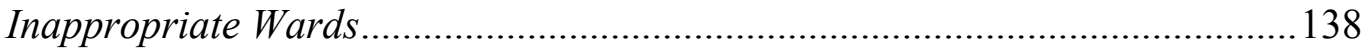

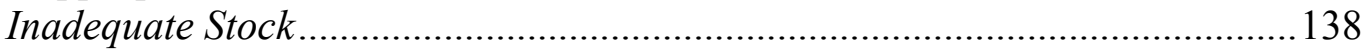

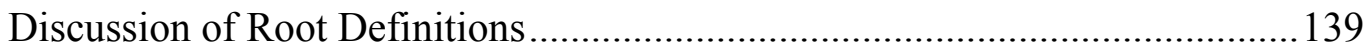

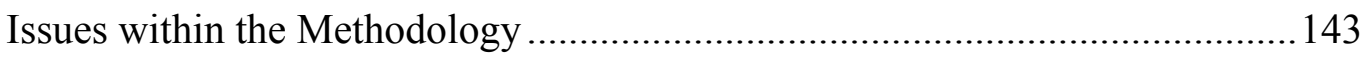

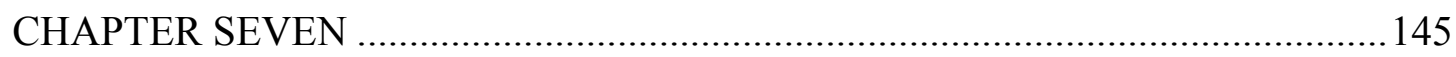

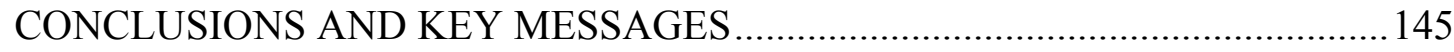

Implications for Future Research ................................................................ 146

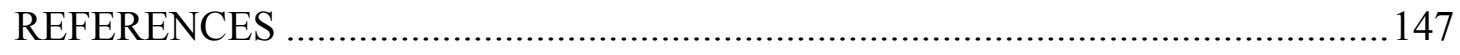

Appendix 1 Bowman \& Thompson - Classification system checklist ....................152

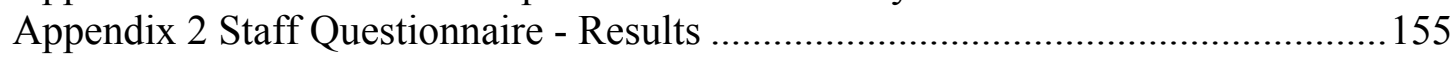

Appendix 3 Table 4.16 Activities and Tasks .......................................................... 160

Appendix 4 Complete List of Disruptive Tasks ...................................................... 162

Appendix 5 Patient Satisfaction Questionnaire - Results ....................................... 163

\section{LIST OF TABLES}

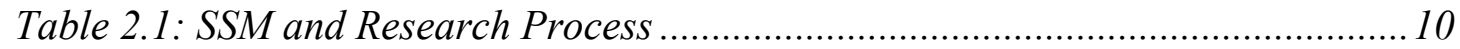

Table 2.2: Inclusion/exclusion criteria for nurse questionnaire .................................. 15

Table 2.3: Inclusion/exclusion criteria for patient questionnaire .............................. 16

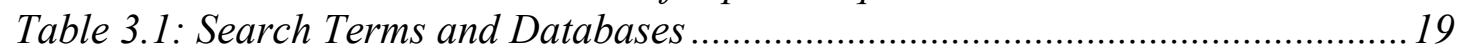

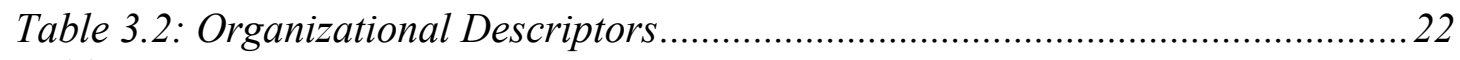

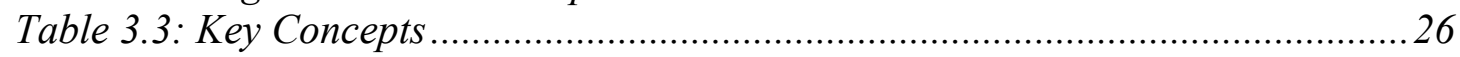

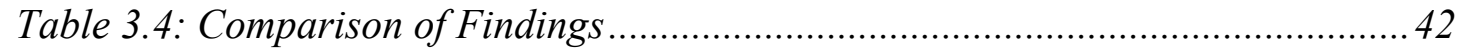

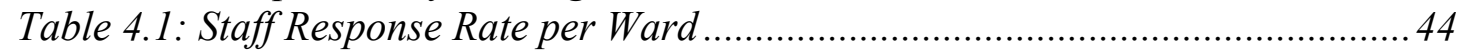

Table 4.2: Response Rate per Grade of Staff.......................................................... 45

Table 4.3: What Inhibits Care - Qualitative Comments.............................................. 46

Table 4.4 What Enhances Care - Qualitative Comments........................................47

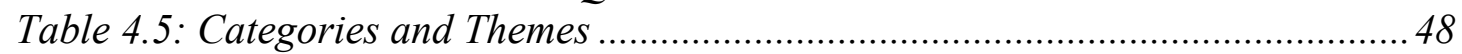

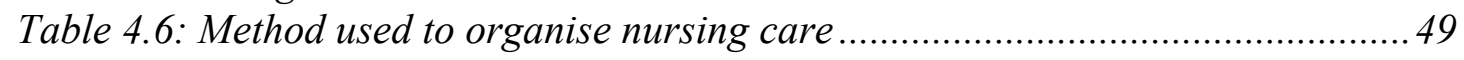

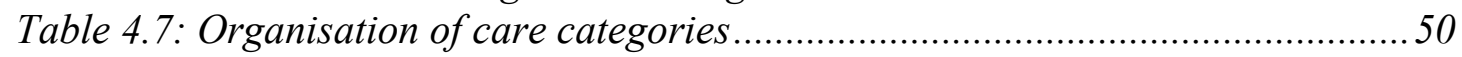

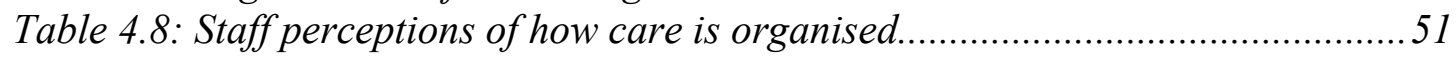

Table 4.9: Professional issues in the organisation of care ..........................................52

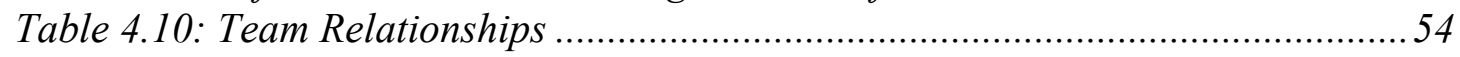

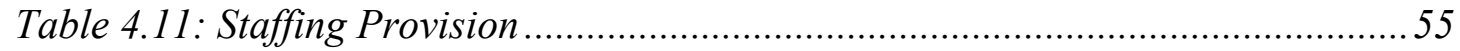




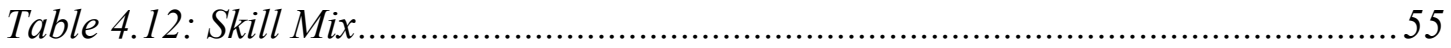

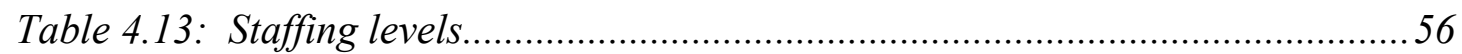

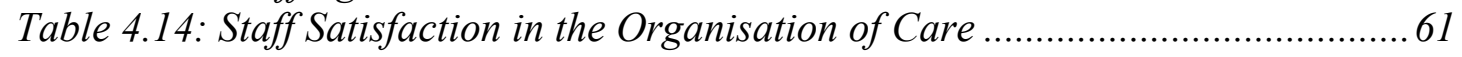

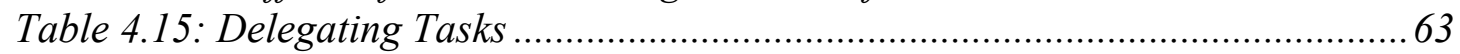

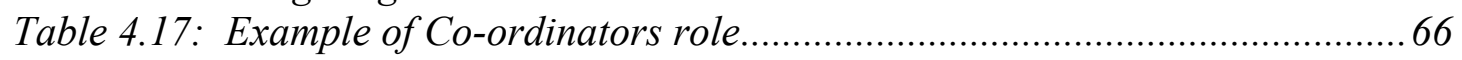

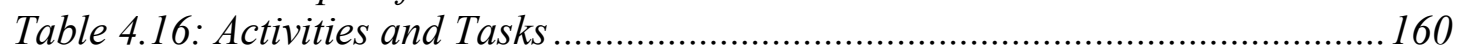

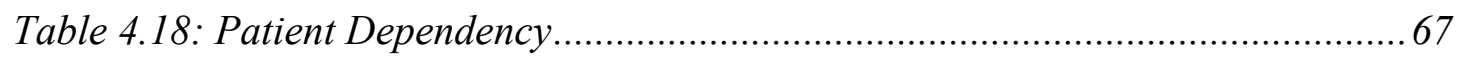

Table 4.19: Tasks which Inhibit Nursing Care Delivery ...................................... 72

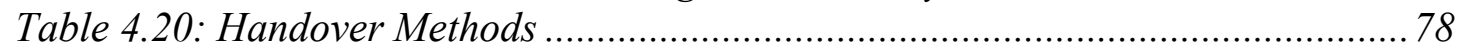

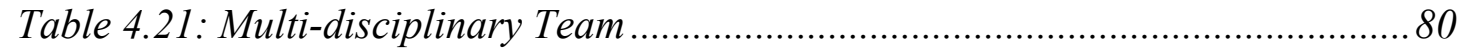

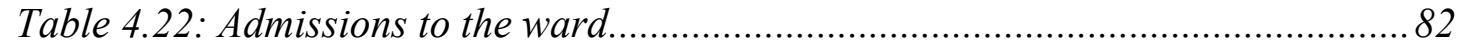

Table 4.23: Professional Attitudes to Care Delivery................................................... 85

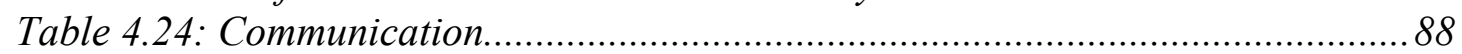

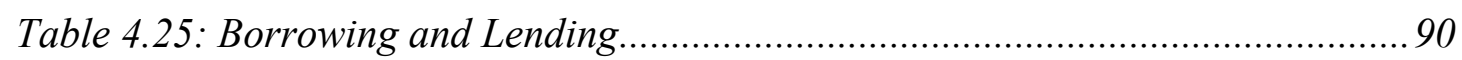

Table 4.26: Ward Layout ...................................................................................... 91

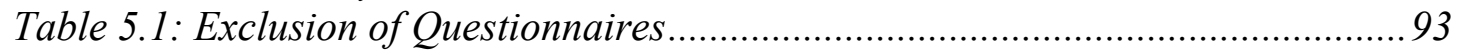

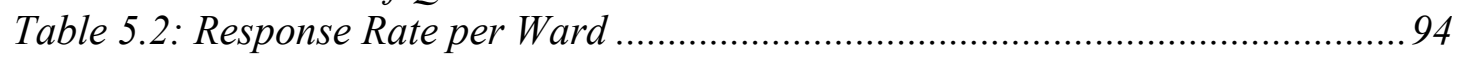

Table 5.3: Qualitative Positive Comment Response Rate .......................................... 95

Table 5.4: Qualitative Negative Comment Response Rate ........................................96

Table 5.5: Categories and Themes ....................................................................... 97

Table 5.6: Positive Key Words Used to Describe Nurses Bedside Manner .............. 104

Table 5.7: Treated as an Individual /Care Preferences ............................................ 108

Table 5.8: Waiting for care - Too busy ..................................................................... 110

Table 5.9: Patient Perception of Delivery of Information ....................................... 113

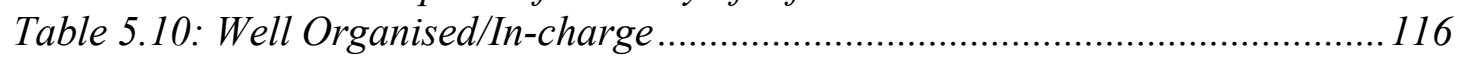

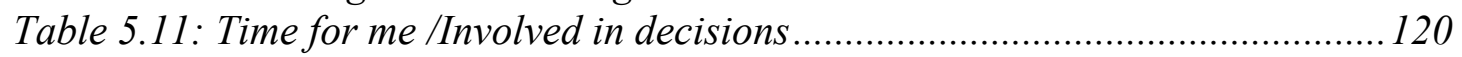

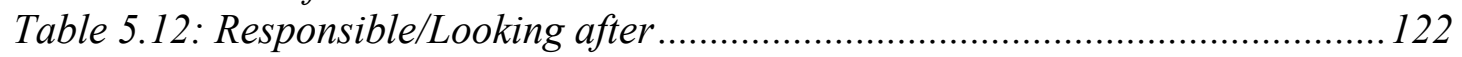

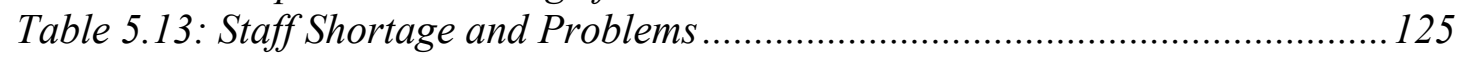

Table 5.14: Ward Cleanliness - Apposing Perspectives ........................................... 127

\section{List of Figures}

Figure 3.1: Rich Picture - Organisation of Care Concepts .......................................41

Figure 6.1: Phase 5 Soft Systems Methodology ...................................................129

Figure 6.1: Rich Picture - Influences on the Organisation of Care Concepts............. 142 


\section{ACKNOWLEDGEMENTS}

The research team would like to thank all the patients and nursing staff who participated in the research study. The time given to completing the questionnaires and attending focus groups was greatly appreciated. The staff working on the wards that were observed in the study offered a warm welcome to the researcher performing non-participant observation, for which she was grateful.

From the Trust the research team would first like to acknowledge and thank the Trust R\&D Committee for providing financial support to the project. The co-operation of Graham Fullerton from the Trust Information Department was pivotal to obtaining the appropriate patient information and for his help we are very grateful. Similarly thanks go to Hemlata Fletcher (Access \& Equality Manager) for advising and guiding the researchers to ensure ethnic minority groups had equal opportunities to participate in the research study.

Thanks also to Allison Barnes, Research Secretary (University of Salford), who assisted with the transcription and data organisation given the volume of work the study produced.

A final acknowledgement goes to Professor Brendan McCormick who peer reviewed the developing research protocol and provided advice on issues that resulted in a stronger study being developed. 


\section{EXECUTIVE SUMMARY}

In 2002, a team of researchers from the School of Nursing, University of Salford were commissioned by Bolton Hospitals NHS Trust to evaluate the delivery and organisation of patient-centred nursing care across the acute nursing wards within the Royal Bolton Hospital.

The key driver for the commissioning of this study arose from two serious untoward incidents that occurred in the year 2000. Following investigation of both these events the Director of Nursing in post at that time believed that poor organisation and delivery of care may have been a contributory factor. Senior nurses in the Trust had also expressed their concern that care may not be organised in a way that made best use of the skills available.

\section{Research Aims and Objectives}

The aim of the research was to evaluate the organisation and delivery of nursing care and the effective use of staff skills/resources on acute wards within Bolton Hospitals NHS Trust. The study had five specific objectives:

- To compare and contrast the systems used with the current literature

- To identify the experiences and perceptions of patients and staff to understand the wider context and focus of the study

- To identify and develop a baseline of the organisation and delivery systems utilised within all the acute wards

- Describe the organization and nature of staff activity

- To identify the staff and patient perceptions of the delivery and organisation of care and the use of their individual skills 


\section{Methods}

The evaluation utilises Soft Systems Methodology (SSM) to provide a framework for the research process. This method facilitates the development of a theoretical model and identification of concepts which in this case refer to the organisation and delivery of nursing care. To take this one step further the theoretical model can then be compared and contrasted with the reality of organising and delivering patient care within a busy trust. A combination of qualitative and quantitative methods was applied in two stages to address the research objectives.

Stage One - identified the key concepts to organising and delivering nursing care from within the literature. Staff and patient perceptions were sought through focus groups to gain an initial overview and ensure the data collection tools utilised in stage two were appropriate.

Stage Two - utilised three data collection instruments (questionnaires) to generate a deeper understanding of the nurses and patients perceptions of how nursing care was organised, delivered, what hindered and enhanced care and what specifically did the patient like and dislike. One questionnaire was administered to the ward manager to gain an insight into the model of care that determined how nursing was organised. Non-participant observation of a selection of study wards confirmed findings.

Quantitative data was analysed using SPSS for Windows and qualitative responses was captured and analysed using a thematic approach. Approval for the study was obtained from Bolton Local Research Ethics Committee and Bolton Hospitals NHS Trust Research Governance Committee. All participants were provided with an information sheet. Written consent was obtained from the focus group participants and patients responding to the questionnaire (as recommended by the ethics committee). Consent was presumed from nurses who returned completed questionnaires. Verbal consent was obtained from both patients and nurses prior to non-participant observation. 


\section{Key Concepts}

Organisation of care was defined as: A system owned and operated by health care staff which aims to provide high quality care to patients and is impacted upon by collegial and institutional pressures, patient experiences and expectations and which can affect the autonomy, professional growth $\&$ relationships and job satisfaction of nurses.

How much independence nurses have in organising their care (autonomy) ${ }^{1}$ contributes to the amount of cross-disciplinary working they participate in (collaborative working). Melchior et al. (1999) note that nurses who are autonomous are more likely to find collaborative working achievable, this in turn contributing to how work is organised in the clinical area (systems of organising work). Whilst it is acknowledged that staff resources (Adams and Bond, 1997), the strain of meeting collegial pressures in terms of support and supervision of junior staff (McKenna, 1995) and the demands and expectations of the institution (institutional pressures) can affect how care is organised (systems of organising work). Mäkinen et al. (2003b) suggest that job satisfaction is impacted upon by all of the elements incorporated in the organisation of care. However, Boumans and Landeweerd (1999) suggest a correlation between all of these factors and work related stress. Therefore the 'ideal' model for nursing care is seen as a multi-factorial concept which can contribute to the well-being and job satisfaction of the practitioner as well as ensuring high quality care for patients.

From a patient perspective, literature would suggest that family influences contribute to the overall patient experiences (Aharony and Strasser, 1993). As do individual expectations (Staniszewska and Ahmed, 1999) and psychological aspects such as fear and previous experiences (Larsson, 1999). Unfortunately, the lack of patient involvement in Stage One prevented the comparative analysis between the 'ideal' model for the organisation of nursing care and the patients' perspective at this stage.

\footnotetext{
${ }^{1}$ Italics refer to elements identified in the rich picture
} 


\section{Summary of Key Findings}

- The overall model of organisation of care in the acute wards of Bolton NHS Trust is that of team nursing, with a small minority organising care by way of task allocation.

- It was clear from the results obtained that the majority of patients were satisfied with the organisation and delivery of their care with the total number of positive comments outnumbering negative ones across most wards. There was an indication of polarisation of patient experience, with some wards being seen as efficient and effective in the delivery of their care whilst others attracted more negative comments.

- The overall opinion of the patients who responded was that, regardless of mode of organisation, the wards were well run. Nonetheless there were a minority of patients' who felt that the organisational practices of the ward required some improvement.

- Problems with receiving timely and appropriate prescribed medication featured prominently in the negative patient comments received. A medication locker by the patient's bedside was seen as good practice. However there was a clear requirement for better stocking procedures and for the pharmacy to improve the service they provide at weekends. There was a lot of time wasted by the ward staff on searching for drugs.

- Effective use of the ward co-ordinator to check all IV's each morning to avoid encroaching on the time of other qualified staff was a further aspect of good practice. In addition, the trial method of administration of one particular medicine (Oromorph) by one qualified nurse rather than two is commendable as an effective and efficient use of nursing time. 
- On the whole nursing care was positively appraised and patients found the majority of staff to be helpful kind and caring. However, reports of poor levels of basic care, in some cases, were directly attributable to staff having to prioritise care as a result of staff shortages. Linked to this point was negative staff manners reported by a small number of patients but not actually observed on any of the wards. Abrupt or rude behaviour can also be a result of excessive pressure of workload for staff.

- Both patients and staff acknowledged that the issue which has the biggest impact upon both the organisation and delivery of care is staffing levels. The patients perceived the wards as short staffed and often cited night time as an area of particular concern.

- Patients and nurses spoke of the use of bank/agency staff as a barrier to the provision of good care since such staff were seen as transitory in nature and disadvantaged in that they did not know the ward or the patients in the way that the permanent staff did.

- There was evidence on a small number of wards, both from staff comments and through the observation that effective leadership was occurring within the coordinator role. On those wards where the co-ordinator role was compromised through reduced staffing levels the leadership was limited and often reduced to 'fire-fighting' ward problems or consumed by administrative duties.

- The leadership from the nursing staff needs to be more visible when it comes to the organisation of doctors ward rounds. It was observed, that at present, many ward rounds took place at times when activity on the ward is excessive and the nurses have other priorities.

- Good practice was witnessed on wards that instigated 'respected' meal times for patients where visitors and medics were not allowed on the ward or to disturb patients, or patient tests were not performed. 
- Observations highlighted that bed meetings were listed as a disruptive task and were a draw on the co-ordinators time (or staff nurses). They were expected to leave the ward and hand over bed status when they could be doing more on the ward to help with patient care. During observation periods it was noted that many co-ordinators didn't attend bed meetings as they were too busy.

- Quantitative data identified that dealing with telephone calls was the most disruptive task closely followed by excessive paperwork. Patient comments supported the repetitive nature of the paperwork and that nurses' time could be used more effectively.

- The Trust computer system caused delays in obtaining patient information and much of the information is collected many times which leads to unnecessary repetition of work and documentation. Observation highlighted either difficulties accessing the system or repeating paper based information onto the computer system.

- The referral process and the chasing up of referrals to other agencies was a feature noted in the observation periods that was a significant draw on nurses' time. The use of existing paperwork instead of copying information and the confirmation of receipt of the referral by the ward clerk could improve this issue in the short term.

- Taped handover appeared less effective than verbal handover for facilitating discussion and allowing clarification of patient progress and care. In the small cases observed taped handover did not appear to save any time and the research suggests that verbal handover could be a more effective communication tool.

- The use of the printed patient communication sheets (providing a summary of each patient) were good practice and were seen to be used effectively by all the multi-disciplinary team.

- Ward staff expressed concern and worried about the quality of care provided to 'inappropriate' patients admitted to wards that were not equipped to nurse their 
particular speciality. Patients commented on a 'bed shortage' and this along with determining which patients were admitted to which ward was not within the control of the nursing team.

- There was clear evidence of a borrowing and lending culture across the wards. From the comments provided by the nurses and the patients, reinforced by the observation of activity there were problems with the lack of stock items, such as drugs, dressings and linen items (theatre gowns, blankets and linen bags). The result of not having available items led to heightened dissatisfaction, time wasting trying to locate an item on a different ward and stress due to the delays placed on the delivery of patient care.

\section{Strengths and Limitations}

The data collection in this study was informed by a number of methods. Efforts were made to obtain in-depth data from both staff and patients by holding two focus groups at the beginning of the study. Unfortunately response was limited. No patients managed to attend the focus group and only a restricted number of Trust staff members were able to participate in the staff focus group. Response rates to the questionnaires were low both for staff and for patients. Although response rates for questionnaires are often lower than for other data collection methods, the potential for bias must be acknowledged since a majority of both patients and staff are unrepresented.

The observational element of the study was seen as contributing concept validity in that it allowed for the experiences and opinions reported by staff and patients to be corroborated in the clinical environment. The observation was carried out by one member of the research team which could potentially imply a degree of bias in terms of incidents observed. However the use of observation, triangulated with the other methods used helped to reduce that threat. 
The underpinning framework for analysis which supported these data collection methods was Soft Systems Methodology as described by Checkland and Scholes, (1992). This approach proved to be useful in terms of focussing the problem, defining what different approaches to organising nursing care mean and developing an overview of the elements and impacting factors that make up organisation and delivery of care. A weaker element of SSM as a theoretical framework was, however, that it proved limited on offering structure to the delivery of nursing care.

\section{Conclusions and Key Messages}

When comparing the reality of organisation and delivery of care within Bolton NHS Trust with the key concepts identified from the literature it was clear that some of the elements played a bigger part in the management of acute care than others. For example, staffing issues were at the forefront of both the staff and patients perspectives. Institutional directives added to the pressure on the nursing staff to realise the organisational agenda alongside delivering quality patient care. There was a dichotomy between the clinical autonomy of the staff which they acknowledged and the apparent lack of managerial autonomy. Ward rounds need to be organised when it is appropriate for the nurses and the medical staff and promoting a more collaborative working environment. The amount of ownership that nurses have upon the organisation of the care they provide is strongly affected by the demands of other health care professionals and the administrative demands both of the ward environment and the overall organisation.

Whilst patient responses were favourable on the whole, some patients felt that elements of their care could have been significantly improved. Issues that are a threat to personal integrity, such as slow delivery of hygiene related care or late delivery of care were the main cause of patient dissatisfaction. Concerns expressed by a minority of patients regarding the attitudes of staff maybe allied to the pressures of work. In conclusion, although the majority of users of the Trust services are satisfied with the care they receive and staff morale is generally good there are areas for improvement, notably amongst experienced staffing levels. 
The evaluation examined how nursing care was organised and delivered from the perspective of both patients and staff. This provides the Trust with a benchmark from which to develop more patient-centred care. For the future, this work could be built upon by the use of a rigorous time and motion study to provide insights into exactly what nurses do, for who and for how long. 


\section{CHAPTER ONE \\ BACKGROUND AND PROJECT AIMS}

This chapter describes the background and rationale of the study. It is important to understand the institutional context in which the study was located and from where it originated to fully comprehend the research findings that emerged. Therefore an overview is provided alongside the project aim and objectives.

\section{Background to the Evaluation}

Over the past 30 years the literature has been replete with articles, books and monographs devoted to the topic of nurse staffing. With few exceptions the answer to the question of how to identify the "right" level of staffing, has been the implementation of patient classification systems, or more appropriately entitled, nursing workload measurement systems. Use of these systems promised a more 'scientific' approach to replace the subjective (and thus considered biased) judgement of the nurse. There was also an underlying assumption that such systems would lead to efficient utilisation of nursing resources. However, even now little attention has been paid to the fact that a significant portion of nurses' time continues to be spent in non-direct patient care activities many of which do not utilise their skills and knowledge of nurses.

With the continued rapid change in the complexity of both care required and the settings where that care is provided, it is questionable that such systems can provide accurate long-term staffing information. The various instruments used in the UK have not been adequately tested. It maybe time to refocus on the evaluation of nursing practices to yield information on the efficacy of nursing care. Research related to staffing predictions would seem less important than that which focuses on the costs and outcomes of care. 
Dependency has been seen as a useful tool for measuring the numbers and type of nursing staff required to meet the needs of those individuals in their care (Gibbings, 1995). However, often the concept of quantity rather than quality of care is uppermost and dependency has to be viewed as a compromise solution at best (Needham, 1997). One of the obvious assumptions is that the activities undertaken by nurses are appropriate and that they result in an acceptable standard of care (Balogh, 1992). What nurses do depends more on the number of nurses available and hence the time at their disposal rather than the dependency of the individual patients (Chang et al., 1998). There is some evidence also, that suggests job satisfaction and quality of care can be linked to the manner in which nursing work is organised (Johansson et al., 1994) A useful method of analysing the system of care delivery comprehensively is via soft systems methodology (Checkland, 1991). This promotes a wider perspective of contemporary nursing, and means that nursing activities such as environment and personnel management can be evaluated as well as direct patient care delivery. This comprehensive approach allows the wider questions surrounding the structures and processes of care and the outcomes for patients, for their relatives and for nursing practice to be addressed (Balogh, 1992).

\section{Institutional Context}

\section{The Trust}

Bolton Hospitals NHS Trust was formed in April 1994 to serve the population of Bolton (around 270,000) plus some neighbouring areas. The Trust is performing well overall, but has not quite reached consistently high standards (CHI website 2003). A significant majority of the Trust's services are based at the Royal Bolton Hospital in Farnworth, in the South West of the Bolton Borough which was the site of this study. This main site employs over 3,500 staff and has a budget of approximately $£ 120 \mathrm{~m}$ (http://www.boltonhospitals.nhs.uk).

The Royal Bolton Hospital is an acute district general hospital and one of the busiest emergency hospitals in Manchester, drawing patients from a wider area than the 
boundaries of Bolton. The Trust has close academic links to the Universities of Salford, Bolton and Manchester.

\section{Trust Organisation}

The Trust provides the following services:

- Accident and Emergency care

- General Surgery

- Specialist Surgery

- Acute Medical Care

- Maternity and Obstetrics

- Children's Services

- A full range of diagnostics \& therapy services supporting the above

At the time of the study the Trust had 6 clinical directorates grouped by major speciality. This study focused on three of those clinical directorates.

Each clinical directorate was headed by a Clinical Director, in most cases this was a doctor, Directorate Manager and a Head of Nursing Service (the most senior nurse). Although in three of the Directorates the Head of Nursing Service and Directorate Manager post was amalgamated. The Head of Nursing was supported by modern matrons, the number of which varied according to the size of the directorate and number of specialties.

During the life of the project there was a major change in board level executive directors. The Director of Nursing left the Trust to take up a similar position in another Trust. A new Director of Nursing joined the Trust in late 2003. In 2004 there was a further change to the senior management team as a new Chief Executive took up post. During 2005 a consultation took place on options for the reorganisation of the management structure and formation of a divisional structure. This was known locally as 'Fit for the Future' (Bolton Royal Hospitals NHS Trust, 2005a). For staff at ward 
level, in some areas, this meant a change in their senior management team and subsequently to whom they would directly report.

The Trust recognises that health care is rapidly changing and that the hospital will be a very different place in the next five years and it was important that the management structure was best placed to meet the needs of the local population and national agenda. In order to deliver this agenda the Trust was reorganised into four clinical divisions during 2005. Accordingly, the Trust recruited new people into key leadership positions.

\section{Trust Aims and Objectives}

The Trust recently consulted on its 'Vision and Strategy' (Bolton Royal Hospitals NHS Trust, 2005b) within which they identify three key aims, these are:

- To provide best possible care to ensure services are safe and effective, there when they are needed, are provided efficiently and without waste and most importantly they focus on what matters to patients.

- To improve the health of Bolton, respecting the needs of our patients beyond just their physical needs, and making sure that we work together with other services to get it right for patients.

- To create a good working environment where staff are clear about what they are expected to do, are encouraged to learn and develop, can exchange views honestly and are supported to make changes which make it better for patients.

The Trust has identified five goals that they propose to focus on over the next five years:

- To be a provider of emergency care of the very highest quality 
- To provide a range of leading services for patients who need planned diagnostic tests or treatments, without long waits

- To be a centre of excellence for the care of women, children and babies

- To work with health professionals in the community to see that patients have first rate care in and out of hospital

- To be a leader in providing hospital care that is safe and of the highest standards and provides value for money

During the early part of 2005 it was not uncommon in the Trust for medical patients to be nursed on surgical wards. In order to meet the Department of Health target of $98 \%$ of patients seen in accident and emergency to be admitted to a bed within 4 hours, services were reconfigured and admission and discharge processes redesigned and improved. As a result the Trust is now able to achieve $98 \%$ on a regular basis.

\section{Nurse Staffing}

In 2000-2001 the Trust took part in the Audit Commissions work 'Making best use of ward staffing resources' (Audit Commission, 2001). This project benchmarked the nurse staffing in Bolton against similar Trusts and wards nationwide. The results revealed a high use of temporary staff and the need to review skill mix. Following publication of the results the Trust launched an initiative locally know as 'New Deal for Nurses' (Bolton Royal Hospitals NHS Trust, 2004). The aim of which was to improve nurse staffing levels to be in line with benchmarked trusts and reduce reliance on temporary staffing. The skill mix was reviewed on each ward and department over a period of 2 years. Ward sisters and matrons were consulted on appropriate staffing and revised staffing establishments agreed and implemented at a cost of $£ 1.5$ million. Action is being taken to reduce the unacceptable levels of sickness and absence which is considered the main reason for the increased use of temporary staff (Bolton Royal Hospitals NHS Trust, 2004). 
The Commission for Audit and Inspection (2005) undertook another review of Ward Staffing in 2005. The results of this work revealed a comparable but a richer skill mix than other trusts. This is significant when considering the impact of this on income under the 'Payments by Results' (DoH, 2006a; DoH, 2006b) system and further discussions are being held with ward sisters and managers to remedy the situation.

The Trust, like any other, uses both bank and agency staff to cover shortfall in staffing. In order to control spiralling costs the preference is to use bank staff before resorting to agency staff. The Trust has its own nurse bank and of those staff that are registered on the bank all but approximately 100 are permanent members of staff employed by the Trust.

\section{Agenda for Change}

Agenda for Change (DoH, 2006c) is the term used for the nationally agreed system of pay. During 2005 all jobs within the NHS other than those of Executive Directors were subject to evaluation. This was undoubtedly a time of concern for nurses and specifically those who had previously experienced clinical grading in the 1980s.

\section{Information Technology}

The Trust is committed to using information technology to provide real time data on patient activity and outcomes. Staff have access to computers in the work place for access emails, the Intranet to access information on Trust activity, Trust Board papers and policies, procedures and guidelines, and where appropriate patient records and results of pathology investigations. Staff members also have access to the Internet and North West NHS Libraries facilities via Aditus. Staff on the wards use computers on the wards to admit, transfer and discharge patients. This is important as it can provide real time data for bed management and patient activity. Nursing staff also use computers to plan the nursing care for the patient (Crescendo). ${ }^{2}$ Information on

\footnotetext{
${ }^{2}$ Crescendo is the trade name for the computerised care planning software used by the Trust. It consists of a library of evidence based core care plans from which staff can choose and personalise depending
} 
staffing activity is recorded using a professional judgement workload methodology known as 'Teamwork' ${ }^{3}$ in the computer.

\section{Nursing Records and Documentation}

Nurses record nursing care using both information technology (Audit Commission, 2001) and a paper record. The assessment is recorded in the patient's nursing paper record and the plan of care is then created on the computer. Finally the patient's progress, evaluation of care and any communication is recorded in the patient's nursing notes. The Trust has implemented, in some areas, a collaborative patient record to which all disciplines involved in the patient's care contribute.

\section{Communication}

All staff access to the Trust intranet site which communicates regular newsletters and team briefings. The Chief Executive regularly distributes a personal newsletter to all staff members via email. A café session is held every two weeks to which all staff members are invited. Current developments and consultations are discussed at these sessions and it provides an opportunity for staff to raise questions to senior managers and executive directors.

Since 2003 the current Director of Nursing has met twice a year with ward managers and team leaders. These meetings provide an opportunity for all ward managers and team leaders to hear at first hand the key messages from the Chief Executive, Director of Nursing and Performance Improvement. In addition they provide an opportunity for networking, sharing ideas and practice developments and provide a platform for raising concerns and issues.

\footnotetext{
on the individual the needs of patients. The system also allows staff to record when care has been met or achieved.

${ }^{3}$ Teamwork is the trade name for the nursing workload methodology used in the Trust. The system allows staff to record the number of staff on duty each shift, any extra staff used, admissions, discharges, transfers, interventions off the ward, patients requiring special nursing care. The system also requires the staff to make a professional judgement on the level of care that staff achieve for the patients on a given shift. This information is downloadable by staff at ward level and senior management level and would provide evidence to support under or over staffing.
} 


\section{Leadership}

The Trust is committed to developing leadership skills in nurses. Since 2000 nurses have had access to a number of leadership development opportunities including; Leading an Empowered Organisation [LEO] (University of Leeds, 2006) a three-day intensive training course in effective self management and the management of others; Leadership at the Point of Care (LPC), a three-day leadership development programme for front line staff in the NHS who have a direct and immediate impact on patient care (University of Leeds, 2006). Whilst the Trust has invested in these clinical leadership programmes it recognises the need to develop the clinical management and leadership skills of ward managers. Accordingly during 2004/2005 a group of ward sisters, charge nurses and team leaders completed the Royal College of Nursing's Clinical Leadership programme, a year-long development course looking at issues around patient experience, transforming the care environment, effective selfmanagement and the management of others.

\section{Why Evaluate the Delivery and Organisation of Nursing Care?}

The key driver for the commissioning of this study arose from two serious untoward incidents that occurred in the year 2000. Following investigation of both these events the Director of Nursing in post at that time believed that poor organisation and delivery of care may have been a contributory factor. Senior nurses in the Trust had also expressed their concern that care may not be organised in a way that made best use of the skills available but more importantly provided patient centred nursing care. In addition senior nurses were keen to identify any areas of good practice and innovation.

As a result, in 2002, a team of researchers from the School of Nursing, University of Salford were commissioned by Bolton Hospitals NHS Trust to evaluate the delivery and organisation of patient-centred nursing care across the acute nursing wards within the Royal Bolton Hospital. The decision to focus the evaluation on acute nursing care and not chronic care reflected earlier concerns. 


\section{Study Aim}

To evaluate the organisation and delivery of nursing care and the effective use of staff skills/resources in acute wards within Bolton Hospitals NHS Trust.

\section{Objectives}

Stage One:

- Compare and contrast the systems used with the current literature

- Identify the experiences and perceptions of patients and staff to understand the wider context and focus of the study

Stage Two:

- Identify and develop a baseline of the organisation and delivery systems utilised within all the acute wards

- Describe the organization and nature of staff activity

- Identify the staff and patient perceptions of the delivery and organisation of care and the use of their individual skills 


\section{CHAPTER TWO \\ METHODS}

This chapter outlines the methods for the evaluation. Following a brief summary of the overall approach adopted, it details the different methods used in Stage One and Stage Two of the study. Questionnaire design and administration is described, alongside the response rates and details on the nature and profile of each group of respondents. Data analysis methods are highlighted and ethical issues addressed.

\section{Overall Approach}

The evaluation utilises Soft Systems Methodology (SSM) to provide a framework for the research process. Soft Systems Methodology uses 7 phases to describe, explore and examine a real world situation; in this instance the organisation and delivery of nursing care, with existing theoretical concepts and recommendations. Using SSM, the evaluation develops in two distinct stages focusing on the first 5 phases of SSM (see table 2.1). Phases 6 and 7 concerned with implementing and evaluating change could be considered the focus of subsequent research studies.

Table 2.1: SSM and Research Process

\begin{tabular}{|c|c|c|}
\hline & SSM - Phases 1-5 & Research Focus \\
\hline$\stackrel{\mathscr{E}}{\tilde{0}}$ & $\begin{array}{l}\text { 1. The problem situation unstructured } \\
\Rightarrow \text { The stimulus for investigation }\end{array}$ & $\begin{array}{l}\text { Is nursing care organised and } \\
\text { delivered the same throughout the } \\
\text { acute nursing wards? Is there good } \\
\text { practice that could be shared? }\end{array}$ \\
\hline 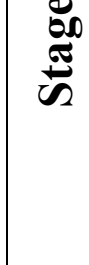 & $\begin{array}{l}\text { 2. The problem situation structured } \Rightarrow \\
\text { The articulation of the research } \\
\text { objectives }\end{array}$ & $\begin{array}{l}\text { What are the nurses and patients } \\
\text { perceptions of how nursing care is } \\
\text { organised and delivered? How is } \\
\text { nursing care organised and }\end{array}$ \\
\hline
\end{tabular}




\begin{tabular}{|c|c|c|}
\hline & & delivered? \\
\hline & $\begin{array}{l}\text { 3. The development of root definitions } \\
\text { of relevant systems } \Rightarrow \mathrm{A} \text { root } \\
\text { definition is a concise definition of } \\
\text { an activity, which captures a } \\
\text { particular view or aspect }\end{array}$ & $\begin{array}{l}\text { Literature review captures the } \\
\text { theoretical concepts of the different } \\
\text { methods utilised when organising } \\
\text { and delivering nursing care. } \\
\text { Staff and patient focus groups } \\
\text { within the study environment } \\
\text { provide an initial overview of the } \\
\text { real situation. }\end{array}$ \\
\hline \multirow[t]{2}{*}{$\underset{⿱ 乛}{E}$} & $\begin{array}{l}\text { 4. Making \& testing of conceptual } \\
\text { models } \Rightarrow \text { Root definitions can be } \\
\text { used to develop conceptual models } \\
\text { in tandem with the findings of the } \\
\text { literature review }\end{array}$ & $\begin{array}{l}\text { In-depth exploration of research } \\
\text { participants perceptions and } \\
\text { experiences describe what is } \\
\text { actually happening in the real } \\
\text { situation. } \\
\text { Comparative analysis of the real } \\
\text { situation with theoretical concepts } \\
\text { identified within the literature } \\
\text { generate clear definitions of care } \\
\text { organisation }\end{array}$ \\
\hline & $\begin{array}{l}\text { 5. Comparing conceptual models with } \\
\text { reality } \Rightarrow \text { Comparison used to } \\
\text { generate debate about possible } \\
\text { changes that can be made in order } \\
\text { to alleviate the gap between models } \\
\text { and reality }\end{array}$ & $\begin{array}{l}\text { Discussion explores the differences } \\
\text { between reality and theory and } \\
\text { proposes recommendations/changes } \\
\text { that could enhance the delivery and } \\
\text { organisation of nursing in the future }\end{array}$ \\
\hline
\end{tabular}

\section{Stage One}

The aim of Stage One was to develop an overview of the context in which the study was to take place and provide a baseline of the issues pertinent to the staff and patients to focus the data collection in Stage Two. This involved two main activities: 
- Literature Review

- Focus Groups

\section{Literature Review}

The comprehensive literature review was used to elicit theoretical recommendations and clarify the nature of evidence surrounding nursing activity and the organisation of care. An iterative process was used to scope primary research studies and reviews of evidence from nine locally accessible databases, covering clinical and management literature, on the organisation and delivery of patient centred care. Initial assessment of relevance was based on available abstracts, and searches were revisited in light of the relevant literature identified. An initial timeframe of 1990 - present day was adopted.

A representative number of databases were used to inform the literature review. For example, the clinical perspective was obtained from the British Nursing Index (BNI), Caredata, Cinahl, Cochrane Library, Medline; the management view from Health Management Information Consortium (HMIC), Emerald Library; and a research perspective from National Research Register (NRR), Research Findings Electronic Register (ReFeR). Search and analysis strategies were developed utilising the Cochrane Reviewers Handbook as an analytical framework.

\section{Focus Groups}

The plan was to run two focus groups, one of nurses and one of patients. The objective of each of these groups was to elicit the perceptions from the users/recipients of the nursing care and the nurses providing the care. This data was then utilised to inform the development of the (SSM) root definitions of patientcentred care.

All focus group participants were recruited by a letter with a reply slip and an information sheet and asked to return the reply slip if interested in being involved in the 
focus group. Written consent to be involved in the focus group was obtained from each individual participant on the day of the focus group by the researcher(s).

Patient Focus group - A purposive sample of 12 patients discharged from the acute wards was selected from the Trust database to ensure different age groups and genders were equally represented within the focus group.

Nurses Focus Group - A purposive sample of 10 nurses representing each acute care directorate (Women's Health Care, Specialist Surgery, General Surgery, Respiratory, Rehabilitation, Elderly, Diabetes, Gastroenterology, Cardiology, Acute Medicine) were invited to attend the focus group alongside two Trust nursing management representatives. Senior nurses were initially targeted as they were perceived to have a more general overview of the issues impacting on the organisation and delivery of nursing care. Where a senior nurse was unable to attend another nurse from the same area was contacted. The nurse focus group also provided an opportunity to pilot two previously validated questionnaires.

\section{Stage Two}

The aim of Stage Two was to explore, in-depth, how nursing care was organised and delivered across the acute wards in the trust from the perceptions of the users and providers of the service. This involved:

- Ward Organisational Questionnaire

- Nurses Questionnaire

- Patient Questionnaire

- Non-Participant Observation

The multi-method approach facilitated the triangulation of emerging data enabling the confirmation of both the quality and validity. The findings from Stage One created a platform on which to build the theoretical aspects of the study. 
All participants selected to complete a study questionnaire were recruited via a letter and information sheet, enclosed with the questionnaire and a stamped addressed envelope. For the nurses and ward questionnaire consent was presumed on return of a completed questionnaire. However for the patient sample a consent form was enclosed with the questionnaire and study information for participants to provide written consent at the same time as completing the questionnaire, a recommendation of the Local Research Ethics Committee.

\section{Ward Organisational Questionnaire}

The purpose of the ward questionnaire was to identify the mode of working performed on the ward from the perspective of the manager such as primary, team or task allocation. It was decided at the onset to exclude the acute wards concerning the care of children and obstetrics. Therefore out of a possible 25 acute wards, 23 were included in the final total sample. A total sample of 23 Senior Nurses in charge of the study wards were contacted to be recruited for the study. A questionnaire about the organisation and delivery of care on their particular ward was coded and administered with a return stamped addressed envelope direct to the research team. The outcome of piloting two different validated tools with the participants of the focus group in Stage One resulted in the decision to use the Bowman and Thompson Classification system checklist which examines 13 components of the nurses' work (Appendix 1).

Senior nurses were targeted for this particular questionnaire as they were perceived to have the most comprehensive overview of nursing care on the ward. In addition it was important to elicit the overview of the managerial perspective and then compare it with the perspective of individual nurses working on the same ward.

\section{Nurses Satisfaction Questionnaire}

The purpose of the nurses' satisfaction questionnaire was to elicit their individual perception of how nursing care was organised and identify what enhances and hinders nursing care delivery. All nurses working on acute wards within the Trust formed the target population for this part of the study. Initially each individual ward was 
contacted, via the telephone by the researcher, and asked to provide a breakdown of the number of staff (D-I grade, including assistant practitioners) working on the ward. A total of 391 staff members were identified. Anonymous coded questionnaires were distributed manually to each ward by the researcher and the name of each member of staff written onto the sealed envelope of the questionnaire, reproduced direct from the off duty rota. As a result the research team did not contact any nurse directly, hold or review any staff details. Table 2.2 shows the specific inclusion/exclusion criteria for recruitment to this part of the study.

\section{Table 2.2: Inclusion/exclusion criteria for nurse questionnaire}

\begin{tabular}{|c|c|}
\hline Inclusions & $\begin{array}{l}\text { - All staff registered on the off duty as a qualified member of staff } \\
\text { grades D-I on the } 13^{\text {th }} / 16^{\text {th }} \text { May } 2005 \text { who were actually working } \\
\text { shifts or an annual leave. } \\
\text { - All Assistant Practitioners fully trained and included in the numbers } \\
\text { as a qualified member of the team (C grade) who were actually } \\
\text { working shifts or an annual leave. }\end{array}$ \\
\hline Exclusions & $\begin{array}{l}\text { - All staff registered on the off duty as a qualified member of staff } \\
\text { grades D-I on the } 13^{\text {th }} / 16^{\text {th }} \text { May } 2005 \text { who were on long term sick or } \\
\text { maternity leave for the period of the study. } \\
\text { - All Assistant Practitioners fully trained and included in the numbers } \\
\text { as a qualified member of the team (C grade) who were on long term } \\
\text { sick or maternity leave for the period of the study. } \\
\text { - All Trainee Assistant Practitioners } \\
\text { - All Health Care Assistants } \\
\text { - All agency/bank staff }\end{array}$ \\
\hline
\end{tabular}

\section{Patient Satisfaction Questionnaire}

The purpose of the patient satisfaction questionnaire was to highlight the patients' experience of nursing care on the wards and their likes and dislikes of how nursing care was organised and delivered. Eligible patients were identified by the Trust, from 
their admission/discharge database, for inclusion in the study. A consecutive sampling method was used. The first 50 patients discharged from the ward over specified dates were sent a self reporting questionnaire. Database checks were made to ensure that such patients were still living prior to posting the questionnaire. Eligible patients were recruited into the study by letter and information sheet and invited to complete a questionnaire sent out by the Trust. The research team did not contact any patient directly, hold or review any patient details. Three consultants withheld permission for 'their' patients to be contacted as a result these patients were excluded from the study sample. In addition, it was decided to exclude patients who were discharged to the discharge lounge from a ward. The reason for this was to maintain the rigor of the patient responses and ensure comments corresponded to the ward where they had been treated, thus minimising the potential for any confusion. Table 2.3 highlights the inclusion/exclusion criteria for the patient sample.

Table 2.3: Inclusion/exclusion criteria for patient questionnaire

\begin{tabular}{|l|l|}
\hline Inclusions & $\begin{array}{l}\text { - Individual patients are to be included only once in the patient sample } \\
\text { even if they have been discharged repeatedly from the ward over the } \\
\text { study period } \\
\text { - Patients who are alive and discharged home direct from the ward } \\
\text { - Patients over } 18 \text { years }\end{array}$ \\
\hline Exclusions & $\begin{array}{l}\text { - Patients discharged to the discharge lounge prior to home } \\
\text { - Patients }<18 \text { years old } \\
\text { used for the study }\end{array}$ \\
\hline
\end{tabular}

\section{Non-Participant Observation}

The purpose of non-participant observation was to develop a greater understanding of how nursing care is organised and delivered and as a way of assessing concept validity (are they really doing what they say they are doing?). It was perceived that wards would be grouped and stratified according to the mode of working (i.e. 
primary, team or task allocation nursing) which would be identified from the ward organisational questionnaire. From this framework a representative purposeful sample of six wards was selected for further investigation. Observation sessions lasted a morning shift of six hours $(7.30-1.30 \mathrm{pm})$ as this was perceived to be when the majority of nursing activity took place. Nurses and patients on the wards selected for observation were recruited to the study via information sheet and verbal consent to be observed was obtained prior to all observation sessions.

\section{Analysis}

To maintain confidentiality wards were coded with numbers. For the purpose of the ward questionnaire (Appendix 1) the consecutive coding ran as W1, W2, W3 etc. Each grade of staff was coded separately according to grade and number of staff at that grade on the ward. For example D1, D2,....E1, E2 ...F1, F2 ... G1, etc. Assistant Practitioners were coded as AP1, AP2 ..... For the purpose of the staff questionnaire a combined coding system was used that allowed the research team to identify which ward the respondent worked upon and what grade they worked at (for example, combined coding $=\mathrm{W} 1 / \mathrm{D} 1$, or $\mathrm{W} 1 / \mathrm{E} 1$ or $\mathrm{W} 12 / \mathrm{E} 6 \ldots)$.

Data within all the questionnaires was entered on the Statistical Package for Social Sciences (SPSS). Analysis was restricted to simple descriptive statistics. Open questions from the questionnaires and observational data were analysed using appropriate thematic analysis techniques.

\section{Ethical Issues}

All stages of the study were approved by the Bolton Local Research Ethics Committee (LREC) and the University of Salford Ethics Committee. The protection of participants was a key factor at every phase of the project. In line with the LREC recommendation all patients who were recruited to complete a questionnaire were also asked to complete a written consent form. This contrasted with the usual strategy of 
questionnaire return implying participant consent so patients had an extra form to complete.

As was normal practice at Bolton Hospitals NHS Trust the patient information sheet and questionnaire (where appropriate) had a clause outlining where to obtain translation services included for patients' for whom English was not their first language. The clause informed participants that they could access the 'Language Line' Translation service to facilitate and enhance their understanding of the study material. It was hoped that this strategy would enable all patients within the multicultural community to be eligible for recruitment to the study. However, no patient took up this option.

All patients and nurses prior to participating in any part of the study received a full information sheet outlining the aims and objectives of the study. Patient information sheets were also made available to all patients on the observation wards, with verbal clarification if required, prior to any observation of care taking place. Verbal consent for non-participant observation was obtained from all participants (both nurses and patients) in specific clinical areas. The presence of the observer was fully explained to patients and any patients who did not wish to participate were excluded from the study. The researchers did not have any clinical involvement in patient care and no patient information was accessed as the focus of this work is upon the organisational and care delivery aspects of the nursing day. 


\section{CHAPTER THREE STAGE ONE - FINDINGS AND ROOT DEFINITION}

Chapter three describes the findings of Stage One of the study. The data from the focus groups together with that from the literature review was used to develop root definitions of nursing care practice. A pictorial diagram illustrating the organisation of nursing care based on these initial findings is compiled.

\section{Literature Review}

It has long been that the organization of nursing care is an amorphous concept and that attempts to describe systems of work are often vague, inaccurate and confusing (Bowman et al., 1995). The literature itself reflects this lack of clarity. This literature review provides a critical analysis of some of the key papers that inform the development of nursing work methods, organization of care and staff and patient satisfaction. The search parameters included articles published in English within the last 10 years (1993-2003) excluding grey literature. Search terms and databases used are outlined in table 3.1 .

Table 3.1: Search Terms and Databases

\begin{tabular}{|c|c|}
\hline Search Terms & Database \\
\hline $\begin{array}{l}\text { - ((acute-units) or (hospital-wards) or (inpatients) } \\
\text { or (inpatient-care) or (inpatient) or (acute-care) } \\
\text { or (acute- services)) } \\
\text { - }(\text { (nursing-practice) or (nursing-process) or } \\
\text { (multidisciplinary-teamwork) or } \\
\text { (multidisciplinary- teams) or (primary-nursing) } \\
\text { or (patient-focused-care) or (patient-focused) or } \\
\text { (patient-centred) or (nursing-care-plans)) } \\
\text { - } \text { Inpatients } \\
\text { - } \text { Hospital Units } \\
\text { - Primary Nursing Care } \\
\text { - Patient Care Planning } \\
\text { Patient-Centred Care }\end{array}$ & $\begin{array}{ll}\text { - } & \text { Medline } \\
\text { - } & \text { Cinahl } \\
\text { - } & \text { Swets } \\
\text { - } & \text { Helmis } \\
\text { - } & \text { DoH }\end{array}$ \\
\hline
\end{tabular}


- Patient Care Team

- Nursing, Supervisory

- Nurse Administrators

- Nursing Process

\section{Nursing Activity and Skill Mix}

Jinks and Hope (2000) carried out an activity analysis of nursing care on an acute medical ward in a district general hospital (DGH) and a rehabilitation ward located in a community hospital $(\mathrm{CH})$ via non participant observation. They attempted to apply some structure to their observation by identifying 5 domains of nursing function. This structure allowed for the identification of over 150 activities which contributed to these domains. No weighting was given to complexity of task or to patient dependency however Jinks and Hope suggested that only 30\% of activity in the DGH was actually accounted for by direct patient care with up to $70 \%$ of nursing time being focussed upon care management and organizational issues. This reflects the findings of both McClosky (1996) and Chang (1995) who found that registered nurses delegated large amounts of direct patient care to subordinates or unqualified staff.

McKenna (1995) had attempted to evaluate the importance of skill mix upon patient outcomes by evaluating three different assumptions regarding skill mix. He also emphasised the trend for direct patient care to be under the aegis of unqualified and ancillary staff but highlighted that, providing supervision from appropriately qualified personnel was available this did not necessarily impact upon patient care in a negative fashion. However he balanced this viewpoint by suggesting that the ability of qualified staff to 'act down', that is to undertake more basic tasks, was an important skill and one that was not counterbalanced by a corresponding skill in unqualified staff to 'act up'. He further noted that qualified staff could be argued to be a more efficient way of providing direct care since their skills and knowledge meant that they did not need to be told what to do next whilst up to $27 \%$ of a nursing assistant's time was unoccupied. 
Spilsbury and Meyer (2001) attempted to define the contribution of nursing to patient outcomes. They utilised an expert panel to review the literature surrounding nursing activity in an effort to evaluate the impact that nursing had upon patient outcomes. The work was weakened by the dearth of outcome related research that was specific to nursing but suggested that nurses could make a significant contribution to patient education and patient coaching, (although Jinks and Hope demonstrated that less than $2 \%$ of nursing time was spent in these activities) rehabilitation, pain control, discharge planning also having a positive effect upon patients self esteem and general health. They further highlighted that nurse led initiatives generally result in better patient outcomes.

Spilsbury and Meyers note that much outcome based research has focused upon the 'doing' aspects of nursing and has disregarded the invisible elements. These invisible elements tend to be the activities that contribute to the $70 \%$ of care that is non-patient focussed; care co-ordination, provision of clinical judgement and professional leadership. Thus, it is clear that nursing activity cannot be considered unless it is within a framework of organisation of care.

\section{Organisation of Care}

Adams and Bond (1997) noted that although wards tend to share similar staffing resources across specialities differences can be shown to exist within the organizational structures within different ward areas. They noted, for example that acute surgical and orthopaedic wards tend towards a more hierarchical structure than medical wards with medical nurses showing greater autonomy and collaborative working across disciplines than their surgical or orthopaedic colleagues. Like Jinks and Hope (2000) this work, which used a self completion ward profile, focussed not only upon the accomplishment of a range of nursing activities but also evaluated actions across a variety of domains and further expanded this data by asking the ward nurses for their perceptions of the ward organization. By subjecting the profiles obtained from the wards to hierarchical cluster analysis Adams and Bond identified three major organizational descriptors, devolved, two-tier and centralised. Devolved nursing has the elements of primary nursing within it, with care being delivered by 
small teams with overall responsibility resting with one registered nurse. Two-tier nursing is analogous to modular or team nursing in which small teams of nurses are responsible for care delivery to a specific group of patients over the span of one shift. Centralised nursing clearly equates to task allocation in which control is firmly in the hands of the ward managers and tasks are allocated to various members of the ward staff. Whilst the nomenclature of these diverse organizational approaches vary with different authors (see table 3.2) the fundamental elements remain the same.

Table 3.2: Organizational Descriptors

\begin{tabular}{|c|c|}
\hline Organizational Descriptor & Authors \\
\hline $\begin{array}{ll}\text { - } & \text { Devolved } \\
\text { - } & \text { Two-tier } \\
\text { - } & \text { Centralised } \\
\end{array}$ & Adams \& Bond (1997) \\
\hline $\begin{array}{ll}\text { - } & \text { Primary Nursing } \\
\text { - } & \text { Team Nursing } \\
\text { - } & \text { Task Nursing }\end{array}$ & Bowman et al. (1995) \\
\hline $\begin{array}{ll}\text { - } & \text { Primary Nursing } \\
\text { - } & \text { Modular Nursing } \\
\text { - } & \text { Task-centred } \\
\end{array}$ & Johansson, Larsson \& Hamrin (1994) \\
\hline $\begin{array}{ll}\text { - } & \text { Primary Nursing } \\
\text { - } & \text { Team Nursing } \\
\text { - } & \text { Functional Nursing }\end{array}$ & Thomas (1992) \\
\hline
\end{tabular}

It is clear that the understanding and identification of the organizational characteristics of ward care delivery is essential if the pragmatic aspects of patient care are to be explored (Thomas and Bond, 1990). Thomas and Bond likewise stress the importance of separating the reality of organization of care from stated ward philosophy of care management and to this end dispensed a self completion questionnaire, the Work Environment Scale (WES), to ward sisters to allow them to identify the category of care organization used within their own ward area. Thomas and Bond noted that rarely did one ward completely fulfil all the criteria for one specific organizational modality with most wards using an amalgamation of all three methods. Although this work used only a small sample $(\mathrm{N}=36 \mathrm{n}=2163 \%$ response rate) it does highlight the difficulties inherent in attempting to simplify and label a complex issue. In a later work, Thomas (1992) administered the Work Environment Scale to both qualified and 
unqualified ward staff and found that there were differences in work environment perception across the three modalities of care organization and that these differences were exemplified by greater perceptions of support, autonomy and less pressure amongst both categories of staff in clinical areas were primary nursing was the organisational model of choice.

The links between organization of care and level of stress experienced by staff was explored by Mäkinen et al. (2003a) who also used the WES (Thomas and Bond, 1990) to identify organizational characteristics of 27 clinical areas and subsequently followed this up with a validated occupational stress questionnaire to the 537 staff of those areas. Mäkinen and colleagues did not find any statistical relationship between method of organizing care and work related stress levels although they did note that interpersonal relationship problems between staff appeared to be minimised in patient centred approaches such as primary nursing and attributed this to the opportunity the care giver had to write in the patient's notes. Whilst they speculated whether the increased responsibility that accrues to the practitioner when primary nursing is the organizational method of choice may contribute to work related stress they did not find any statistical evidence to support this. Similar findings were presented by Melchior et al. (1999) who contended that, although increased autonomy and responsibility was associated with primary nursing, nurses who were working in a primary nursing system had more control over their work and consequently found their work less complex and stressful rather than more.

This supports the earlier work of Johansson et al. (1994) who found no statistically significant differences in job satisfaction when changes to organization of care from task-centred nursing to modular approaches were introduced on acute surgical wards. They noted a slight improvement in care and a similarly slight deterioration in satisfaction with information amongst staff. There was, however difference between the two wards within the study with ward A scoring favourably in terms of work load issues when modular nursing was introduced and ward B showing improvements in nursing relationships and work stimulation. The conclusion drawn by Johnasson and colleagues was that organization of care from a task-centred approach to modular one did not guarantee improvement in quality of care or work satisfaction but that relationships with colleagues played a more vital part than previously. Whilst it must 
be acknowledged that this is a small study of only two wards it does highlight interesting elements of care organization that have not been widely acknowledged by other authors.

The issue of job satisfaction as determined by organization of care was again explored by Mäkinen et al. (2003b). Mäkinen et al. (2003b) once again identified organizational methods via the WES (Thomas and Bond, 1990) but altered the scale to include a fourth category, that of 'modular' nursing to identify those systems of care that did not fulfil the criteria of primary nursing but were distinct from team nursing. This may cause semantic problems since 'modular' nursing has been used by other authors to mean team nursing. Job satisfaction was evaluated using a validated scale. It was shown that organization of care positively correlated with job satisfaction with patient focussed work allocation and accountability for care being cited together with opportunity to write in patients' notes (this was also a feature of earlier work by Mäkinen et al. (2003a)).

Boumans and Landeweerd (1999) carried out a longitudinal study of well-being and job satisfaction across two nursing units following the introduction of primary nursing in one of them. They found no significant difference in the measured variable between either of the groups in terms of total job satisfaction however the intervention (primary nursing) group did report increased satisfaction with opportunities for personal growth and with clarity of role, although this decreased over time whilst good health appears to have increased in the intervention group $(p=0.5)$. Boumans and Landeweerd also report that job significance decreased over time in the intervention group although they do attribute this to extraneous variables such as Hawthorne effect and changes in hospital policy. They conclude that the positive effects of primary nursing depend strongly upon the way it is introduced and managed. This is an important point since Boumans and Landeweerd do not state that any additional staff members were recruited to the primary care unit. Other authors notably, McKenna, (1995) Johansson et al. (1994) and Adams and Bond (1997) have suggested that an increase in qualified staff can contribute to the success of this care organization modality significantly. 
The relationship between the number of nurses and ward organizational environment was explored by Adams and Bond (2003a) who suggested that fewer numbers of qualified staff were associated with more hierarchical and functional methods of care delivery and consequently lower levels of care. McKenna would argue that this is because unqualified staff have no theoretical foundation upon which to base their practice and therefore are more likely to implement task focussed care. Adams and Bond emphasise that whilst higher levels of qualified staff tend to result in more devolved organization structure they do not necessarily ensure a higher quality of care. Nonetheless there is a correlation (albeit a weak one) between the number of qualified personnel upon a ward and the incidence of collaborative working although there is no evidence to suggest that a higher nurse/bed ratio will translate into innovative practice. Adams and Bond (2003b) also note that staffing resources, the ward ethos or relationship issues tend to have a bigger impact upon care processes and nurses' satisfaction than organization of care although other authors, such as Johansson et al. (1994) have suggested that these concepts cannot be removed from the organization of care equation.

\section{Conclusion}

In conclusion it is clear that differing methods of organisation of care impact upon both the patient experience and the well being of the caregivers in different ways and table 3.3 shows a summary of the key concepts that have been identified. There are demonstrable benefits to staff in terms of improved professional relationships, increased autonomy and responsibility and decreased work-related stress when care organization follows the primary or modular models of care rather than the task allocation model. There is little literature surrounding patient's satisfaction with differing models of organisation of care which can be contended to be unfortunate but this will be addressed within this work. However, the staff benefits of primary or modular nursing can be extrapolated to patients since organisation that produces patient focused work allocation allows for greater familiarity with the patients needs.

From a methodological viewpoint the WES (Thomas and Bond, 1990) is a widely used and well-validated tool that allows for the identification of different organisation 
pattern of care. It can be argued that the introduction of a new, fourth category into the scale by Mäkinen et al. (2003b) did not significantly improve it and may lead to some semantic confusion. There is a strong indication that the application of the WES, together with a follow-up questionnaire to ascertain the experience and opinions of the wards staff is appropriate methodology and it is one that is reflected in this study. The factors that impact on the organisation of care such as staff resources, professional relationships will contribute to the development of a rich picture that should depict the elements of the organisation of care in acute settings.

Table 3.3: Key Concepts

\begin{tabular}{|c|c|}
\hline Key Concept & Reference \\
\hline \multicolumn{2}{|l|}{ Nursing Activity } \\
\hline $\begin{array}{l}\text { - A significant proportion of nursing time is spent } \\
\text { in non-direct patient Care }\end{array}$ & Jinks and Hope (2000) \\
\hline $\begin{array}{l}\text { - Much direct patient care is delegated to } \\
\text { unqualified or junior staff }\end{array}$ & $\begin{array}{l}\text { McKenna (1995), McClosky } \\
\text { (1996), Chang (1995) }\end{array}$ \\
\hline $\begin{array}{l}\text { - Nurse lead initiatives contribute to better patient } \\
\text { outcomes }\end{array}$ & Spilsbury and Meyer (2001) \\
\hline \multicolumn{2}{|l|}{ Organization of Care } \\
\hline $\begin{array}{l}\text { - Hierarchical care can negatively affect nursing } \\
\text { autonomy }\end{array}$ & Adams and Bond (1997) \\
\hline $\begin{array}{l}\text { - The Work Environment Scale can usefully } \\
\text { identify the type of care organisation in use }\end{array}$ & $\begin{array}{l}\text { Thomas and Bond (1990) } \\
\text { Mäkinen et al. (2003) }\end{array}$ \\
\hline $\begin{array}{l}\text { - There are three main types of organisation } \\
\text { modality }\end{array}$ & $\begin{array}{l}\text { Adams and Bond (1997) } \\
\text { Bowman et al. (1995) } \\
\text { Thomas (1992) } \\
\end{array}$ \\
\hline $\begin{array}{l}\text { Primary nursing is contended to be the most } \\
\text { empowering way of organising care, primarily } \\
\text { because of the access to patient records inherent } \\
\text { within it }\end{array}$ & Mäkinen et al. (2003) \\
\hline $\begin{array}{l}\text { - The role of modality of organisation of care and } \\
\text { its correlation to job satisfaction is contentious }\end{array}$ & Johansson et al. (1994) \\
\hline $\begin{array}{l}\text { Organisation of care can be affected by nursing } \\
\text { resources }\end{array}$ & Adams and Bond (2003) \\
\hline
\end{tabular}




\section{Focus Group Findings}

\section{Patient Focus Group}

Unfortunately, although a reasonable number of patients expressed a willingness to participate in the focus group no-one attended the event. The patients who contacted the research team to give their apologies did not attend due to ill health. The potential contribution that this focus group could have made to the development of the stage two questionnaires was obtained via literature review instead.

\section{Nurse Focus Group}

On the day of the focus group five nurses attended from the Trust, two other nurses apologised on the day as they were unable to leave the ward. The focus group met for two hours. Nurses were invited to offer their opinions upon a range of topics which guided the group discussion such as issues surrounding the planning, organisation and delivery of nursing care, prioritising patient care, allocating appropriate patients, and what enhances or hinders patient care delivery.

Nine themes emerged from the nurse focus group:

- Organising care

- Staffing levels

- Patient allocation and resources

- Patient care

- Prioritisation of care

- Patient involvement

- Support and record keeping

- Changes to practice

- Staff satisfaction 


\section{Organising Care}

All the focus group participants indicated that team nursing was used to organise care and this was seen as historical rather than an organisational choice. It was also highlighted that ward layout affected team numbers and organisation of nursing care. Furthermore the group emphasised that the demands of other disciplines, such as physiotherapy, impact on care organisation. In addition, staff felt that the choice of care delivery system was dictated by staffing levels.

'We can't use primary nursing because staff numbers are too low.'

One person had used primary nursing until 18 months ago and stated it was much better and that it gave the nurses more responsibility. Another participant highlighted that when using primary nursing she did not have a patient caseload as ward leader and found stepping back from patient care difficult. The consensus of the group was that primary nursing worked well, until qualified staff numbers dropped at which point the wards reverted to team nursing.

Consensus opinion suggested that a minimum standard expected was that patients had a named nurse for a span of duty. It was acknowledged that patients like to know who their nurse is and like to focus upon their nurses and their area. This was seen as important because:

'Patients and students need to know where the qualified staff are.'

The group suggested that they had to work around the geography of the ward environment and suggested that moving patients around created more work so that patients were generally attached to the same team for the duration of their stay. It was found that if patients are geographically dispersed named nursing is difficult.

It was seen as difficult sometimes to ensure the continuity of patient care across the nursing staff, particularly when nurses needed to move across teams to maintain adequate skill mix. The standard was for nurses to stay in their teams for as long as possible. The consensus of the group was that patients did know who their named 
nurse was. This was attributed to the relationship that nurses build up with their patients. Further evidence of this relationship was offered in the fact that patients' relatives are aware of who the named nurse is and will ask to speak to them.

The entire group described the team nursing approach as 'patchy'. They felt that not only did it not work as well as primary nursing but there was also a tendency for the team nursing approach to fail on the late shift (due to the changes in staff numbers). When this occurred task allocation often takes over as the method of organising care and increased responsibility was given to the Health Care Assistant (HCA).

\section{'Health Care Assistants (HCA) take on more as qualified levels drop.'}

It was also felt that limits to HCA competence may mean workload and skills distribution equates more to task allocation than team nursing even within teams.

There was, however, evidence of innovative approaches to dealing with this problem. One ward manager reported that she had manipulated the workload to spread care over all shifts and allocated more staff onto a late shift to keep team nursing going.

\section{Staffing Levels}

There was a recognised ideal of care within the group which the staff tried to provide although they felt that the reality was different. Staffing levels were seen to have a big impact on care with high sickness levels being identified as contributing to the problem of care organisation. High levels of sickness were perceived by the group as being related to stress.

'There is a feeling that everyone is working on minimum numbers.'

Ward levels of care were perceived as unsafe. All of the ward managers reported recording an increase in clinical incidents based upon professional opinion. Concerns were expressed that ward communication was negatively affected by changes in staffing levels. Furthermore an issue which appeared to affect a number of the participants was maternity leave cover. 
'Wards are not staffed for maternity leave and this causes problems since the bank/agency staff used to cover this gap are often not as experienced and not of the same grade as the missing staff member.'

Teamwork was seen as a contentious issue by the group. Lack of training and written guidelines upon the use of teamwork was seen as a major problem:

'Managers don't know what they want from Teamwork reports and don't know what to ask to get a reasonable report.'

This was seen by some of the group as contributing to a specific problem, namely that the information put into Teamwork does not reflect clinical reality. Other group members felt that Teamwork reports were not acted upon and no feedback available to ward staff. As a result opinion suggested that external service demands impacted significantly upon organisation of nursing care.

\section{Patient Allocation and Resources}

A number of issues influenced the way in which patients were allocated to teams on the wards. Reflecting the findings highlighted in the literature (Needham, 1997), the focus group were dismissive of dependency levels seeing them as a paper exercise. Patients were admitted into empty beds but tended to be moved around the wards in an effort to balance workload across the staff.

Issues such as paper work were seen as influencing patient allocation and patient resources, as were the demands of liaison with other hospitals or disciplines.

\section{'Transfers/interagency care/out of area patients affect care delivery.'}

The co-operation of other disciplines was seen as key in the organisation of nursing care. The group highlighted that some senior staff don't like it when they have to deal with team leaders (staff nurses) or a HCA rather than the ward manager. This was seen by the group as partly due to other disciplines not understanding how nursing 
care was organised. It was acknowledged that ward managers sometimes had to do ward rounds with consultants because team leaders could not be released from patient care to participate. However, it was apparent that record keeping was seen as a time consuming element of team nursing.

'Paperwork can take an hour per day per patient. Staff nurses do this as they are accountable for their own patients.'

Issues such as the demands and perceptions of other disciplines significantly impacted upon patient allocation and resources.

\section{Patient Care}

The group were generally pessimistic about care, feeling that only basic care was being supplied. Concerns were expressed about the quality of patient communication and information the staff felt able to offer, illustrated by comments such as;

\section{'Pressure for beds affects nurse/patient communication'}

and

'There is no time to explain to patients properly.'

The consensus of the group was that there were negative feelings on the wards and this was because of the perceived pressure that the ward was under to meet service demand. The pressure for beds was highlighted as an issue for staff and they felt that they were just pushing patients through the system. A concern was expressed that the staff sometimes felt that patients were discharged home when they were unfit and the group argued that this was supported by the number of readmissions they saw.

Additionally the staff felt that their job satisfaction was affected by the transfer of patients off ward prior to discharge,

'Sending patients to discharge wards means no closure for the ward staff as they are just transferring them elsewhere and not seeing them go home.' 


\section{Prioritisation of Care}

The group agreed that care is initially prioritised on dependency. However they also noted that it was hard to prioritise when there are disparate patient groups on the ward, and they often 'end up just doing'. Once again the demands of other professional groups were seen as impacting upon organisation of nursing care.

'Patients need to be ready for OT and physio.'

The consensus of the group was that impact of this was that basic care began to have a lower priority than some admin roles such as theatre prep and x-ray. Nonetheless, some administration tasks were given priority.

'Early warning Scores (EWS) admin is seen as a priority. No one dies from not having a wash but EW could be crucial.'

There was a feeling that the ward nurses were doing too many jobs. It was acknowledged that often junior staff found it hard to prioritise and that often the person who shouts the loudest gets the most attention. The demands upon the senior staff meant that junior staff did not necessarily get the prioritisation help that they needed.

The staff felt that they had to defend perceived poor care because visitors did not have insight into the prioritisation of care that did go on.

'Visitors may ask for care for other people but this takes the nurse away from other, more important care.' 


\section{Patient Involvement}

The staff felt that patient involvement was not optimal. They identified a number of reasons for this including that:

- Bed pressures mean that patients are more dependent than previously which makes rehabilitation difficult

- There are time constraints in terms of patient engagement and involvement in care planning

- Patients are sometime reluctant to be involved. The UK culture towards nursing is seen as 'you are paid to do this'

The pressure of work was seen as contributing significantly with staff noting that it was sometimes quicker just do things for the patient than help them manage for themselves. This resulted in some feelings of guilt that the nurse/patient relationship is still a parent/child one.

The group felt that one response to this pressure was to encourage relatives to participate in care, along the lines of the European model, and it was suggested that the staff did not engage the patient's relatives enough. However, it was also highlighted that the demands of other professions may be an obstacle to this since one ward manager reported that the consultants on her ward have requested that afternoon visiting be abolished as it was affecting ward rounds.

\section{Support and Record Keeping}

There were a number of issues surrounding the concepts of professional roles and record keeping activities. There was little consensus in the group with some group members arguing that other agencies could make the nurses job easier or take on some of the administration tasks of the nurse. The need for clerical support was highlighted, with referral form completion being seen as a problem. 
Others in the group felt that people should take on their own roles. Concern was expressed that nursing elements of some tasks (for example, feeding) are being overshadowed and a feeling that this shared role should reflect patient need. This was underpinned by the mixed reaction of the group to the new 'housekeeper' role.

In terms of record keeping activities the consensus was that Crescendo (computer care planning) was not widely used. This was mainly as the programme was not of use when addressing complaints, but also because the technology was seen as unreliable. Generally the nurses provided a summary of care in Kardex. Some but not all wards allowed HCAs to write in the Kardex and to record observations such as temperature and pulse, blood pressure, oxygen saturation and early warning scores.

\section{Changes to Practice}

The consensus of the group was that most changes to practice were based on experience and learnt over time. Good practice and innovation was reported on some wards which had set up their own education programmes that allowed staff to be rostered for attendance. Full day in-house sessions are seen to attract better attendance than 1-2 hour sessions. There was a feeling that practice was reviewed after course attendance by staff but it is opportunistic rather than systematic. The value of student nurses in challenging existing practice was appreciated.

Changes tend to be individual to ward area and based upon patient caseload. Regret was expressed that good practice was not shared. It was also noted that good practice was not shared across disciplines.

\section{Staff Satisfaction}

Ward pressures were blamed for the fact that staff felt there was no chance for clinical supervision or team bonding. There was consensus on the benefits of reflection but it was felt that reflection only occurred on poor practice. 
'We only reflect on care when a complaint comes in.'

Although time off was seen as precious, ward staffing pressure meant that people had to attend meetings in their own time. However it was also noted that staff come in to work extra shifts in their own time as bank staff and could be working in excess of 48 hours a week. Staff members are often telephoned on their days off to come in and cover.

This was seen to effect staff retention with staff leaving the 'heavy' wards after a few months. The introduction of intermediate care units was seen to raise dependency levels on the wards but this is not reflected in changes in staffing levels across all disciplines. This translated in to insufficient staff to look after the very dependant patients (Cerebral Vascular Accident, falls, confused, violent), which means that the care of others is sacrificed. Wards were not seen as specialised as in the past and has led to a number of 'inappropriate patients' requiring more care than the ward establishment could provide. It was emphasised by the group that staff levels should be reviewed to reflect changes in patient dependency.

Overall Bolton Hospital NHS Trust was seen as a friendly institution staffed by helpful committed people who were fully signed up to good patient care. Despite the pressures the staff felt that they should try to keep each other going. Awareness of care shortcomings also meant that the staff had the patient's interests at heart.

'Need to stand up for what is right for the patients.'

However staff also felt promises were made but not delivered on for example the Patient Discharge Unit. These promises bolstered staff expectations and so staff felt demoralised when the promised improvements do not materialise. The consensus of the group was that the perception at ward level was that there was little in terms of forward planning which had led to significant amounts of 'fire fighting'. 


\section{Conclusions drawn from the Focus Group}

The following conclusions can be drawn from the findings of the nurse focus group.

- Named nursing was seen as the ideal

- The reality however was that team nursing was carried out but was dependant upon staff levels and service demands

- Staff felt that care was affected by institutional pressures

- The demands of other health care professions affected the organisation of care

- HCAs contribute to record keeping

- There was no perceived strategy for the sharing of good practice

- There was little perceived opportunity for team building or clinical supervision

- Changes in the dependency of ward populations was not reflected by changes in staffing establishment

\section{Root Definitions}

The data from the focus group together with that from the literature review contributed to develop root definitions of nursing care practice. In the SSM that underpins this study a root definition is a concise definition of an activity which captures a particular view or aspect. The development of root definitions allows the research team to have a consistent understanding of the activities being identified. Checkland and Scholes (1992) emphasise that whilst root definitions are used to identify the core transformation carried out by a specific system, they should be carefully constructed. This careful construction is facilitated by considering all of the elements that underpin that transformation. This is done by subjecting the system itself to a CATWOE analysis. CATWOE is the mnemonic that identified the elements under consideration, thus: 


\begin{tabular}{|l|l|l|}
\hline $\mathbf{C}$ & 'customers' & The victims or beneficiaries of ' $\mathrm{T}$ ' \\
\hline $\mathbf{A}$ & 'actors' & Those who would do ' $\mathrm{T}$ ' \\
\hline $\mathbf{T}$ & 'transformation process' & The conversion of input to output \\
\hline $\mathbf{W}$ & 'weltanschung' & $\begin{array}{l}\text { The worldview (or consensus) that makes this ' } \mathrm{T} \text { ' } \\
\text { meaningful }\end{array}$ \\
\hline $\mathbf{O}$ & 'owner(s)' & Those who could stop ' $\mathrm{T}$ ' \\
\hline $\mathbf{E}$ & 'environmental constraints & $\begin{array}{l}\text { The element outside of the system which is takes } \\
\text { as given }\end{array}$ \\
\hline
\end{tabular}

The following four root definitions were identified:

1. Organisation of care

2. Primary nursing

3. Team nursing

4. Task allocation (Functional nursing)

Each definition is presented and described in the CATWOE analysis framework so the differences between the definitions can be clarified.

\section{Root Definition: Organisation of Care}

A system owned and operated by health care staff which aims to provide high quality care to patients and is impacted upon by collegial and institutional pressures, patient experiences and expectations and which can affect the autonomy, professional growth, relationships and job satisfaction of nurses.

\section{CATWOE Analysis:}

Customers - the patients

Actors - the nurses

Transformation - no care $\rightarrow$ quality care

Weltanschung - the health care system

Owners - the institution

Environmental - nursing resources, patient expectations 


\section{Root Definition: Primary Care}

A system owned and operated by health care staff within a specific clinical care area with the aim of ensuring that an identifiable autonomous individual has responsibility for the planning, directing and delivery of high quality health care to a small group of specific patients.

\section{CATWOE Analysis:}

Customers - the patients

Actors - the nurses

Transformation - no specific responsibility for planning directing and delivering care $\rightarrow$ Individual planned quality care formulated by an autonomous identified individual

Weltanschung - Participatory, small group care environments

Owners - the nurses

Environmental - nursing leadership, practitioner autonomy, patient involvement

\section{Root definition: Team Nursing}

A system owned by ward managers and operated by health care staff within a specific clinical care area with aim of delivering care to a specific group of patients with responsibility devolved from the ward manager and shared across a small team of practitioners and support workers.

\section{CATWOE Analysis:}

Customers - the patients

Actors - the nurses

Transformation - no shared responsibility for care $\rightarrow$ responsibility for care shared across a small team of nurses and support workers

Weltanschung - devolved responsibility from ward manager

Owners - ward manager

Environmental - management control 


\section{Root Definition: Task Allocation (Functional Nursing)}

A hierarchical system owned and directed by ward managers who are responsible for the planning and direction of care for an entire specific clinical care area which is delivered to all patients in that care area by health care staff with the aim of supplying patient needs through the completion of a variety of tasks.

\section{CATWOE Analysis:}

Customers - the patients

Actors - the nurses

Transformation - no care organised or delivered $\rightarrow$ care broken into a number of patient tasks which are delivered by a large number of different practitioners across an entire clinical environment

Weltanschung - hierarchical delivery of care

Owners - ward manager

Environmental - management control, non-autonomous practitioners, entire ward population

\section{Conceptual Model of Organisation of Care}

Root definitions can be used to develop conceptual models in tandem with the findings of the literature review. Since the primary focus of this study is the organisation of nursing care, this is the conceptual model that was formulated at Stage One of the study. Conceptual models can be displayed pictorially by the generation 'rich pictures'. Checkland and Scholes (1992) argue that rich pictures can be used to show the existing situation. The rich picture in figure 3.1 is a visualisation of the elements that impact upon the organisation of nursing care, contextualised within the root definition outlined earlier. This rich picture provides the model against which clinical reality was evaluated in Stage Two of the study. 


\section{Understanding the Rich Picture}

The rich picture shows the issues that influence nursing care and patient experience. As the previously presented literature shows, nursing care is impacted upon by a variety of issues and concepts including;

How much independence nurses have in organising their care (autonomy) ${ }^{4}$ contributes to the amount of cross-disciplinary working they participate in (collaborative working). Melchior et al. (1999) note that nurses who are autonomous are more likely to find collaborative working achievable, this in turn contributing to how work is organised in the clinical area (systems of organising work). Whilst it is acknowledged that staff resources (Adams and Bond, 1997), the strain of meeting collegial pressures in terms of support and supervision of junior staff (McKenna, 1995) and the demands and expectations of the institution (institutional pressures) can affect how care is organised (systems of organising work). Mäkinen et al. (2003b) suggest that job satisfaction is impacted upon by all of the elements incorporated in the organisation of care. However, Boumans and Landeweerd (1999) suggest a correlation between all of these factors and work related stress.

So it can be seen that the 'ideal' model for nursing care is the one presented below in the rich picture (figure 3.1) with nursing care being seen as a multi-factorial concept which can contribute to the well-being and job satisfaction of the practitioner as well as ensuring high quality care for patients.

From a patient perspective, literature would suggest that family influences contribute to the overall patient experiences (Aharony and Strasser, 1993). As do individual expectations (Staniszewska and Ahmed, 1999) and psychological aspects such as fear and previous experiences (Larsson, 1999). Unfortunately, the lack of patient involvement in Stage One prevented the comparative analysis between the 'ideal' model for the organisation of nursing care and the patients' perspective at this stage.

\footnotetext{
${ }^{4}$ Italics refer to elements identified in the rich picture
} 
Figure 3.1 Rich Picture: Organisation of Care Concepts

Root Definition: Organisation of Care A system owned and operated by health care staff which aims to provide high quality care to patients and is impacted upon by collegial and institutional pressures, patient experiences and expectations and which can affect the autonomy, professional growth \& relationships and job satisfaction of nurses

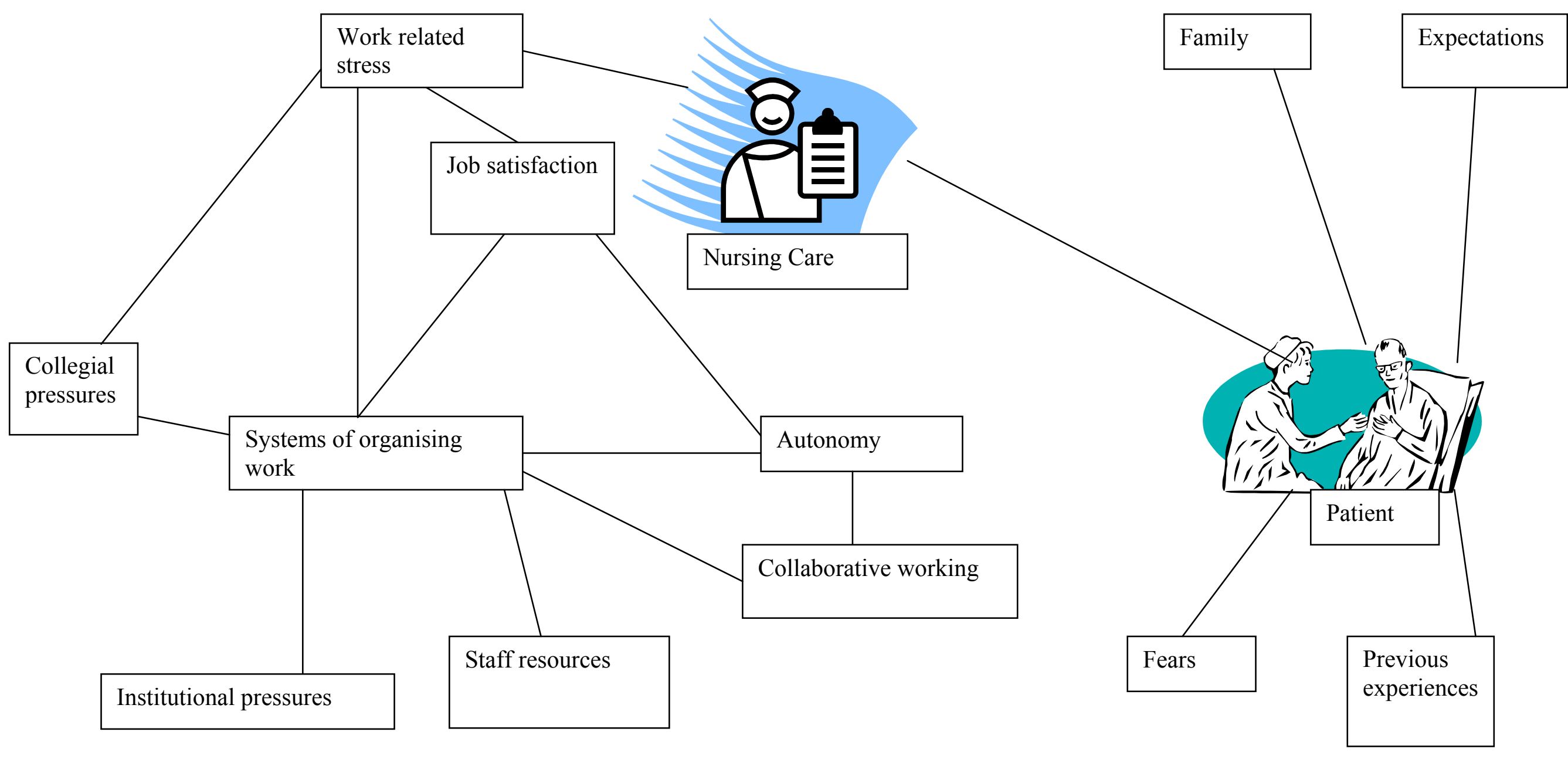




\section{Summary of Findings from Stage One}

Stage One of the study allowed comparisons with the model outlined in the rich picture and the experiences of the focus group participants (table 3.4).

\section{Table 3.4: Comparison of findings}

\begin{tabular}{|c|c|}
\hline Rich picture concept & Comparison findings \\
\hline \multicolumn{2}{|l|}{ Nursing Care } \\
\hline Autonomy & $\begin{array}{l}\text { - Staff generally felt supported and autonomous in } \\
\text { their practice }\end{array}$ \\
\hline Collaborative working & $\begin{array}{l}\text { - Demands of other health care professionals impacted } \\
\text { upon how care was organised } \\
\text { - Other agencies could make the nurses jobs easier }\end{array}$ \\
\hline Staff Resources & $\begin{array}{l}\text { - Staffing levels impact upon patient care } \\
\text { - High sickness rates on some wards }\end{array}$ \\
\hline Institutional pressures & $\begin{array}{l}\text { - Teamwork systems not seen to be useful for } \\
\text { organising and measuring workload } \\
\text { - Dependency levels seen as a 'paper exercise' } \\
\text { - Early Warning paperwork takes priority }\end{array}$ \\
\hline Collegial pressures & $\begin{array}{l}\text { - Covering sickness and working extra shifts affects } \\
\text { staff retention } \\
\text { - Reflection on poor practice only }\end{array}$ \\
\hline $\begin{array}{l}\text { Systems of organising } \\
\text { work }\end{array}$ & $\begin{array}{l}\text { - Record keeping time consuming } \\
\text { - Referral paperwork for patients excessive }\end{array}$ \\
\hline Work related stress & $\begin{array}{l}\text { - Staffing levels } \\
\text { - Increased patient dependency }\end{array}$ \\
\hline Job Satisfaction & $\begin{array}{l}\text { - There was little perceived opportunity for team } \\
\text { building or clinical supervision } \\
\text { - Nurses doing too many jobs }\end{array}$ \\
\hline \multicolumn{2}{|l|}{ Patients } \\
\hline Family & - Not perceived as sufficiently engaged in patient care \\
\hline Expectations & - Do not expect to get involved in their own care \\
\hline Patient & $\begin{array}{l}\text { - } \text { More dependent } \\
\text { - Nursed on inappropriate wards at times }\end{array}$ \\
\hline
\end{tabular}




\section{CHAPTER FOUR}

\section{STAGE TWO - NURSES PERCEPTIONS OF PATIENT CARE}

This chapter presents the findings of Stage Two of the study, describing the nurses' perceptions of the care they provide to patients and what factors inhibit and enhance that care. The findings from the ward questionnaire and the individual staff questionnaires are combined to provide a comprehensive overview of nursing care.

\section{Response Rate}

\section{Ward Questionnaire}

Twenty-three acute wards were identified for the study sample. The manager of each ward was sent a ward questionnaire asking them a series of questions to examine the method of how nursing care is organised and delivered. Nine questionnaires were returned initially, 14 follow up questionnaires were administered and a further ten received. In total 19 questionnaires were completed and returned giving a response rate of $82.6 \%$. Wards $8,13,17$ and 21 chose not to return the ward baseline questionnaire.

\section{Staff Questionnaire}

From the 23 acute wards every member of qualified staff that was on the off-duty rota was sent an individual addressed questionnaire. This excluded staff members who were on long-term sick and maternity leave, but included Assistant Practitioners who had completed their training. In total 391 questionnaires were administered and 97 were returned (24.8\%). Of the 97 questionnaires two questionnaires were excluded, one was returned but had not been completed whereas on the other a staff member had completed the questionnaire then removed the code on the questionnaire so as not to be identified. For the quantitative analysis the no code questionnaire was excluded 
because it was impossible to attach the responses to a specific ward. For the qualitative analysis the no code questionnaire was included and the comments themed along with the other questionnaires. Therefore for some analysis the total sample percentage will be calculated from $95(24.3 \%)$ or $96(24.55 \%)$ questionnaires.

Staff from wards 4 and 15 chose not to respond to the questionnaire. Therefore it is important to note that the findings presented will not reflect the perceptions of the staff from these two wards. Overall the percentage response rate from the staff on the individual wards was low across the grades ranging from $5.55-52.9 \%$ of the total staff sample (table 4.1). Wards 1,3 and 10 show a response rate of $50 \%$ or above.

Table 4.1: Staff Response Rate per Ward

\begin{tabular}{|c|c|c|c|}
\hline $\begin{array}{c}\text { Ward } \\
\text { code }\end{array}$ & $\begin{array}{c}\text { Total No. of } \\
\text { Qualified Staff }\end{array}$ & $\begin{array}{c}\text { Total No. Staff } \\
\text { Respondents }\end{array}$ & $\begin{array}{c}\text { \% Response } \\
\text { Rate }\end{array}$ \\
\hline 1 & 10 & 4 & 50 \\
\hline 2 & 8 & 1 & 12.5 \\
\hline 3 & 18 & 9 & 50 \\
\hline 4 & 20 & 0 & 0 \\
\hline 5 & 17 & 4 & 34.6 \\
\hline 6 & 16 & 2 & 12.5 \\
\hline 7 & 18 & 5 & 27.7 \\
\hline 8 & 18 & 1 & 5.55 \\
\hline 9 & 16 & 8 & 50 \\
\hline 10 & 17 & 9 & 52.9 \\
\hline 11 & 17 & 2 & 11.8 \\
\hline 12 & 19 & 7 & 36.8 \\
\hline 13 & 21 & 2 & 9.5 \\
\hline 14 & 19 & 4 & 21.1 \\
\hline 15 & 17 & 0 & 0 \\
\hline 16 & 15 & 3 & 20 \\
\hline 17 & 19 & 4 & 21.1 \\
\hline 18 & 17 & 4 & 23.5 \\
\hline 19 & 12 & 1 & 8.3 \\
\hline 20 & 23 & 6 & 26.1 \\
\hline 21 & 17 & 8 & 47 \\
\hline 22 & 20 & 8 & 40 \\
\hline 23 & 17 & 3 & $\mathbf{2 4 . 3 \%}$ \\
\hline Total & $\mathbf{3 9 1}$ & $\mathbf{9 5}$ & \\
\hline
\end{tabular}

From the 95 staff questionnaires returned, the breakdown of responses by staff grade is shown in table 4.2. A higher percentage of senior nurses ( $F$ and $G$ grades) 
responded to the questionnaires compared with the total sample breakdown of grades. However, the percentage grade breakdown of the actual sample who responded reflects that of the total sample contacted.

Table 4.2: Response Rate per Grade of Staff

\begin{tabular}{|c|c|c|c|c|}
\hline Grade & $\begin{array}{c}\text { Total No. } \\
\text { Staff } \\
\text { Sample }\end{array}$ & $\begin{array}{c}\text { Total No. } \\
\text { Respondents }\end{array}$ & $\begin{array}{c}\text { \% Response } \\
\text { Rate of Total } \\
\text { Sample of grade }\end{array}$ & $\begin{array}{c}\text { \% Response } \\
\text { Rate of Actual } \\
\text { Sample (n=95) }\end{array}$ \\
\hline AP & 13 & 3 & 23.1 & 3.16 \\
\hline D & 156 & 30 & 19.2 & 31.6 \\
\hline E & 156 & 39 & 25 & 41.05 \\
\hline F & 43 & 14 & 32.6 & 14.7 \\
\hline G & 22 & 9 & 40.9 & 9.5 \\
\hline I & 1 & 0 & 0 & 0 \\
\hline Total & 391 & 95 & \multicolumn{2}{c}{} \\
\cline { 1 - 3 } & \multicolumn{2}{r|}{}
\end{tabular}

The first part of the staff individual questionnaires involved a series of statements where staff members were asked to respond using a likert scale (questions 1-45). In this part some of the data items were missing, for these the total number and percentages were adjusted accordingly. Complete data for each individual question can be found in Appendix 2.

In the second part of the questionnaire staff members were asked to provide descriptive comments (questions 46 and 47). Of the 96 respondents (including the no code responder), 91 (94.8\%) staff members chose to add a qualitative comment to describe what inhibits their nursing care. In total 245 comments were recorded from staff belonging to 20 of the 23 wards studied (table 4.3). 
Table 4.3: What Inhibits Care - Qualitative Comments

\begin{tabular}{|c|c|c|c|c|}
\hline $\begin{array}{l}\text { Ward } \\
\text { Code }\end{array}$ & $\begin{array}{c}\text { Total No. } \\
\text { Comments }\end{array}$ & $\begin{array}{c}\text { No. people } \\
\text { Commenting }\end{array}$ & $\begin{array}{c}\text { Total No. of } \\
\text { Respondents }\end{array}$ & $\begin{array}{c}\text { \% Response } \\
\text { Rate }\end{array}$ \\
\hline 1 & 8 & 4 & 4 & 100 \\
\hline 2 & 4 & 1 & 1 & 100 \\
\hline 3 & 12 & 7 & 9 & 77.7 \\
\hline 4 & 0 & 0 & 0 & 0 \\
\hline 5 & 12 & 3 & 4 & 75 \\
\hline 6 & 10 & 2 & 2 & 100 \\
\hline 7 & 14 & 5 & 5 & 0 \\
\hline 8 & 0 & 0 & 1 & 87.5 \\
\hline 9 & 18 & 7 & 8 & 100 \\
\hline 10 & 20 & 9 & 9 & 100 \\
\hline 11 & 5 & 2 & 2 & 100 \\
\hline 12 & 23 & 7 & 7 & 100 \\
\hline 13 & 5 & 2 & 2 & 0 \\
\hline 14 & 8 & 4 & 4 & 100 \\
\hline 15 & 0 & 0 & 0 & 100 \\
\hline 16 & 6 & 3 & 3 & 100 \\
\hline 17 & 8 & 4 & 4 & 100 \\
\hline 18 & 13 & 4 & 4 & 100 \\
\hline 19 & 1 & 1 & 1 & 87.5 \\
\hline 20 & 17 & 6 & 6 & 100 \\
\hline 21 & 28 & 8 & 8 & 100 \\
\hline 22 & 20 & 7 & 8 & $\mathbf{9 4 . 8 \%}$ \\
\hline 23 & 9 & 3 & 3 & \\
\hline No code & 4 & 1 & 1 & $\mathbf{9 5}$ \\
\hline Total & $\mathbf{2 4 5}$ & $\mathbf{9 1}$ & & \\
\hline & & & & \\
\hline
\end{tabular}

Staff members were asked to describe what enhances their nursing care and 92 (95.8\%) staff completed this question. In total 154 comments were collated (table 4.4). Staff from ward 21 provided the highest number of comments (28) describing problems that impinge and inhibit the nursing care they provide. 


\begin{tabular}{|c|c|c|c|c|}
\hline $\begin{array}{c}\text { Ward } \\
\text { Code }\end{array}$ & $\begin{array}{c}\text { Total No. } \\
\text { Comments }\end{array}$ & $\begin{array}{c}\text { No. people } \\
\text { Commenting }\end{array}$ & $\begin{array}{c}\text { Total No. of } \\
\text { Respondents }\end{array}$ & $\begin{array}{c}\text { \% Response } \\
\text { Rate }\end{array}$ \\
\hline 1 & 7 & 4 & 4 & 100 \\
\hline 2 & 1 & 1 & 1 & 100 \\
\hline 3 & 16 & 9 & 9 & 100 \\
\hline 4 & 0 & 0 & 0 & 0 \\
\hline 5 & 5 & 4 & 4 & 100 \\
\hline 6 & 3 & 2 & 2 & 100 \\
\hline 7 & 11 & 5 & 5 & 100 \\
\hline 8 & 0 & 0 & 1 & 0 \\
\hline 9 & 12 & 7 & 8 & 87.5 \\
\hline 10 & 13 & 8 & 9 & 88.8 \\
\hline 11 & 4 & 2 & 2 & 100 \\
\hline 12 & 11 & 7 & 7 & 100 \\
\hline 13 & 3 & 2 & 2 & 100 \\
\hline 14 & 5 & 4 & 4 & 100 \\
\hline 15 & 0 & 0 & 0 & 0 \\
\hline 16 & 5 & 3 & 3 & 100 \\
\hline 17 & 5 & 3 & 4 & 75 \\
\hline 18 & 7 & 4 & 4 & 100 \\
\hline 19 & 1 & 1 & 1 & 100 \\
\hline 20 & 11 & 6 & 6 & 100 \\
\hline 21 & 15 & 8 & 8 & 100 \\
\hline 22 & 11 & 8 & 8 & 100 \\
\hline 23 & 6 & 3 & 3 & 100 \\
\hline No code & 2 & 1 & 1 & 100 \\
\hline Total & $\mathbf{1 5 4}$ & $\mathbf{9 2}$ & $\mathbf{9 5}$ & $\mathbf{9 5 . 8 \%}$ \\
\hline & & & & \\
\hline
\end{tabular}

For both the additional questions posed there were no additional qualitative comments offered from staff on wards 4, 8 and 15. A higher number of comments were received from the staff on ward 3 regarding what factors enhance the care they provide.

\section{Non-Participant Observation}

In total six wards were observed - wards 4, 6, 16, 17, 20 and 21. Three medical wards and three surgical wards were selected. Observation was repeated on each ward during an early shift for six continuous hours by the same researcher, providing 36 hours of observed nursing practice. The findings of the observation have been integrated within the themes generated from both the ward and staff questionnaire. 


\section{Categories, Themes and Sub-themes}

The quantitative responses from both the ward based questionnaire and the individual staff questionnaire were analysed using descriptive statistics and for the purpose of this section the findings are integrated within the themes emerging from the qualitative data set. The qualitative comments were analysed using a combination of content and thematic analysis methods to isolate and describe aspects of nursing care, which inhibit and enhance the organisation and delivery of nursing care.

Table 4.5: Categories and Themes

\begin{tabular}{|c|c|c|}
\hline \multicolumn{3}{|c|}{ Qualitative Data Themes } \\
\hline Category & Inhibit (No. comments) & Enhance (No. comments) \\
\hline $\begin{array}{l}\text { Organisation } \\
\text { of Nursing } \\
\text { Care }\end{array}$ & $\begin{array}{l}\text { Staff shortages }(71) \\
\text { Low staff morale }(11)\end{array}$ & $\begin{array}{l}\text { General organisation }(15) \\
\text { Team nursing (11) } \\
\text { Good Team relationships }(24) \\
\text { MDT Teamwork (2) } \\
\text { Continuity of Care }(2) \\
\text { Sufficient experienced staff (37) } \\
\text { Support from manager (3) }\end{array}$ \\
\hline $\begin{array}{l}\text { Delivery of } \\
\text { Nursing } \\
\text { Care }\end{array}$ & $\begin{array}{l}\text { Increased roles and expected } \\
\text { workload (16) } \\
\text { Dependency of patients (13) } \\
\text { Lack of Time (10) } \\
\text { Interruptions to care (59) } \\
\text { Bed issues (8) } \\
\text { Doctors (8) } \\
\text { Admissions/Discharges (7) } \\
\text { Relatives / visiting (7) } \\
\text { Staff Education / supervision (7) } \\
\text { Poor communication (8) }\end{array}$ & $\begin{array}{l}\text { Experience and motivation (19) } \\
\text { Appropriate patients/helpful } \\
\text { patients (6) } \\
\text { More time (8) } \\
\text { Less Interruptions to care (5) } \\
\text { Increased Medical support (3) } \\
\text { Education and Training (6) } \\
\text { Good communication (10) }\end{array}$ \\
\hline $\begin{array}{l}\text { Other Ward } \\
\text { Aspects }\end{array}$ & $\begin{array}{l}\text { Lack of equipment / stores (12) } \\
\text { Cleanliness of the ward (2) } \\
\text { Ward layout (3) } \\
\text { Government priorities(3) }\end{array}$ & Environment (3) \\
\hline
\end{tabular}

The themes were naturally grouped in two main categories, 'Organisation' and 'Delivery' of nursing care. Again a further category termed 'Other Ward Aspects' emerged concerned with environmental themes such as the ward layout, cleanliness and lack of equipment and stores. Table 4.5 summarises the main categories and themes/sub-themes, from the qualified staff perspective, for aspects that enhance and 
inhibit nursing care. The findings are presented under the main categories, grouped under the identified themes.

\section{Organisation of Nursing Care}

The organisation of nursing care category received a comparable number of comments describing inhibiting factors (82) and enhancing factors (94). Five distinct themes emerged:

- General Organisation of Nursing Care

- Team Working

- Staff Provision

- Staff Morale

- Leadership

\section{General Organisation of Nursing Care}

The majority of the ward managers, 95\% (18) perceived that the care on their ward was organised within a model of team nursing. Only one manager felt that the ward used a primary nursing approach (table 4.6).

Table 4.6: Method used to organise nursing care

\begin{tabular}{|l|l|}
\hline Primary Nursing & $1(5 \%)$ \\
\hline Team Nursing & $18(95 \%)$ \\
\hline Task Allocation & $0(0 \%)$ \\
\hline
\end{tabular}

The in-depth analysis based upon the responses to the entire questionnaire confirmed that the overall method of organisation of care was that of team nursing. Table 4.7 shows the care organisation categories that were determined from the questionnaire responses. It indicates that $47 \%$ (9) of the wards were operating team nursing at a low level and $10.5 \%$ (2) of the ward were organising their care via a task allocation model. No wards evaluated operated a primary nursing approach. 
Table 4.7: Organisation of care categories

\begin{tabular}{|c|c|c|}
\hline & $\begin{array}{l}\text { No. of } \\
\text { Wards }\end{array}$ & Ward Code \\
\hline Strong team & 1 & 9 \\
\hline Moderate Team & 7 & $1,4,5,15,16,19,23$ \\
\hline Weak Team & 9 & $2,3,6,7,11,14,18,20,22$ \\
\hline Strong Task & 1 & 10 \\
\hline Moderate Task & 1 & 12 \\
\hline Total & 19 & \\
\hline
\end{tabular}

The nurse questionnaire findings verified that team nursing is seen as the most used model, with $83 \%$ (79) of staff respondents highlighting that care is organised in teams on their ward always or often (table 4.8).

Observation highlighted that all wards were organising nursing care within a team framework in varying degrees. Five out of six wards operated three teams and one ward with a reduced number of patients organised nurses into two teams. For four of the wards off duty was organised into teams of the same staff, one ward organised off duty as a whole and another operated self-rostering. The overall view was that staff usually worked where they had previous experience of the patients, continuity for the patient was seen as more important than staying in a particular team. The off duty skill mix and patient dependency on the day of the shift influenced where and who worked in which team.

There are indications that task allocation is more widely used than suggested by the data obtained from the ward questionnaire with $38.9 \%$ of staff using task allocation always or often. 
Table 4.8: Staff perceptions of how care is organised

\begin{tabular}{|l|c|c|c|}
\hline & Always/Often & Occasionally & Rarely/Never \\
\hline Care is organised in teams on & 79 & 2 & 13 \\
my ward & $83.1 \%$ & $2.1 \%$ & $13.7 \%$ \\
\hline $\begin{array}{l}\text { We use primary nursing to } \\
\text { organise patient care }\end{array}$ & 63 & 4 & 22 \\
\hline I work in a task orientated & $66.3 \%$ & $4.2 \%$ & $23.2 \%$ \\
environment & 37 & 23 & 35 \\
\hline $\begin{array}{l}\text { Patient care on the ward is well } \\
\text { organised and of a high quality }\end{array}$ & $82.9 \%$ & $24.2 \%$ & $36.8 \%$ \\
\hline
\end{tabular}

Nurses $(86.4 \%)$ perceived that the patient care on the wards was well organised and of a high quality. It was however suggested that patient care is enhanced when there is effective organisation on the ward. Fifteen descriptive comments suggested that effective organisation and 'good time management' or 'time management skills' ensure that:

'...patients get a good quality of care and ensures all ward tasks are completed and that the ward runs smoothly and efficiently, therefore enhancing the care that patients receive.' (W11)

The organisation of patient care is enhanced when there is:

'Enough time and staff to spend quality time with patients'. '(W9)

'A ward co-ordinator who is not attached to a team to run and manage the ward.' (W7)

'Good team leader to co-ordinate the ward.' (W21)

'Effective team management by shift leader/ward manager.' (W21)

Eight staff identified that the team nursing approach enhanced patient care and improved the organisation of the nursing care.

'Well organised team approach to providing a high standard of nursing care.'

'Teamwork, nursing staff organised into 3 teams on the ward.' (W10) 
'Keeping to team nursing. This way, if you continuously work in your own team

- off duty must reflect this - you have a very good picture of where each

individual patient's care and planned discharge is up to. Nothing gets missed.'

(W16)

'Allocated bay means you can concentrate on your group of patients.' (W22)

Working in teams, providing qualified staff with a group of patients to care and be responsible for was considered a useful approach to facilitate autonomy and job satisfaction amongst nurses.

I think allowing qualified staff their own team of patients and autonomy allows for their satisfaction and development and confidence. The patients and visitors respond to this style of rapport and gives them confidence and build up a holistic approach in getting to know them as a person and their life as an individual, rather than a patient in a bed.' (W21)

When staff were asked if they worked autonomously, only one respondent (1.1\%) felt that they were unable to practice in an autonomous manner with $89.5 \%$ (85) of respondents indicating they always or often practised autonomously and had the authority to direct patient care (table 4.9).

Table 4.9: Professional issues in the organisation of care

\begin{tabular}{|l|c|c|c|}
\hline & Always/Often & Occasionally & Rarely/Never \\
\hline $\begin{array}{l}\text { I can work autonomously and } \\
\text { have the authority to direct } \\
\text { patient care }\end{array}$ & 85 & 9 & 1 \\
\hline $\begin{array}{l}\text { I have more responsibility than I } \\
\text { can cope with }\end{array}$ & $29.5 \%$ & $9.5 \%$ & $1.1 \%$ \\
\hline
\end{tabular}

Two nurses highlighted that only when they are able to organise their own workload freely the patient care they provide is enhanced, this suggests that at times their autonomy is constrained. 
'Being able to organise workload effectively.' (W20)

'Being able to organise your work freely.' (W20)

Opposing perceptions of the amount of responsibility were equivalent with $30.5 \%$ (29) of respondents indicating that they always or often had more responsibility that they could cope with and $28(29.5 \%)$ suggesting that this was rarely or never the case.

Two other responses suggested that by organising care into teams the continuity of patient care is enhanced.

'Providing care for the same group of patients, I feel enhances care.' (W21)

\section{Team Working}

Twenty-four staff (of which 20 were D/E grades) took the opportunity to highlight the importance of team working and good relationships between team members that enhances the standard of patient care provided.

'Nursing team work together well.' (W12)

'Good teamwork.' (W21)

'Willing staff - working together as a team.' (W23)

'Good staff relationships.' (W3)

Important factors that are perceived to promote and facilitate the effectiveness of a team working together can be isolated. These include, supporting each other, having a team with a good skill mix, sharing the same goal of achieving a high standard of patient care, being flexible and communicating effectively.

'All the staff work well together and have the patients' best interests at heart.' (W10)

'A lot of goodwill from junior staff. All staff work above and beyond their paid hours each week.' (W7) 
'A good team of nurses with good skill mix is important and helps to provide patient care properly.' (W11)

'Working as a team, trying to achieve patient care to maximum with limited resources and staff.' (W12)

'Teamwork - working in teams which remain the same helps you learn how others in your team work and you get along with each other, knowing who does what in your team.' (W16)

Overall the strength of relationships both within nursing teams and as part of the multi-professional team were seen as positive with $62.1 \%$ of respondents (59) feeling that they had the respect of professional colleagues and $66.3 \%$ feeling that team relationships enhanced patient care (table 4.10).

Table 4.10: Team Relationships

\begin{tabular}{|l|c|c|c|}
\hline & Always/Often & Occasionally & Rarely/Never \\
\hline Team relationships enhance the & 63 & 16 & 13 \\
way you organise your care & $66.3 \%$ & $16.8 \%$ & $13.7 \%$ \\
\hline $\begin{array}{l}\text { Multi-professional team members } \\
\text { respect the nursing care and }\end{array}$ & 59 & 30 & 6 \\
integrate their care well & $62.1 \%$ & $31.6 \%$ & $6.4 \%$ \\
\hline $\begin{array}{l}\text { My manager treats me as an } \\
\text { individual }\end{array}$ & 71 & 7 & 3 \\
\hline I am listened to and get a lot of & $69.8 \%$ & $7.4 \%$ & $3.3 \%$ \\
support from my colleagues & $77.6 \%$ & 18 & 8 \\
\hline
\end{tabular}

Collegial support is perceived to be high with $77.6 \%$ of respondents obtaining support from their co-workers, also perceptions of line mangers are positive with $74.8 \%$ (71) stating that they were treated as an individual by their manager always or often. Support from the manager is considered to be important for both nurses and patients.

'Supportive/active/involved senior staff enable other staff to carry out duties more efficiently, knowing they have help at hand should it be needed. This impacts on the patients' perception of staff capabilities.' (W20) 


\section{Staff Provision}

In the main staff questionnaire nurses were asked to rate how often or if at all, staffing levels influenced how much care they could provide and whether there were sufficient numbers of nurses available to organise and deliver patient care (table 4.11).

\section{Table 4.11: Staffing Provision}

\begin{tabular}{|l|c|c|c|}
\hline & Always/Often & Occasionally & Rarely/Never \\
\hline $\begin{array}{l}\text { Staffing levels directly influence } \\
\text { how much care you can provide }\end{array}$ & 81 & 14 & 0 \\
for the patients & $85.2 \%$ & $14.7 \%$ & $0 \%$ \\
\hline $\begin{array}{l}\text { The are a sufficient number of } \\
\text { nurses available to provide } \\
\text { adequate care for patients }\end{array}$ & $33.7 \%$ & 26 & 35 \\
\hline
\end{tabular}

The majority of staff $(85.2 \%)$ perceived that staffing levels always/often influenced how much patient care could possibly be provided. Opinion however, was split on how often there were sufficient nurses to provide adequate patient care, a slight majority of $36.9 \%$ suggested that it was rare to come on a shift and have sufficient staff.

Table 4.12: Skill Mix

\begin{tabular}{|l|c|c|c|}
\hline & Always/Often & Occasionally & Rarely/Never \\
\hline $\begin{array}{l}\text { Working with inexperienced staff } \\
\text { changes the way you organise your } \\
\text { patient care }\end{array}$ & $66.5 \%$ & 19 & 10 \\
\hline $\begin{array}{l}\text { The skill mix within the team is } \\
\text { sufficient to provide a high quality } \\
\text { of patient care }\end{array}$ & $71.6 \%$ & $20.0 \%$ & $10.6 \%$ \\
\hline $\begin{array}{l}\text { Inexperienced staff within the } \\
\text { team result in patient care } \\
\text { becoming task orientated }\end{array}$ & $31.6 \%$ & $38.9 \%$ & 7 \\
\hline
\end{tabular}

The problem nurses face when organising care is not just a shortage of staff but $69.5 \%$ of respondents identified that working with inexperienced staff directly influences how nursing care can be organised. It was perceived that the skill mix was often 
(71.6\%) sufficient to ensure a high standard of patient care was achieved. However it was acknowledged that inexperienced staff, occasionally $(38.9 \%)$ or often $(31.6 \%)$, cause a disruption to team nursing (table 4.12). To use nurses' skills effectively, care is organised through tasks.

Observation highlighted that all wards ran the teams with minimum staffing levels (table 4.13). Usually there was one qualified staff member working in each team supported by health care assistants or house keepers.

Table 4.13: Staffing Levels

\begin{tabular}{|c|c|c|c|c|}
\hline $\begin{array}{l}\text { Ward } \\
\text { Code }\end{array}$ & $\begin{array}{c}\text { No } \\
\text { patients }\end{array}$ & $\begin{array}{l}\text { No Qualified } \\
\text { staff }\end{array}$ & $\begin{array}{c}\text { No. of } \\
\text { Unqualified staff }\end{array}$ & $\begin{array}{c}\text { Patient / } \\
\text { Qualified Nurse } \\
\text { ratio }\end{array}$ \\
\hline 4 & 27 & $\begin{array}{l}3 \text { Qualified } \\
1 \text { F grade - CO* }\end{array}$ & $\begin{array}{l}2 \mathrm{HCAs} * \\
1 \text { student } \\
1 \mathrm{WC}(+2 \mathrm{HCWs} \\
\text { training as WCs) }\end{array}$ & $9: 1$ \\
\hline 6 & 27 & $\begin{array}{l}3 \text { Qualified } \\
1 \text { G grade - CO }\end{array}$ & $\begin{array}{l}3 \text { HCAs } \\
2 \text { students } \\
1 \text { WC }\end{array}$ & $9: 1$ \\
\hline 16 & 27 & $\begin{array}{l}4 \text { Qualified } \\
1 \text { F grade - CO }\end{array}$ & $\begin{array}{l}2 \text { HCAs } \\
2 \text { students } \\
1 \text { WC }\end{array}$ & $\begin{array}{l}8: 1 \text { (2 teams) } \\
8: 2(1 \text { team })\end{array}$ \\
\hline 17 & 15 & $\begin{array}{l}2 \text { Qualified } \\
1 \text { G grade - CO }\end{array}$ & $\begin{array}{l}1 \mathrm{HCA}(1 \mathrm{HCA} \text { off } \\
\text { sick) } \\
1 \mathrm{HK}^{*} \\
1 \mathrm{WC}\end{array}$ & $8: 1$ \\
\hline 20 & 25 & $\begin{array}{l}2 \text { Qualified } \\
1 \text { AP* } \\
1 \text { E grade agency (1 E } \\
\text { off sick) } \\
1 \text { I grade }-\mathrm{CO} \\
\text { (morning only) }\end{array}$ & $\begin{array}{l}2 \text { HCAs } \\
1 \text { TAP } \\
1 \text { student } \\
\text { (WC off sick) }\end{array}$ & $8: 1$ \\
\hline 21 & 25 & $\begin{array}{l}2 \text { Qualified (1 E } \\
\text { emergency holiday) } \\
1 \text { G grade - CO }\end{array}$ & $\begin{array}{l}2 \text { HCAs (1 A grade } \\
\text { agency off sick) } \\
1 \mathrm{HK} \\
1 \mathrm{WC}\end{array}$ & $8: 1$ \\
\hline $\begin{array}{l}\text { Key: } \\
* C O= \\
* W C=\end{array}$ & $\begin{array}{l}\text { rdinator } \\
\text { d Clerk }\end{array}$ & $\begin{array}{l}* H C A=\text { Health Care Ass } \\
* T A P=\text { Trainee Assistant }\end{array}$ & $\begin{array}{l}\text { unt } * H K=\text { House } 1 \\
\text { actitioner } * A P=1\end{array}$ & ant Practitioner \\
\hline
\end{tabular}

It was observed on ward 16 only, that two qualified staff worked together in one team increasing the patient to qualified staff ratio to $8: 2$ from the average $8: 1$. Across the 
six wards on the day of observation three of the wards experienced staff sickness. In total one qualified nurse, two health care assistants (one of which was agency) and one ward clerk were unable to work. One other ward had a staff nurse take an emergency holiday which left the teams depleted of qualified staff and resulted in the ward co-ordinator having to take an allocation of patients.

Seventy-one respondents $(74.7 \%)$ reiterated through their qualitative comments that a shortage of staff, and inappropriate skill mix upon the wards inhibited the delivery of patient care. Staffing provision was described as 'inappropriate', 'inadequate', 'insufficient', 'poor staffing levels, 'shortage of staff' and 'lack of staff'.

The insufficient number of qualified staff on shifts impacts directly on how patient care is organised. This proved a particular problem for D (31\%) and E (45\%) grade staff nurses. It is perceived that patient care is often compromised or the standard of care provided not as high, as a result of staff shortages, this at times causes care to become task orientated rather than patient orientated.

'Shortages mean that sometimes care is compromised as other priorities have to be dealt with.' (WI)

'There are rarely enough trained staff on a shift to ensure high standards of care.' (W7)

'When doing the work of two, unable to give patients what I consider to be quality care. Care becomes task-orientated, not patient-orientated. Feel like I am made to cut corners in order for basic care and tasks to be given.' (W21)

'Nurses spread too thinly, not enough HCA's particularly. Feel rushed, tired, often low spirits of staff. Want to give more one-to-one attention with patients, but feel unable to.' (W21)

The organisation of patient care is further disrupted when staff members are 'borrowed' by other wards experiencing a staff crisis, usually due to staff sickness. This impacted further by an increasing workload.

'Staff being taken away to other wards to make up their numbers, leaving us short-staffed of qualified staff, especially at night.' (W12) 
'Increasing workload not matched to staffing levels.' (W16)

'Insufficient numbers of staff on duty on a shift. Can at times become very difficult doing multiple admissions as well as providing care to existing patients with limited numbers of staff on duty.' (W20)

'Inhibiting factors are often minimum numbers on the ward - 3 qualified, no coordinator. Co-ordinator trying to manage a team and do everything else within the ward... If someone becomes poorly or deteriorates, difficult to cope on a busy acute ward.' (W21)

Inappropriate skill mix of staff is also a real problem for the nurses organising patient care. It is perceived that patient care is inhibited as a result of the need for constant supervision of junior staff. Delegating tasks is difficult and patients are sometimes allocated to inexperienced staff based on the 'quietest bay' rather than what specific care is required and whether staff possessed the necessary skills to provide it.

'Staffing levels and inappropriate skill mix can affect nursing care within the ward area.' (WI)

'You are not able to delegate - you end up doing everything yourself.' (W12)

'Constant supervision of inexperienced staff is also an issue in an acute setting. I need experienced staff to care for the patient but this doesn't always occur.' $(W 7)$

'I look at the patient dependency in each bay, the amount of empty beds, patients expected, also time of day, and then select nurse to each bay. Unless they have been in the same bay the day before and patients are the same, I would place the least experienced nurse in the 'quietest bay' which may inhibit quality care.' (W20)

'Working with inexperienced staff and expected to organise own group of patients' care, and oversee staff as well.' (W21)

At times a shortage of staff leaves nurses feeling like the care they provide is not good enough or that they are not meeting the needs of their patient group.

'Feel like I am made to cut corners in order for basic care and tasks to be given.' (W21) 
'Feeling unsupported in the care I deliver, knowing that I cannot meet all the needs of my patients.' (W12)

A high proportion of nurses $(89.5 \%)$ recognised that staff sickness always/often or occasionally compromised patient care. Eight staff, in particular five F grades, reported devoting extra time to sort out staffing levels and cover shifts, which impacted on their time available to provide direct patient care.

'Sorting out problems, managing (staff) sickness-therefore lower levels. Due to time consumption, takes you away from the patient, variable on day-to-day basis.' (W1)

'Constant interruptions, staffing issues such as sickness and covering shifts.' (W3)

To try and make up the shortfall in staff, agency nurses are called upon to deliver patient care and maintain adequate staffing levels. This is perceived to inhibit the organisation of patient care as the majority of agency staff were both unfamiliar with the ward and the patient group. A result of using agency staff the standard of care is perceived to be compromised.

'Bank/agency staff employed to nurse these patients do not always provide same standard of care.' (W2)

Usually 3 of the 6 staff on duty every morning are bank staff, not so familiar with ward and not knowing patient.' (W10)

'Lack of qualified staff who know the ward (working short-staffed or with bank staff regularly).' (W10)

Ward 20 had recruited a bank/agency worker who regularly covered shifts for the ward. This meant that they were already familiar with the ward layout, routine and organisation and when observed functioned as a valuable member of the nursing team.

It was no surprise that when asked what would enhance patient care 37 staff members suggested having 'enough staff' and 'appropriate staffing levels.' This would enable them to deliver a high standard or patient-centred care rather than achieving the 
minimum level of care they feel they are providing, and it would also facilitate the organisation of nursing teams.

'Having adequate staff, therefore having time to actually deliver patient care. It is really good when I can actually provide total care to a patient.' (W6)

'Balance staffing level in each shift to provide proper care to patients.' (W9)

'Being fully staffed with the appropriate grades of staff so that the three teams of nurses managing three smaller groups of patients on the 26-bedded ward can deliver primary care nursing correctly.' (W12)

'Being given the appropriate amount of time and members of staff to deliver a high standard of care to all patients. Spending time talking to them and looking after their psychological, as well as physical, well-being.' (W22)

For some staff members having a full compliment was not enough. Nine staff went further to suggest a 'good skill mix' and 'competent' staff, so the responsibility for patients was shared evenly across team members.

'Skilled, competent staff at all levels, who are reliable and have effective communication and organisational skills.' (W5)

'Good skill mix. This enables me to delegate tasks appropriately, i.e. HCA with NVQ at level III to admit patients and record observations. This gives me more time to spend discussing pre and post-op care, counselling patients and discussing various procedures carried out.' (W13)

\section{Staff Morale}

Staff responses indicated ambivalence towards staff morale with $28.5 \%$ (27) feeling that morale is always or often high amongst the staff, 32.6\% (31) arguing that it was rarely or never high and 35.8\% (34) feeling that morale was occasionally high. A large majority however, $75.7 \%$ (72) felt that the nursing staff were always or often overtired and overworked (table 4.14). 
Table 4.14: Staff Satisfaction in the Organisation of Care

\begin{tabular}{|l|c|c|c|}
\hline & Always/Often & Occasionally & Rarely/Never \\
\hline Staff morale is high & 27 & 34 & 31 \\
& $28.5 \%$ & $35.8 \%$ & $32.6 \%$ \\
\hline Nurses are tired and overworked & 72 & 20 & 3 \\
& $75.7 \%$ & $21.2 \%$ & $3.2 \%$ \\
\hline
\end{tabular}

From the qualitative comments ten $\mathrm{D} / \mathrm{E}$ grade staff made reference to staff morale being 'low'. Various reasons were offered to explain why morale was thought to be low: insecurity of staff jobs and grades; lack of enthusiasm; feeling dissatisfied with the level of patient care being provided; feeling rushed and tired; staff attitudes and moaning; and the pressure of the workload. The examples below capture staff perceptions.

'Low staff morale can make difficulties due to lack of enthusiasm.' (W13)

'You can only do so much in one shift. I try to prioritise what I do and delegate to others what they can do, but I find myself giving second-rate care on some shifts, which leaves me extremely dissatisfied and de-motivated.' (W16)

'Feel rushed, tired, often low spirits of staff.' (W21)

'Staff attitude. Making others feel isolated.' (W10)

'Not working together in a team - the vibes and attitudes.' (W12)

'Pressure at work.' (W17)

Nurses identified that negative personalities or specific people on the ward interfere with how care is organised, always/often or occasionally (62.1\%).

\section{Leadership}

Overall $63 \%$ of ward managers perceived that leadership on the wards operated using a mixed method approach, with the senior nurse at times independently making decisions and at other times involving staff. The remaining 37\% identified that all staff were involved in making decisions. Two managers had opposing views regarding the role of the senior nurse in making decisions regarding nursing care, one 
perceived it to be a central role and the other advisory. The other ward managers (17) felt that they were both central and advisory in their approach to making decisions about nursing care.

Shift managers/team leaders were perceived by $92.7 \%$ staff to positively influence how nursing care is organised, either always/often or occasionally. The majority view (48.4\%) was that shift managers/team leaders rarely/never caused nursing care to be disorganised. However, a further $50.6 \%$ staff indicated that occasionally (40\%) and always/often (10.6\%) shift managers/team leaders did cause care at times to become disorganised.

One E grade suggested that if a team/ward has good leadership then morale is improved, another E grade intimated that a contented workforce achieves more.

'When a team is led well morale is improved. A good manager of the ward is very important and leads the team well and morale is improved.' (W11)

'A happy workforce reaps rewards.' (W13)

Effective leadership was clearly observed on some wards demonstrated by the person within the role of the co-ordinator. Some co-ordinators took the time to advise staff, assist in patient care, and to a lesser degree to explain and teach clinical practice.

\section{Delivery of Nursing Care}

The delivery of nursing care category received three times more negative comments describing inhibiting factors (143) compared with enhancing factors (57). Seven key themes emerged:

- Who Does What?

- Patients Dependency

- Lack of time

- Interruptions to Nursing Care Delivery

- Supervision/Education 
- Personality and Experience

- Communication

\section{Who Does What?}

Professionally qualified staff members were unanimous in their perceptions of full accountability for the care they provide. Only four respondents (4.2\%) felt that they only rarely or never got the opportunity to use all of the skills at their disposal. Although $34.7 \%$ (33) specify that there is always or often sufficient staff on wards to provide care, $60 \%$ of respondents (57) indicated that patient care was being delegated to less qualified staff and a further $31.6 \%$ (30) suggested that this was the case occasionally (table 4.15).

Table 4.15: Delegating Tasks

\begin{tabular}{|l|c|c|c|}
\hline & Always/Often & Occasionally & Rarely/Never \\
\hline $\begin{array}{l}\text { To achieve the patient care expected } \\
\text { nurses need to delegate many tasks to less } \\
\text { qualified staff }\end{array}$ & 57 & 30 & 7 \\
\hline $\begin{array}{l}\text { Delegating tasks to inexperienced staff } \\
\text { reduces the quality of the patient care }\end{array}$ & $26.3 \%$ & $31.6 \%$ & $7.4 \%$ \\
\hline
\end{tabular}

When asked about the roles and responsibilities of others in the team, $85.3 \%$ of respondents identified that role definition was clear. However, workload was described as 'heavy' and many qualified staff needed to delegate tasks and aspects of nursing care to less qualified staff.

Observation of the six wards highlighted that for three out of the six wards (wards 4 , $6,20)$ much of the basic personal care of the dependent patients was performed by health care assistants. Two wards have been selected to demonstrate the differences in the activities and tasks performed by the qualified and unqualified staff (see table 4.16 in Appendix 3). 
On ward 6 health care assistants performed 'double' care for the more dependent patients, usually in pairs, not attached to any particular team. The qualified nurses' time was consumed administering medication and performing technical nursing tasks. Without delegating personal care the patient would have waited for a wash as this was less of a priority than ensuring all patients received their medication, intravenous and controlled drugs at the appropriate time. The health care assistants on ward 6 were very attentive to the needs of more dependent patients, taking time to ensure they had help eating and drinking and were comfortable. This observation was a snapshot in time and the activities and tasks observed could change daily reacting to the dependency of the patients and the staff skill mix.

A similar delegation took place on ward 21 , where the qualified member of staff administered medication and health care assistants cared for patients who could not wash themselves. On both these wards and ward 4, a more task orientated organisation approach to nursing care was adopted to achieve the expected workload and provide patient care with the staff available.

On ward 16 however, where two nurses were available to provide care to more dependent patients (allocated to the two bays observed) roles changed and the nurses were able to provide total patient care. This suggests that when there are 'sufficient' nurses available, care resorts back to being controlled and administered by the qualified nurse. On this ward the medicine round took less time generating more time for the nurses to provide personal care for their patients. A framework of total care was provided for all patients within the team by the qualified staff, rather than task allocation where the care of the patient is split between many different staff doing different tasks.

On ward 17 during the period of observation there were less dependent patients and nurses had the time available to perform much of the direct patient care. Ward 21, in the bays observed the patients appeared less dependent which was fortunate as the qualified staff time was consumed with administering and reviewing medication. 
Two staff commented on the increased technical aspects of nursing care which inhibited the care they could provide for patients. One staff member saw these technical tasks as a way to spend time at the patient's bedside and build a relationship with the patient.

'More responsibilities/tasks placed on the nursing staff from junior doctors.' $(W 21)$

'Nurses are adopting more clinical based skills, i.e. junior doctor!' (W22)

'Staff on the Unit have many extended roles - cannulation, bloods, e.g., male catheterisation. Most of our work is extended but it helps build up good relations with the patient.' (W3)

Five out of the six wards had a co-ordinator on the shift observed. One particular issue arose with the role of ward co-ordinator for $\mathrm{F}$ grade nurses. This was the conflict between having to co-ordinate the ward, look after a team of allocated patients and perform managerial duties.

'No clear, acceptable definition of my role. I am expected on most shifts to take charge and co-ordinate the ward, have a case load of patients and be responsible for the bleep which covers 2 wards. It appears that management issues, such as problem solving, covering staff sickness, dealing with anxious relatives, takes precedence.' (W7)

'I often feel inhibited due to external factors, especially if am ward coordinator, and have a team. There too many other demands made upon me that stop me from providing the care I want to provide.'(W17)

'Being in charge of the 25 bed unit and also looking after 7-10 patients, some acute admissions causes an inability to assess the patient effectively.' (W20) 'Also if I am co-ordinating the unit and have to take a bay of 7-9 patients, it compromises care and support for other staff.' (W20)

There was a problem observed with juggling these activities and ultimately the patient care suffered or was delayed as a result of other activities which needed to be done. 
'No-one to act as a co-ordinator so lots of time is spent on ward rounds, answering queries and telephone calls.' (W22)

This conflict of caring for patients and co-ordinating the ward was evident on ward 21 where due to an emergency annual leave day the ward was short staffed and the coordinator needed to care for a group of patients. Whilst trying to provide patient care the qualified nurse was repeatedly interrupted to answer phone calls (eight times), check intravenous drugs (ten times), answer queries from the ward clerk (four times) and answer questions (three times) from other agencies on the ward (for example Drug Team, Venepucture and Specialist Team for Older People). These interruptions would normally have been resolved by the ward co-ordinator and the qualified nurses would spend more time providing patient care.

\section{Table 4.17: Example of Co-ordinators role}

- Organises patient case conference

- Helps nurses provide patient care - lifting patients and washing dependent patients

- Communicates patient care to physiotherapist

- Checks controlled drug with staff nurse and administers medication to patient

- Checks and administers Oromorph to patients freeing up the time of the staff nurse

- Communicates continually to members of the different teams

- Speaks to patients relatives

- Covers nurses during breaks and works in their team area

- Gets clean sheets and makes beds

- Gets notes ready for ward round

- Communicates with COAD Team in preparation for a patients discharge

- Talks to bed manager

- Twice takes bed status to another ward to report to bed manager as too busy to attend planned bed meeting

- Takes 8 minute call regarding transfer of patient from another hospital

- Sorts out medicine query for staff nurse with doctor

- Reminds relatives regarding visiting policy during meal times

- Checks intravenous drugs with nurses

- Accompanies doctors on ward round

- Organises patient discharges to discharge lounge

- Telephones patients relatives regarding discharge

- Telephones bed manager regarding discharges

Ward 16 demonstrated an effective co-ordinators role and the activities performed have been captured and listed in table 4.17, it's important to remember this was what 
was observed so it may not be an exhaustive list but provides a good overview. This effective management structure supported the team nurses at the patient's bedside to provide direct patient care.

\section{Patient Dependency}

Patient dependency always or often has a direct impact on how patient care is both organised and delivered (table 4.18). Care is difficult to organise when there are demanding patients. Conversely, when the patient assists in their own care it facilitates the organisation and delivery of nursing care.

\section{Table 4.18: Patient Dependency}

\begin{tabular}{|l|c|c|c|}
\hline & Always/Often & Occasionally & Rarely/Never \\
\hline $\begin{array}{l}\text { The level of patient dependency } \\
\text { impacts on how care is organised }\end{array}$ & 80 & 9 & 5 \\
\hline $\begin{array}{l}\text { The more a patient becomes } \\
\text { involved in their care the easier it } \\
\text { is to organise }\end{array}$ & $69.2 \%$ & $9.5 \%$ & $5.3 \%$ \\
\hline $\begin{array}{l}\text { Care is hard to organise when a } \\
\text { patient is demanding or requires a } \\
\text { lot of attention }\end{array}$ & $55.8 \%$ & $22.2 \%$ & $4.2 \%$ \\
\hline $\begin{array}{l}\text { Patient care is organised around } \\
\text { the needs of the individual patient }\end{array}$ & $98.6 \%$ & $37.9 \%$ & 6 \\
\hline $\begin{array}{l}\text { Patients who shout loudest get the } \\
\text { most attention and the best care }\end{array}$ & 21 & 4 & $6.4 \%$ \\
\hline
\end{tabular}

It was observed on ward 4 and ward 16 that the co-ordinator of the ward assisted certain teams with more dependent patients to provide the personal care for those patients, freeing up the staff nurse to check and administer medications. Within the current staffing levels patients would wait longer for care without this support. This was observed as an effective use of the co-ordinator role. Ward 6 chose to organise care by delegating tasks to the health care assistants who worked in pairs to provide care for more dependent patients, so the staff nurses could focus on administering medication. 
Patient dependency issues were raised by 13 respondents within the qualitative comments. The first issue identified by 11 respondents was that they perceived patient dependency to have increased with more 'poorly' or 'high dependency' patients being admitted.

'The high volume of DHU/ICU step-downs and palliative care patients inhibits all patients' care.' (W20)

'Patients on ward are usually high maintenance.' (W9)

'Increasingly, poorly patients admitted onto ward or become unwell after transport.' (W10)

'Heaviness of patient care, dependency of patients and extent of their illnesses.' $(W 7)$

Three respondents explained that the reduced level of staff and increased patient dependency resulted in some patients not getting the 'time and attention' they require and the need to delegate tasks to unqualified staff to accomplish the expected workload.

'Patient dependency and not enough staff to provide care.' (W9)

'Reduced numbers of staff, in that the ratio of nurse to patients is reduced and, if your team of patients are requiring a lot of time and attention, you know some of them are not going to get the time needed, due to the demands of the other patients.' (W13)

'Inadequate staffing levels and high patient dependency. Have to delegate to HCA's/unqualified staff.' (W18)

One D grade highlighted the conflicts of having to care for highly dependent patients and constantly being aware of the other pressures of work.

'At times the unit is very stressful, people having life-threatening arrhythmias or going into LVF. While this work takes a lot of time up staff are conscious of the fact that all bloods, ECG's and male catheterisation are waiting to be done.' (W3) 
Two respondents commented on the demanding nature of some patients which impedes patient care delivery.

'Unfortunately I feel the patients are a burden sometimes and they prevent me from administering medications and doing the chores which I have to do on a nightly basis. It's a race against time to get the lights out at night, and it's usually about 1.00 am that they do get switched off.' (W21)

'Unruly, abusive and over-demanding patients.' (W22)

Not only the patient being dependent but patients being admitted from different specialities were perceived to inhibit both the organisation and delivery of patient care. Two reasons were suggested, the variety of specialities resulted in being unable to plan ahead and this was further hindered by the skills and knowledge of the staff in the team.

'Unable to plan anything because no routine to bed usage and variety of specialities admitted.' (W2)

It was perceived that if patients were admitted to a specific ward corresponding to a speciality ward it would facilitate the cultivation of a team of nurses with specialised knowledge and encourage the ward to become a centre of excellence.

'When only our own patients are on ward, therefore ensuring they all get the same expert standard of care and allows for staff development.' (W2)

'To make my clinical area of practice a centre of excellence for patients, staff and students.' (W16)

Three comments hinted that patient care is enhanced if both the patient and their relatives assist the nurses to deliver care. This was supported by $68.5 \%$ of respondents reporting that a relative always/often or occasionally can help organise and deliver patient care thus reducing the pressure on the nurses. Conversely $28.4 \%$ of respondents felt that this rarely or never happened.

'Help from family and relatives... Support from patient.' (W20) 
Observation indicated that wards do not measure the dependency of the patients despite there being a tool available on the computer system. Verbal comments suggested that the tool was 'time consuming' and 'gives little benefit to managing workloads.'

\section{Lack of Time}

Ten respondents identified that a lack of sufficient time inhibits nurses trying to achieve quality care and the expected patient care daily workload.

'Time constraints, I work a long day, 13.5 hours per shift, and there is never enough time to facilitate the best practice available.' (W9)

Staff would like more time to organise work, listen and teach junior colleagues and examine and develop practice.

'Time to organise your work.' (W20)

'Time to sit and listen, time to work with and develop junior staff, time to develop practice.' (W17)

However if staff were not interrupted to provide information or to complete managerial paperwork then more time could be given to patient care.

'Taking time that could be used on patient care to provide information that could easily be obtained from non-nursing staff.' (W16)

'Time constraints due to having to do other duties such as managerial paperwork.' (W6) 
Eight respondents perceived that patient care is enhanced if time is made available to care for patients appropriately and when there is time to support colleagues within the team.

'Having the time to spend with a patient who requires it, not rushing because you know you still have 7 or so to still sort out, plus emergency admission, plus several trips to theatre.' (W13)

'Taking time to give my team members support/supervision in delivering high standard of care in my clinical practice in a professional manner.' (W16)

'Time and help from other staff.' (W20)

'Having time to care for each patient. Not being pulled every which way.' $(W 21)$

\section{Interruptions to Nursing Care Delivery}

Other duties were indicated that remove qualified and experienced staff from bedside care delivery $(65,68.7 \%)$. Respondents described a number of clear tasks and activities which impeded and interrupted the time the nurse could spend delivering direct patient care. Respondents were provided with two opportunities to comment, within the quantitative questionnaire staff were asked to list the most disruptive task they have to do which inhibits the care they provide and again in the qualitative comments further descriptions highlighted more interruptions experienced.

The more commonly cited tasks that were specified by respondents that disrupt care delivery are shown in figure 5.1 and a complete listing can be found in Appendix 4. It is clear to see that dealing with telephone calls is perceived by respondents as the task that most distracts them from care delivery; 27 of the 55 respondents who listed disruptive tasks cited telephone calls. This equates to $30 \%$ of the overall sample. 


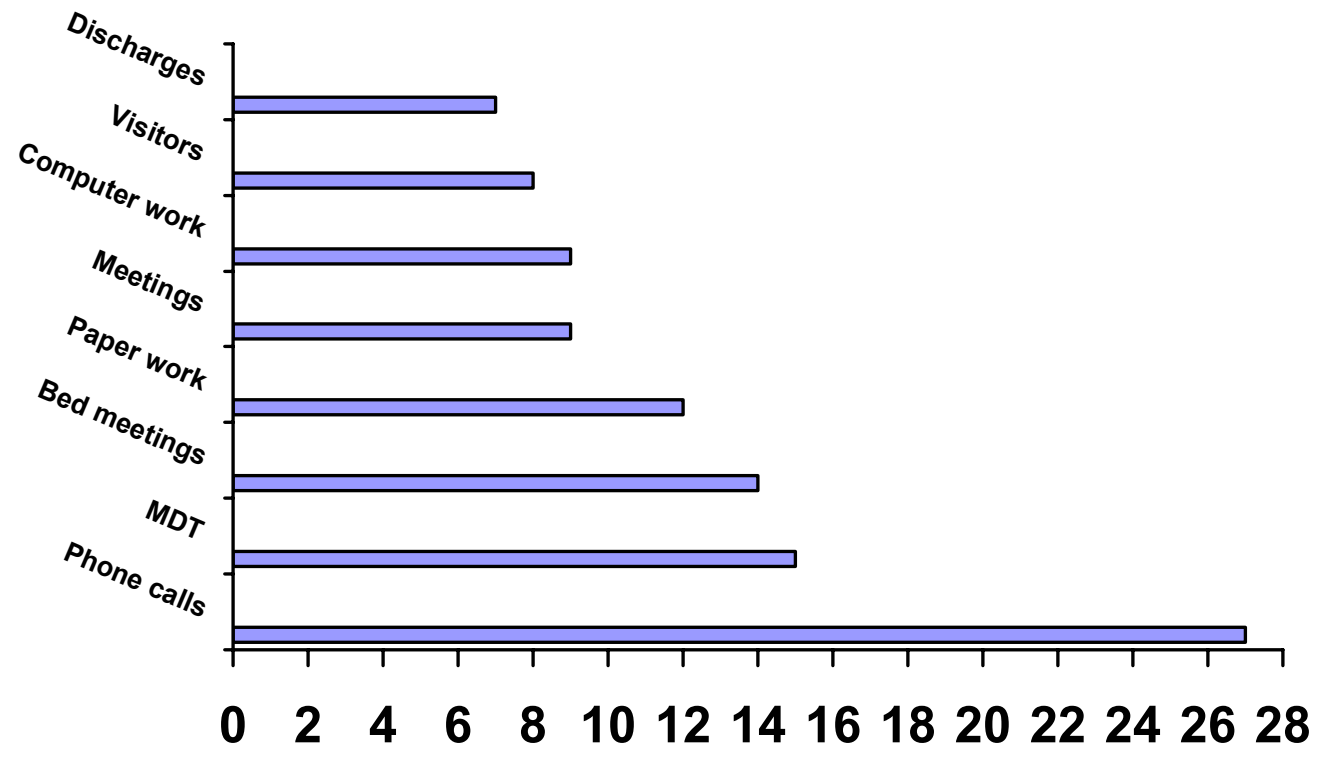

Within the respondents qualitative comments a similar list of activities emerged that inhibited the both the amount and quality of the nursing care they could deliver (table 4.19).

Table 4.19: Tasks which Inhibit Nursing Care Delivery

\begin{tabular}{|c|c|}
\hline Task / Activity & No. of Comments \\
\hline Answering the telephone & 12 \\
\hline Drug rounds & 4 \\
\hline Handover & 2 \\
\hline Paperwork/ IT & 24 \\
\hline Ward rounds & 6 \\
\hline Interruptions by MDT & 5 \\
\hline Chasing Doctors & 8 \\
\hline Bed issues/ meetings & 8 \\
\hline Admissions /discharge & 7 \\
\hline Relatives & 7 \\
\hline Total & 83 \\
\hline
\end{tabular}

Five comments indicated that patient care could be enhanced if the amount of interruptions was reduced and nurses had the time to provide the care required. 
'Having the support and ability to give complete patient care without being interrupted.' (W7)

'Feeling I'm in control of my environment. The fewer disturbances I have. I know doctors etc need to see patients and others, e.g. physios, need to speak with me, but ...this takes me away from my patients.' (W20)

'Less interruptions, less phone calls.' (W23)

To fully understand and appreciate the impact the tasks/interruptions (highlighted in table 4.19) have on the delivery and organisation nursing care, each interruptions will be described in more detail.

\section{Telephone Calls}

27 staff identified answering the telephone as the most disruptive task and this was supported by an additional 12 comments.

'Constant interruptions from phone calls when ward clerk not on duty-always having to break off tasks to answer the telephone.' (W3)

'Interruptions, such as telephone ringing.' (W13)

'Constantly going to phone to deal with matters anyone can deal with, e.g. ward clerk.' (W23)

As mentioned earlier the qualified nurse on ward 21, where there was no co-ordinator, was interrupted eight times to answer phone queries whilst caring for patients, once in the middle of doing a dressing. On this ward there was a ward clerk but it was observed that the phone did not stop ringing all morning, so despite the ward clerk answering many queries she still had to ask the nurse regarding others. Similarly, on other wards the ward clerk fought off many patient enquiries but the phone ringing was observed to increase when they left the ward. 
Paperwork and Computer Work

The majority of respondents $70.5 \%$ (68), highlighted that always/often writing patient documentation was time consuming and reduced the time available to them to provide patient care. Similarly, $95 \%$ of ward managers indicated that some or a lot of the nurses' role is taken up with administrative duties. In total, 12 staff indicated paperwork and nine staff computer work as the most disruptive tasks. A further 24 staff took the opportunity to comment on how unnecessary paperwork /form filling and working on the computer inhibits patient care. The paperwork for admissions and discharges was a particular problem for some staff members as it was perceived to be very repetitive.

'Poor IT systems on ward - very slow, constant problems with breakdowns, not user-friendly.' (W5)

'Form filling, endless paperwork that needs to be filled in, much of it repetitive. Worse since the arrival of the computer, which is another problem. They are slow and spend much of the time with the 'system down', so care plans can't be produced, blood results can't be obtained, all of which is very time-consuming, taking the nurse away from the intended goal, to care for the patient.' (W3)

'More paperwork, e.g. discharges - repetitive in most cases.' (W5)

'They need forms for everything - admission, discharges - times.' (W10)

'Too much bureaucracy in the organisation that inhibits the way I provide patients' care.' (W16)

Locating patients' nursing notes was also an issue for two staff on different wards.

'Looking for paperwork, kardex, is time-consuming.' (W21)

'Looking for kardex.' (W22)

Staff members usually plan to do paperwork when the activity of the ward is reduced so it is often an activity performed in the afternoon. The observation of ward activity took place in the morning shift the amount of paperwork observed is variable. There were three situations observed concerning different paperwork which consumed 
nurses' time. On ward 17 a qualified nurse was observed spending over 30 minutes completing discharge planning processes for a patient, this involved preparing district nurse referral, patients charter referral, ordering urostomy supplies, changing computer information, arranging appointments and preparing discharge summary. Field notes indicated that the researcher was unsure why some of these tasks could not be delegated to the ward clerk.

On ward 16 a qualified nurse was observed on three different occasions totalling 38 minutes completing a patients Continuing Care Form. On ward 6 the time of the nurse was occupied with a lengthy occupational therapy referral process. Although the patient form did not take the nurse long to complete, the process of faxing the form through to the department, having to use a fax machine in another ward, then repeatedly telephoning to ensure the fax was received was a strain on the nurse time. Qualitative comments reinforced this issue.

'Lack of time due to being tied up arranging social service packages. This often takes up a large amount of time on the telephone, taking nurses away from direct care.' (W1)

'Referral paperwork time-consuming.' (W9)

'Most of the time goes for referrals and other paperwork.' (W18)

One nurse felt that the referral of patients to social workers out of the Bolton area delayed the patients discharge and hindered patient care.

'OT referrals are sent and it can take a couple of days to respond. Out of area social workers, are very difficult to work with. They are slow to respond to referrals and are very reluctant to visit the wards, resulting in delayed discharges.' (W1)

\section{Drug Rounds}

Drug rounds were described by only four staff members as a task which inhibits the delivery of patient care. Although administering medication is part of the delivery of patient care it was perceived, 'medications and fluids were given late or not at all' 
which hindered patient care 'being constantly disturbed when trying to do 'drug rounds' resulted in them becoming 'time consuming' and impacted on what care could be delivered to patients. It was a surprise that this theme received such little attention as much of the qualified nurses activity observed centred around, reviewing, locating, preparing, checking and administering different types of patient medication.

Individual medication dispensed from bedside lockers was perceived by one nurse as enhancing patient care. It was observed that the close proximity of the medication (by the patient's bed) facilitated its quick administration. However, the bedside lockers were only effective when they contained the appropriate or sufficient medication for the patient. Across all wards problems were observed with incorrect supplies, low or no stock of particular crucial drugs (such as paracetamol and cyclizine). Drugs were borrowed from other patients and other wards to ensure the correct prescription was administered at an appropriate time.

The pharmacy technician usually visited the ward twice a day and re-stocked lockers and accommodated any changes in patient prescriptions. However many drugs were then not obtained until after $5 \mathrm{pm}$ at which time if there were any medications missing it was difficult to resolve until the morning. This posed a particular problem over the weekend when the pharmacy works on reduced staffing levels and cover to wards is limited. Monday morning observation highlighted that many lockers contained inadequate or incorrect supplies of drugs. This was due to new admissions or prescribed drug changes that meant the medicine round took twice as long as nurses were often searching for drugs from elsewhere, or that patients had to wait for prescribed medication.

A further activity which impacted on the delivery of patient care was the constant need for two nurses to check intravenous or controlled medication. Qualified nurses were observed across all wards hunting for other qualified nurses and waiting until they were free to check drug after drug. The only ward where the checking of drugs was better organised was Ward 16 where the co-ordinator of the ward made herself available at appropriate times to assist nurses based in the ward teams to check drugs for their patients. As a result the time of nurses providing patient care in other teams was not encroached. One comment reiterated this point: 
'When I'm asked again and again to check things for other staff and other bays, this takes me away from my patients. '(W20)

In addition, the co-ordinator on Ward 16 was piloting the single administration of a drug called Oromorph which previously required two nurses to check and administer. This initiative utilised the ward nurses' time more effectively enabling them to provide increased patient care at the bedside.

\section{Handover}

Only two members of staff through their qualitative comments indicated staff handover was that it was of poor quality and could at times take too long which inhibited the patient care being delivered.

The observation of staff handover identified a variety of methods used on the six wards. The type, length and quality of the handovers also varied between verbal and taped approaches (table 4.20).

From this observation no single method seemed quicker but the verbal approach facilitated greater discussion and clarification of patient care which enhanced the quality of the patient information communicated. Where taped handovers were used the information was limited and the time taken to record the tape could have been spent communicating the information directly. The idea behind the taped handover is to keep the night staff caring for patients on the ward whilst handover takes place. However, taped handover used throughout the day but observation identified that staff were too busy to update the tape on one ward so late staff listened to the previous night tape and then staff went in and updated the handover. The updating of a tape seems an added pressure on a shift for nurses whose time is limited.

In five out of the six wards a printed sheet with the list of patients and their status was available for all staff at handover. Unqualified staff used this communication sheet to check which patients could eat or drink. The sheets were also utilised by member of the multi-disciplinary team entering the ward and updated by the night and day staff 
after every shift. The communication sheet saved the nurse writing individual patient information and ensured everyone had the same information documented. On the ward where a printed sheet was not utilised the turnover patients was such that it would not be feasible to keep updated.

Table 4.20: Handover Methods

\begin{tabular}{|c|c|c|c|}
\hline Ward & Handover Method & Who to? & Time Taken \\
\hline 4 & $\begin{array}{l}\text { - Verbal handover of all patients by one night } \\
\text { staff in the office } \\
\text { - Not much discussion and no direction on day } \\
\text { care }\end{array}$ & $\begin{array}{l}\text { Qualified and } \\
\text { unqualified } \\
\text { staff }\end{array}$ & 7 minutes \\
\hline 6 & $\begin{array}{l}\text { - Taped handover produced by different night } \\
\text { staff listened to in day room (one recording } \\
\text { very difficult to hear and understand voice) } \\
\text { - All patients reviewed again by sister and care } \\
\text { directed }\end{array}$ & $\begin{array}{l}\text { Qualified and } \\
\text { unqualified } \\
\text { staff }\end{array}$ & 30 minutes \\
\hline 16 & $\begin{array}{l}\text { - Comprehensive verbal handover by different } \\
\text { team leaders on night staff } \\
\text { - Afterwards care of patients discussed and plan } \\
\text { of day care - at nurses station } \\
\end{array}$ & $\begin{array}{l}\text { Qualified staff } \\
\text { and students }\end{array}$ & 33 minutes \\
\hline 17 & $\begin{array}{l}\text { - Taped handover by night staff in kitchen } \\
\text { - Not much discussion of patient care, team and } \\
\text { patient allocation confirmed at end of report }\end{array}$ & $\begin{array}{l}\text { Qualified staff } \\
\text { only }\end{array}$ & 5 minutes \\
\hline 20 & $\begin{array}{l}\text { - Three simultaneous verbal handovers from } \\
\text { night staff in the ward area where teams work } \\
\text { - Clarification of patient care with night staff } \\
\text { where necessary }\end{array}$ & $\begin{array}{l}\text { Qualified staff } \\
\text { allocated to } \\
\text { the specific } \\
\text { team }\end{array}$ & 20 minutes \\
\hline 21 & $\begin{array}{l}\text { Three separate verbal handovers, two } \\
\text { consecutive handover's from one night staff } \\
\text { to two different team leaders in office, one } \\
\text { simultaneous hand over to coordinator/team } \\
\text { leader at nurses station } \\
\text { - Opportunity to clarify care where necessary }\end{array}$ & $\begin{array}{l}\text { Qualified staff } \\
\text { only }\end{array}$ & $\begin{array}{l}25 \text { minutes } \\
(15+10 \\
\text { minutes }) \\
15 \text { minutes }\end{array}$ \\
\hline
\end{tabular}

Ward Rounds

Six respondents described problems associated with ward rounds. These included the increased length of time taken to complete a ward round, the frequency of ward rounds, and the changing of times and days for ward rounds by doctors which impacts directly upon how nurses can deliver and organise their patient care. 
'Ward rounds with doctors that can take 2/3 hours!' (W9)

'All doctors/consultants coming on the ward first thing in the morning, all expecting to have your time.' (W14)

'Ward rounds being changed from week to week. Instead of doctors carrying out ward rounds on their specified days and at specific times, they sometimes come to do ward rounds as and when they feel like, which is sometimes inappropriate and when staffing levels are strained.' (W16)

Ward rounds were observed on all wards during the observation period. They lasted anywhere between 15 minutes and 2 hours. Most ward rounds were arranged by the co-ordinator of the ward except in ward 21 where the nurses' in-charge of their teams took responsibility for the ward round when in their area. The ward round on ward 16 took only 15 minutes of the co-ordinators time. This was because the doctors had previously spent time discussing all the patients off the ward in the office, thus not encroaching on nursing care then selected specific patients who needed a medical review to see on the ward. This was observed to be a more effective use of both the doctors' and the nurses' time. This practice was also observed on ward 6 where 20 minutes was spent in the office and 25 actually reviewing patients on the ward. This approach also facilitates a more private discussion in the office rather than at the patients' bedside.

On ward 20, just after 8am there were two ward rounds in operation with two teams of doctors reviewing patients who had been admitted overnight by way of/from casualty. At one point in time one doctors ward round involved over 12 different people who were all crowding round a patient's bed. With at least 20 people in two groups circulating round the ward it appeared overcrowded and the organisation of nursing care seemed impossible.

A verbal comment by staff from ward 16 indicated that different doctors have different approaches to the ward round. One doctor comes at a pre-arranged time another turns up on the ward when appropriate to them and insists that a nurse is available to attend the ward round. Unscheduled ward rounds do not allow for the preparation of patients' notes, the organisation of patient care or the availability of appropriate staff. 
It was perceived by $62.1 \%$ of nurses that the multi-disciplinary team always/often respects nursing care. However, it was also noted that members of the multidisciplinary team always/often $(21.1 \%)$ or occasionally (46.4\%) interrupt nurses and disturb patient care delivery (table 4.21). Indeed in the quantitative questionnaire 15 out of 55 staff who responded indicated that the multi-disciplinary team took the nurse away from providing patient care (see earlier figure 4.1).

Table 4.21: Multi-disciplinary Team

\begin{tabular}{|l|c|c|c|}
\hline & Always/Often & Occasionally & Rarely/Never \\
\hline $\begin{array}{l}\text { Multi-professional team members } \\
\text { respect the nursing care and } \\
\text { integrate their care well }\end{array}$ & 59 & 30 & 6 \\
\hline $\begin{array}{l}\text { Members of the multi professional } \\
\text { team interrupt patient care and } \\
\text { disturb the planned nursing care }\end{array}$ & $21.1 \%$ & $31.6 \%$ & $6.4 \%$ \\
\hline $\begin{array}{l}\text { Nurses work separately to the rest } \\
\text { of the multi-professional team }\end{array}$ & $17 \%$ & $46.4 \%$ & $31.6 \%$ \\
\hline
\end{tabular}

Further comments described how interruptions from different professions inhibit the delivery of nursing care.

'Recurrent interruptions from other disciplines.' (W9)

'People entering the ward and requiring your time to ask the same questions as someone else has asked one hour before, for example discharge co-ordinators or bed managers.' (W14)

'While giving care, MDT comes and interrupts the work.' (W18)

\section{Medical Staff}

Eight staff raised issues about the medical support available to nurses. Care of patients was inhibited because doctors were hard to locate, there was no medical cover or 
patients were waiting for a medical review. This was a particular issue for staff on wards 2, 10 and 12 .

'Very difficult to get different specialities doctors to review their patients, therefore length of admission extended.' (W2)

'Lack of support from doctors. No ward doctor on occasions, ward cover by doctor 1 hour, but not every day.' (W10)

'Difficulty at times getting doctors to review patients.' (W10)

'No planned regular medical cover. Patients have to wait to be reviewed. This leads to anxious distressed relatives.' (W10)

For four staff from wards 14, 21 and 22 chasing doctors and looking up scan and blood results for the doctors impacted on the their patient care time.

'Chasing doctors, scans, x-rays, etc. Blood results - looking up results for doctors, Blood forms - making sure forms are done for patients.' (W21)

'Trying to contact doctors who decide not to answer their bleeps. This is common practice amongst doctors.' (W22)

'Workload is very variable and seeking medical backup can sometimes be extremely problematic.' (W14)

It was perceived that nursing care would be enhanced if there was 'good medical support' and 'getting doctors to see their patients with ease' would inform 'what the next step is regarding their recovery to home.'

Doctors were observed on each ward throughout the morning, thus the observation provided no evidence to suggest doctors were hard to locate.

\section{Admissions /Discharges}

The organisation and delivery of nursing care was perceived by to be always /often (49.5\%) or occasionally (25.3\%) improved if admissions to the ward were planned. Unplanned admissions interrupted nursing care and reduced the time available to spend with patients (table 4.22). 
Respondents' comments support this finding and also believe events such as the transfer of outlying patients without prior notification and the fast turnover of patients lead to an increased workload and cause nursing care to be rushed.

'Outlying patients, due to the fact they are extra to normal workload. Very little notification given.' (W2)

'Fast turnover of patients.' (W20)

'The fact that many patients need to be moved to other areas before you have time to plan care, due to the amount of admissions.' (W20)

Table 4.22: Admissions to the Ward

\begin{tabular}{|l|c|c|c|}
\hline & Always/Often & Occasionally & Rarely/Never \\
\hline $\begin{array}{l}\text { Planned admissions enable the nurse to } \\
\text { organise and deliver patient care easier }\end{array}$ & 47 & 24 & 12 \\
\hline $\begin{array}{l}\text { Unplanned admissions interrupt the } \\
\text { nurses organised care and reduce the }\end{array}$ & 29 & $25.3 \%$ & $12.6 \%$ \\
$\begin{array}{l}\text { level of patient care achieved in the } \\
\text { shift }\end{array}$ & $30.6 \%$ & 41 & 19 \\
\hline
\end{tabular}

For three staff in particular discharges were a problem, in particular the fact that nurses were pressured to facilitate a patient's discharge quickly. Seven staff felt that discharging a patient took them away from providing nursing care to other patients.

'Sorting out problems, i.e. delayed discharges, takes you away from the patient.

Variable on day-to-day basis.' (W1)

'Too fast discharge planning.' (W6)

'Pressure to discharge quickly.' (W17)

One member of staff felt strongly that the Trust was driven to achieve government targets at the expense of patient care.

'Government targets! Processing a person through a system which is financially driven and corporately driven, to the expense of individual and holistic care,' $(W 7)$ 
The observation highlighted the movement of patients to the discharge lounge to free up beds. Indeed many patients were sent to the lounge whilst waiting for discharge prescriptions. On one ward the hurry to get patients out of the ward and prepare for the next patient was evident when a patient's area was cleaned and bed re-made for a new admission before the patient had left the ward. The patient was then delayed which resulted in them eating their dinner in the clean bed space, putting their bag on the clean bed, then sitting on another patients bed to move out of the way.

\section{Relatives}

The constant interruption from relatives enquiring about their family member either on the telephone or when they came to the ward to visit disrupted the nurses' time to deliver patient care. Although it is an essential part of care delivery, to care for relatives, seven staff found this sometimes frustrating particularly the amount of time it could involve.

'Dealing with difficult relatives/patients who are very time-consuming.' (W7)

'Patients' relatives' complaints/enquiries time-consuming.' (W9)

'Constant interruptions whilst on ward, relatives wishing to speak to primary nurse/SR.' (W12)

'Talking to relatives.' (W22)

'Several members of one family ringing with enquiries.' (W23)

Of the list of disruptions to patient care delivery, visiting from relatives proved to be one of the main difficulties listed by seven staff. Only one qualitative comment indicated that visiting was a problem.

'Due to the ward having an open visiting, I find it difficult at times to deliver patient care, due to visitors asking about the patient.' (W10)

Wards 16, 17 and 20 had protected patient meal times which meant that relatives and visitors were not allowed to enter the ward during this time to allow patients time to digest their meal. Observation of respected mealtimes highlighted that staff had more 
time without interruptions to provide support to those patients who needed assistance during mealtimes and this policy facilitated the delivery of nursing care. It was however, also observed that relatives despite being aware of the policy repeatedly tried to stay or enter the ward during this time.

\section{Bed Issues and Meetings}

Bed meetings and the hassle for freeing up beds was an issue raised by eight staff in the qualitative comments and listed by 14 staff as a disruptive duty taking them away from delivering patient care. This was not just seen as a problem for managerial staff but across all grades of staff.

\footnotetext{
'Attendance off ward at bed meetings etc., disrupting patient care.' (W10)

'Too many staff involved with one issue, e.g. bed management issues. Ward staff having to attend bed management meetings, therefore depleting carers for patients.' (W5)

'Having to sort out other problems first, i.e. bed state for bed managers meeting - time-consuming and at wrong time of day.' (W7)

'Having to attend bed meetings Mon-Fri, therefore taking time off the ward and compromising patient care.' (W10)

'Staff having to go to bed meetings 2-3 times daily.' (W12/D2)

'Ongoing hassle from bed managers and MAU for beds.' (W5)
}

It was observed that planned bed meetings imposed on the qualified nurses' time. Bed meetings were scheduled for a member of staff to attend from each ward at 8.30am and $1.30 \mathrm{pm}$, both at times when activity of the ward is increasing. Three out of the six wards did not have the staff available to attend as they were too busy, and on one ward the late staff waited around for the co-ordinator to return before handover could take place. Despite communicating bed status at these times the bed manager was observed twice on different wards asking co-ordinators about patients being discharged and searching for potential free bed space. 


\section{Supervision and Education}

Some staff, $53.7 \%$ of respondents (51) felt that they were supported in their professional development but conversely this left $46.4 \%$ (44) who perceived that they were only occasionally, rarely or never supported in professional development matters (table 4.23).

Table 4.23: Professional Attitudes to Care Delivery

\begin{tabular}{|l|c|c|c|}
\hline & Always/Often & Occasionally & Rarely/Never \\
\hline I feel supported in my professional & 51 & 32 & 12 \\
learning & $53.7 \%$ & $33.7 \%$ & $12.7 \%$ \\
\hline I feel that I use all my professional & 82 & 9 & 4 \\
skills at work & $86.3 \%$ & $9.5 \%$ & $4.2 \%$ \\
\hline
\end{tabular}

However, only one D grade mentioned the lack of protected study time to develop clinical knowledge as an issue.

'Protected study time to develop clinical knowledge and remain up to date. Never get study time. Rarely get back any time owing.' (W21)

The remaining comments (7) highlighted how training and supervising junior staff and students inhibited the nursing care provided and often leaving was little time to supervise other staff.

'Also having junior staff that need supervision as well as students. All these factors inhibit patient care that I provide, therefore I feel I provide little patient care (direct/hands on).' (W6)

'There are rarely enough trained staff on a shift to ensure high standards of care and supervision of students and more junior staff.' (W7)

'Constant supervision of inexperienced staff is also an issue in an acute setting.' $(W 7)$ 
'Too many students can also affect the care you provide, as too much time is taken up trying to teach students on the ward and ever-increasing workload of teaching NVQ students, and the amount of paperwork required to be done which most people end up doing at home and in their annual leave.' (W11)

Despite the perception that there was a reduced amount of time available to educate junior staff and trainees there was an acknowledgment that by offering staff training opportunities and increasing the knowledge of staff patient care would be enhanced. Although many praised the training opportunities provided one respondent requested 'more training - when available'.

'Being kept up to date with education. This enables all the staff to work in the same way, giving the patient the correct up to date care and information.' (W3)

'The most important is the training and education that the Trust provides.' (W9) 'Changes in Trust structure - enhanced leadership and motivation.' (W17/G1)

'Education, the more knowledgeable I am about a patient's condition the quality of care I can provide is improved.' (W22)

Whilst carrying out the ward observations a staff nurse on one ward should have been attending medical devices training and then cascade this training through to all staff on the ward. However, on the day of the training there was shortage of staff which resulted in her not being able to attend. Good teaching and supervision of students was observed on Ward 6 where students worked continually with qualified nurses. However on Ward 4 the student looked to be floating across teams, not mentored by any specific qualified member of staff and ended up working with the health care assistant.

\section{Personality and Experience}

Overall 20\% of respondents (19) took the opportunity to describe different personality traits which were perceived to enhance the delivery of patient care. These included qualities such as motivation, experience and knowledge. 
'Attention to detail - accuracy of medical data, good observation, picking up all indications including non-medical problems.' (W1)

'Being experienced in patient care, asking the doctor when problems arise.' (W3)

'Knowledge of speciality.' (W6)

'My skills and competence.' (W14)

'Experience of acute surgical emergencies allows me to make important decisions on delegation of staff and ensuring patient care is not compromised by inexperience $A$ lot depends on the experience and skills of the staff on your shift.' (W20)

Some staff described their own qualities and what they brought to their role and how this enhanced the patient care. This included always striving to maintain high standards.

'My own motivation to maintain high standards.' (W7)

'I can utilise all my skills and experience to give optimum care without it being at the expense of the other patients. I can teach my skills to junior staff and students. I can feel that I couldn't have done anything more for my patient.' $(W 7)$

'I am a conscientious person and I would not let patients suffer, and I try to give them the best care to the best of my ability.' (W21)

Some took the opportunity to praise the qualities of colleagues that were caring, others felt that listening and getting to know patients enhanced and informed the care delivered.

'I feel I work with experienced and caring colleagues.' (W9)

'Getting to know the patient, to know what is required.' (W22)

'Leadership Programme - listening to patients' stories and observing care.' (W17) 
Other factors that would enhance patient care were staff who were aware of 'their own limitations' and have the 'ability to prioritise care' although it was perceived by a G grade that 'not all people accept that we need to prioritise'.

\section{Communication}

Poor communication between team members was perceived to inhibit the organisation and delivery of patient care, always/often (32.7\%) and occasionally (42.1\%) by staff (table 4.24). Even more pronounced was the poor communication from the multidisciplinary team where $82.1 \%$ of staff felt that the lack of appropriate information regarding patient investigations inhibited the planning of the nursing care.

\section{Table 4.24: Communication}

\begin{tabular}{|l|c|c|c|}
\hline & Always/Often & Occasionally & Rarely/Never \\
\hline $\begin{array}{l}\text { Poor communication between nursing } \\
\text { team members causes a breakdown in } \\
\text { patient care }\end{array}$ & 31 & 40 & 24 \\
\hline $\begin{array}{l}\text { Poor communication between multi- } \\
\text { disciplinary team members regarding } \\
\text { patient investigations/ inhibits the } \\
\text { organisation of nursing care }\end{array}$ & $42.7 \%$ & $42.1 \%$ & $25.3 \%$ \\
\hline
\end{tabular}

The perception that communication between team members was poor was highlighted further by eight staff through their descriptive comments. Four staff described the lack of information communicated about individual patients, either at handover, when patients are transferred, or because staff do not look after the same patients.

'There is lack of continuity of care and communication gets more difficult.' (W11)

'Not having sufficient information regarding individual patient.' (W12)

'Lack of communication. When your colleagues have not properly handed an important investigation or message regarding the care of a patient.' (W12)

Poor communication when outlying patients transferred (WI) 
A further four staff focussed on communication between multi-disciplinary team members and departments.

'Poor communication - unable to contact key professionals, having to leave messages, therefore waiting for replies.' (W5)

'Poor communication - this is a long-standing and widespread problem, . information is inadequate.' (W13)

'Breakdown in communication between the multi-disciplinary teams, especially doctors.' (W19)

'Ineffective communication between nursing staff, doctors, MDT and investigative departments.' (W21)

Effective communication would enhance both the delivery and organisation of patient care. Ten members of staff made suggestions with regard to how communication could be improved to facilitate patient care.

'Being kept up to date with education. This enables all the staff to work in the same way, giving the patient the correct up to date care and information.' (W3)

'Time to talk and understand the experiences of nurses.' (W6)

'Open, clear communicating between relatives/patient, keeping them informed frequently, building a friendly, trusting relationship.' (W9)

'Good communication amongst staff. Everybody knows there is support at all times if needed. Plan for each patient communicated to all.' (W10)

'Correct handover/information on that individual patient.' (W12)

'Effective communication between departments, theatre, $x$-ray (e.g. theatre contacting ward when patient is to be sent to theatre, to check if ready. Also porter just turning up with patient, to contact staff if able to receive patient).' (W20)

On all wards it was observed that the co-ordinator was a gate keeper of information. There appeared to be effective communication between the co-ordinators and the nurses in charge of the patient teams as conversations took place regularly. However, 
the managerial skills of the team nurses developed through running ward rounds and organising patient discharges could be marginalised as a result of the strong administrative role adopted by the co-ordinator.

\section{Other Ward Aspects}

Although two members of staff identified that 'the cleanliness of the ward' (ward 12) and 'cleaning up after medical colleagues' was an issue no other staff members commented on whether cleanliness inhibited the delivery or organisation of patient care. Twenty staff described other ward aspects which inhibited and enhanced patient care delivery and the two main themes generated from the comments focused on the lack of facilities/equipment and the environment or ward layout.

\section{Lack of Facilities / Equipment}

It was perceived that the equipment on most wards was lacking, stock levels were low and linen in particular was in short supply. Observation highlighted that supplies were often borrowed from or lent to other wards causing unnecessary work for staff, indicating that stocks need to be reviewed (table 4.25).

Table 4.25: Borrowing and Lending

\begin{tabular}{|c|c|}
\hline Ward & Borrowing and Lending \\
\hline 4 & $\begin{array}{l}\text { - HCA goes to off ward to find red linen bags } \\
\text { - } \quad \text { Qualified nurse comes to borrow rolls of tape }\end{array}$ \\
\hline 6 & $\begin{array}{l}\text { - Qualified nurse goes off ward to use fax machine to fax patient referral } \\
\text { documents } \\
\text { - Student goes off ward to borrow pyjama bottoms }\end{array}$ \\
\hline 17 & $\begin{array}{ll}\text { - } & \text { HCA comes to ward to borrow theatre gown (non available) } \\
\text { - } & \text { Housekeeper goes off ward to borrow theatre gown for patient } \\
\end{array}$ \\
\hline 20 & $\begin{array}{l}\text { - HCA goes off ward to borrow stock drugs (paracetamol and cyclizine) } \\
\text { - } \quad \text { Housekeeper goes off ward to borrow blankets } \\
\text { - } \quad \text { Qualified nurse comes to ward to borrow a theatre gown }\end{array}$ \\
\hline
\end{tabular}


Twelve staff commented on having to borrow from other wards which wasted time that could have been used to deliver patient care. The lack of appropriate equipment hindered the continuity of patient care it was suggested that patient care would be enhanced if there was 'correct and adequate equipment.'

'Lack of facilities and equipment.' (W3)

'Shortage of supplies.' (W9)

'Lack of resources...or finding resources, e.g. pads, wipes, from other wards.' (W10)

'Unable to locate equipment due to lack of equipment on the unit.' (W20)

'Equipment not available/working.' (W21)

'Not enough stock.' (W22)

'Lack of linen at times.' (no code)

\section{Environment/Ward layout}

A clear majority of staff (84.2\%) perceived that the ward layout positively influenced how patient care was organised. In particular $77.8 \%$ of staff perceived that working in geographical areas enhanced how nursing care was delivered (table 4.26).

Table 4.26: Ward Layout

\begin{tabular}{|l|c|c|c|}
\hline & Always/Often & Occasionally & Rarely/Never \\
\hline $\begin{array}{l}\text { The layout of the ward positively } \\
\text { influences how patient care is } \\
\text { organised }\end{array}$ & 57 & 23 & 13 \\
\hline $\begin{array}{l}\text { Working in geographical areas in the } \\
\text { ward enhances how nursing care is } \\
\text { organised and delivered }\end{array}$ & $53 \%$ & $24.2 \%$ & $13.7 \%$ \\
\hline
\end{tabular}

In line with these views three staff went onto indicate that the layout of their ward inhibited the delivery and organisation of patient care, one ward was open planned the 
other had closed bays. The open-plan ward had problems with 'noise levels often disturb patients, resulting in frayed tempers.'

The environment outside of the physical attributes of the ward was also important, three staff talked of an 'open, more relaxed atmosphere', a 'happy environment in which patients feel comfortable and settled' and a 'nice working environment' for staff. 


\section{CHAPTER FIVE}

\section{STAGE TWO - PATIENTS PERSPECTIVE OF NURSING CARE}

Questionnaires were distributed to patients from each of the 23 study wards. This chapter presents the response rate and findings of the study, describing the patients' perspective of the acute nursing care received during their stay on the study wards. The findings from both the quantitative and qualitative sections of the questionnaire have been combined to provide an overview of the majority patient perspective alongside identifying individual issues for groups of patients.

\section{Response Rate}

The total number of patient questionnaires administered to each study ward was 50 (per ward) except for ward 10 where 39 questionnaires were sent out. The questionnaires were sent to 1139 patients and 233 questionnaires were returned a response rate of $20.4 \%$, from which $28(12.1 \%)$ were excluded from the study for a number of different reasons (table 5.1).

\section{Table 5.1: Exclusion of Questionnaires}

\begin{tabular}{|c|c|}
\hline Reason for exclusion & Number \\
\hline Questionnaire not completed & 16 \\
\hline Client unable to complete questionnaire & 7 \\
\hline Client not at address shown & 2 \\
\hline Deceased & 2 \\
\hline Questionnaire completed by relative & 1 \\
\hline Total & 28 \\
\hline
\end{tabular}

As a result 205 patient questionnaires were included in the subsequent data analysis, giving a response rate of $17.9 \%$. There was an even split of male (46.8\%) and female (49.8\%) patients who responded to the questionnaire with seven $(3.4 \%)$ respondents choosing not to indicate their sex. A higher percentage of female patients responded 
compared with the percentage proportions found within the target population $(50.2 \%$ male and $49.8 \%$ female). The response rate from patients across the wards ranged from $8 \%$ of the total sample per ward up to $30 \%$ with an average of $17.8 \%$. The breakdown of the response rate from each of the wards is shown in table 5.2.

Table 5.2: Response Rate per Ward

\begin{tabular}{|c|c|c|c|c|c|}
\hline Ward & $\begin{array}{l}\text { Total No. } \\
\text { returned } \\
\text { per ward }\end{array}$ & $\begin{array}{l}\text { \% response rate } \\
\text { perward of total } \\
\text { sample }\end{array}$ & Ward & $\begin{array}{l}\text { Total No. } \\
\text { returned } \\
\text { per ward }\end{array}$ & $\begin{array}{l}\text { \% response rate } \\
\text { per ward of total } \\
\text { sample }\end{array}$ \\
\hline 1 & 8 & 16 & 13 & 12 & 24 \\
\hline 2 & 6 & 12 & 14 & 9 & 18 \\
\hline 3 & 9 & 18 & 15 & 7 & 14 \\
\hline 4 & 10 & 20 & 16 & 10 & 20 \\
\hline 5 & 6 & 12 & 17 & 15 & 30 \\
\hline 6 & 5 & 10 & 18 & 14 & 28 \\
\hline 7 & 6 & 12 & 19 & 13 & 26 \\
\hline 8 & 10 & 20 & 20 & 10 & 20 \\
\hline 9 & 5 & 10 & 21 & 15 & 30 \\
\hline 10 & 3 & 8 & 22 & 7 & 14 \\
\hline 11 & 8 & 16 & 23 & 10 & 20 \\
\hline 12 & 7 & 14 & Total & $\mathbf{2 0 5}$ & \\
\hline
\end{tabular}

The first part of the questionnaire involved a series of statements where patients responded using a likert scale (questions 1-23). In this part some data items were missing, for these the total number and percentages were adjusted accordingly. Complete data for each individual question is found in Appendix 5.

Of the 205 patients who responded to the questionnaire, $159(77.5 \%)$ gave positive comments on the aspects of the nursing care they liked best (question 24). Comments came from patients who had been cared for across all 23 wards included in the sample and a total number of 244 positive comments were recorded.

One hundred and one (49\%) patients from the total number responding to the questionnaire (205) chose to provide negative comments on the aspects of nursing care they did not like (Question 25). Again the comments were received from patients 
cared for across all 23 study wards and a total of 198 negative comments were recorded.

Tables 5.3 and 5.4 show the number of patients per ward who offered positive and negative comments. In both tables a percentage is shown of the number of patients offering positive or negative comments compared with the total number of patients responding to the questionnaire.

Table 5.3: Qualitative Positive Comment Response Rate

\begin{tabular}{|c|c|c|c|c|}
\hline Ward & $\begin{array}{l}\text { Total No. of } \\
\text { positive } \\
\text { comments }\end{array}$ & $\begin{array}{c}\text { No. people } \\
\text { offering positive } \\
\text { comments }\end{array}$ & $\begin{array}{l}\text { Total No. } \\
\text { people } \\
\text { responded }\end{array}$ & $\%$ positive \\
\hline 1 & 9 & 8 & 8 & 100 \\
\hline 2 & 13 & 5 & 6 & 83 \\
\hline 3 & 15 & 7 & 9 & 78 \\
\hline 4 & 11 & 8 & 10 & 60 \\
\hline 5 & 4 & 3 & 6 & 50 \\
\hline 6 & 9 & 5 & 5 & 100 \\
\hline 7 & 4 & 4 & 6 & 67 \\
\hline 8 & 14 & 9 & 10 & 90 \\
\hline 9 & 6 & 4 & 5 & 80 \\
\hline 10 & 1 & 1 & 3 & 33 \\
\hline 11 & 9 & 7 & 8 & 88 \\
\hline 12 & 9 & 6 & 7 & 86 \\
\hline 13 & 17 & 11 & 12 & 92 \\
\hline 14 & 12 & 7 & 9 & 78 \\
\hline 15 & 9 & 5 & 7 & 72 \\
\hline 16 & 19 & 10 & 10 & 100 \\
\hline 17 & 16 & 11 & 15 & 73 \\
\hline 18 & 18 & 13 & 14 & 93 \\
\hline 19 & 10 & 7 & 13 & 53 \\
\hline 20 & 9 & 7 & 10 & 70 \\
\hline 21 & 15 & 10 & 15 & 67 \\
\hline 22 & 3 & 3 & 7 & 43 \\
\hline 23 & 12 & 8 & 10 & 80 \\
\hline Total & 244 & 159 & 205 & \\
\hline
\end{tabular}

Wards 5, 10 and 22 received a lower number of positive comments from the total number of patients who responded to the questionnaire. In contrast to wards 1, 6, 8, 13 and 16 that received $90-100 \%$ of positive comments from all patients who returned the questionnaire. Ward 16 received the highest number of positive comments on 
different aspects of nursing care, 19 were recorded from ten different patients, whereas ward 10 received only one positive comment from one patient (table 5.3).

Wards 3, 7 and 22 received a lower number of negative comments from the total number of patients who responded to the questionnaire, 17, 22 and $29 \%$ respectively. In contrast wards 12,15 and 16 received $70-86 \%$ of negative comments from those patients returning the questionnaire. However, ward 21 received the highest number of negative comments, 36 from ten different patients (table 5.4).

Table 5.4: Qualitative Negative Comment Response Rate

\begin{tabular}{|c|c|c|c|c|}
\hline Ward & $\begin{array}{l}\text { Total No. of } \\
\text { negative } \\
\text { comments }\end{array}$ & $\begin{array}{c}\text { No. people } \\
\text { offering negative } \\
\text { comments }\end{array}$ & $\begin{array}{l}\text { Total No. } \\
\text { people } \\
\text { responded }\end{array}$ & $\%$ negative \\
\hline 1 & 8 & 4 & 8 & 50 \\
\hline 2 & 4 & 3 & 6 & 50 \\
\hline 3 & 6 & 2 & 9 & 22 \\
\hline 4 & 5 & 4 & 10 & 40 \\
\hline 5 & 4 & 3 & 6 & 50 \\
\hline 6 & 4 & 3 & 5 & 60 \\
\hline 7 & 1 & 1 & 6 & 17 \\
\hline 8 & 8 & 5 & 10 & 50 \\
\hline 9 & 4 & 2 & 5 & 40 \\
\hline 10 & 2 & 1 & 3 & 33 \\
\hline 11 & 12 & 5 & 8 & 63 \\
\hline 12 & 10 & 6 & 7 & 86 \\
\hline 13 & 10 & 6 & 12 & 50 \\
\hline 14 & 7 & 3 & 9 & 33 \\
\hline 15 & 9 & 5 & 7 & 71 \\
\hline 16 & 11 & 7 & 10 & 70 \\
\hline 17 & 10 & 5 & 15 & 33 \\
\hline 18 & 9 & 6 & 14 & 43 \\
\hline 19 & 14 & 8 & 13 & 62 \\
\hline 20 & 12 & 5 & 10 & 50 \\
\hline 21 & 36 & 10 & 15 & 67 \\
\hline 22 & 3 & 2 & 7 & 29 \\
\hline 23 & 9 & 5 & 10 & 50 \\
\hline Total & 198 & 101 & 205 & \\
\hline
\end{tabular}




\section{Categories, Themes and Sub-themes}

The quantitative responses were analysed using descriptive statistics and for the purpose of this section the findings are integrated within the themes emerging from the qualitative data set. The qualitative comments were analysed using a combination of content and thematic analysis methods to isolate and describe the aspects of nursing care patients liked and disliked. The themes were naturally grouped in two main categories, 'Organisation' and 'Delivery' of nursing care (similar to the presentation of the nurses perceptions provided in chapter four). A further category emerged termed 'Other Ward Aspects' concerned with specific environmental themes such as the ward atmosphere, cleanliness and visiting issues. Table 5.5 summarises the main qualitative categories and themes identified from the patients' perspective, for both the positive and negative aspects of nursing care.

Table 5.5: Categories and Themes

\begin{tabular}{|c|c|c|}
\hline \multicolumn{3}{|c|}{ Qualitative Data Themes } \\
\hline Category & Positive (No. comments) & Negative (No. comments) \\
\hline $\begin{array}{c}\text { Delivery of } \\
\text { Nursing care }\end{array}$ & $\begin{array}{l}\text { Good nursing care (45) } \\
\text { Nurses' bedside manner (82) } \\
\text { Some nurses better (7) } \\
\text { Treated as an individual (11) } \\
\text { Time taken to care (20) } \\
\text { Technical expertise (5) } \\
\text { Communication/information } \\
\text { (18) }\end{array}$ & $\begin{array}{l}\text { Poor basic nursing care (34) } \\
\text { Nurses' bedside manner (27) } \\
\text { Waiting for care (9) } \\
\text { Lack of knowledge (6) } \\
\text { Communication/information (17) }\end{array}$ \\
\hline $\begin{array}{l}\text { Organisation } \\
\text { of Nursing } \\
\text { care }\end{array}$ & $\begin{array}{l}\text { Well organised (16) } \\
\text { Routine (6) } \\
\text { Prompt to respond to needs (8) } \\
\text { Did their best under heavy } \\
\text { workloads (4) } \\
\text { Other (4) }\end{array}$ & $\begin{array}{l}\text { Disorganised (9) } \\
\text { Waiting for investigations (5) } \\
\text { Clerical Work (6) } \\
\text { Routine (med/handover) (11) } \\
\text { Overlooked (3) } \\
\text { Prioritising the care of others (2) } \\
\text { Lack of continuity (8) } \\
\text { Staffing levels / skill mix (30) } \\
\text { Inappropriate wards/ moving } \\
\text { wards (12) }\end{array}$ \\
\hline $\begin{array}{l}\text { Other Ward } \\
\text { Aspects }\end{array}$ & $\begin{array}{l}\text { Good Environment/ } \\
\text { Atmosphere (8) } \\
\text { Clean ward (7) } \\
\text { Generous visiting hours (3) }\end{array}$ & $\begin{array}{l}\text { Poor Environment/ } \\
\text { Atmosphere (11) } \\
\text { Dirty wards (6) } \\
\text { Inadequate visiting hours (2) }\end{array}$ \\
\hline
\end{tabular}


The qualitative and quantitative findings are described and presented using the main themes identified.

\section{Delivery of Nursing Care}

The delivery of nursing care category received the most comments from patients, with 188 positive comments compared with 93 negative comments. Patients chose to comment on the quality of the nursing care received and the manner in which the nurses delivered the care, including the level of communication and the provision of information. Ward 18 received the highest number of positive comments (16) and ward 21 received the highest number of negative comments (17) from patients regarding the delivery of nursing care.

Within the category of the delivery of nursing care seven main themes emerged:

- Basic nursing care (Good and Poor)

- Diet and Nutrition (Food)

- Nurses bedside manner

- Treated as an individual

- Time to care versus waiting for care

- Knowledge and expertise

- Communication and information

\section{Basic Nursing Care -Good Nursing Care}

Patients were asked if they agreed or disagreed to the statement 'I was satisfied with the care I received' during their stay on the ward. The majority of patients 171 (83.4\%) agreed and were happy with the nursing care they received, 29 patients (14.1\%) were unsure about or dissatisfied with the nursing care. 
Thirty-nine respondents $(25 \%)$ who offered positive comments $(n=159)$ across 18 different wards commented directly on how much they liked the nursing care. These comments ranged from 'okay' and 'satisfactory' to 'excellent' and 'completely satisfied.' The highest number of positive comments from patients regarding the basic nursing care was recorded for ward 19 (five comments).

'All the nurses and staff were wonderful and I had every care possible' (w1/29)

'The nursing care was excellent' (w4/193)

'I was completely satisfied' (w14/653)

'The nursing care was very good, I am very happy with the service' (w19/949)

One patient described their experience as 'felt safe and in good hands' (w4/164).

Two patients singled out night staff as being 'excellent' with more time to care for patients and make them comfortable. Two others described the emergency department and all the staff in the team as 'excellent'.

'The night staff had time and concern for us, all making sure we were comfortable' (w22/1085)

'The Emergency Department were BRILLIANT, very good, hard worked' $(w 8 / 394)$

Seven patients were clearly grateful for their care and took the opportunity on the questionnaire to thank the staff that looked after them and offer their support and encouragement for the work they do.

'I am very grateful for all that was done for me' (w8/375)

'I can't thank them enough' (w9/448)

'I thank God there are such people about' (w4/164)

'Carry on the good work' (w4/193) 


\section{Basic Nursing Care - Poor Nursing Care}

In contrast, 34 patients (34\%) described aspects of the basic nursing care they perceived to be poor and below the standard they had expected. Overall, ward 21 received the highest number of negative comments regarding the delivery of basic nursing care, 14 in total compared to other wards that received four or less negative comments. Two general comments recorded reflected a complete dissatisfaction with the care, from patients on wards 18 and 19.

'I had an awful time in hospital' (w18/896)

'Didn't like any part whatsoever' (w19/929)

The negative aspects of basic nursing care identified and described by patients from across all wards can be grouped under four sub-themes:

- Maintaining patient safety

- Elimination

- Prevention of cross infection

- Personal hygiene

- Diet and nutrition (food)

These aspects are described in more detail to highlight the problems patients faced but it is important to be mindful this is data generated from a small number of patients.

\section{Maintaining Patient Safety}

Six different patients took the time to describe their experiences how their safety or that of others was compromised. One patient wandered off the ward in a confused state and the other was left in a discharge lounge uncovered and cold.

'I thought the ward was very poor as I had no name band on for 4 days whilst I was in hospital. I was on diamorphine. I was allowed off the ward, no-one knew who I was as I only had my pyjamas and dressing gown on.' (w21/1041) 
I was told to wait in the discharge lounge ...was given no cover for my shoulders - I did not have any of my clothes with me and nothing for my feet - it was cold.' (w8/389)

Four other patients described how the clinical practice of the nurses was a concern either for themselves or for others.

'Nurse and auxiliary by my bed. Auxiliary suddenly exclaims "Oh I forget to tell you, the lady in the end bed's temperature is up". (I had overhead that her temperature was high about 3 hours previous). Shortly after she was put on a monitor and drip.' (w21/1022)

I think one or two of the nurses want practice in taking blood. Some left you bruised, others not a mark.'(w4/163)

'I am a diabetic and twice they allowed me to fall into a coma.' (w11/511)

'When my drip 'needle' (cannula) became dislodged during sleep, she seemed cross, tried unsuccessfully to reinsert it, and then said this would have to be reinserted by a doctor as the nursing staff could not find a suitable vein. This did not happen, and I was discharged without any further reference to the situation, though I brought it to the notice of staff several times.' (w19/912)

In addition, the administration of medication was a negative aspect for a further six patients, in particular the waiting for prescribed medication to be given. One patient asked repeatedly for an injection for their arthritic joints which they had regularly at home, it was promised but never given. Two patients raised the late hour that medication was given out, ten o'clock medicines being administered after 12 o'clock and sleeping tablets being given so late (12.45am) to be ineffective. Another questioned the erratic times their injection was administered and indeed some days the omission of an injection altogether. One patient resented having to wait until 'teatime' to receive their prescription for discharge, another patient described having to wait for pain relief because they had visitors.

'The nurse wouldn't give me pain relief when I asked, even though I was way overdue, because he said I had visitors. Once they left, I had to ask again 
before he would give me anything, then all he would give me was Paracetamol, even though I was also written up for Ibruprofen.' (w20/956)

\section{Elimination}

One patient on ward 21 described four separate episodes of poor nursing care with respect to the elimination of bodily fluids. Issues ranged from incorrect positioning of bedpans, not knowing how to assist someone after using a bedpan and the observation of another person's experience of incontinence.

'One member of staff first put it under me the wrong way round and said "Is that right?" I said "Did they not tell you which way to put the bedpan?" She said "No"! The same girl came back when I buzzed to tell her I had done a poo. She paused, looking alarmed for a few minutes. So I told her to get an apron and some gloves and instructed her on what to do.' (w21/1022)

'I have been put on the bedpan again by a different person (the wrong way round).' (w21/1022)

'Opposite me one night a lady repeatedly wet the bed-bedpan response not quick enough, but could she have not been put on incontinence pads to save time and work? The carers were shattered and I heard one say "Oh no, not again!'” (w21/1022)

A further problem this patient experienced involved the prescription of codeine that led to constipation and unbearable discomfort, which they felt could and should have been avoided.

\section{Prevention of Cross Infection}

Three different patients described four observations of nursing practice that could have resulted in the spread of infection on the ward, three of which occurred on ward 21.

'I saw one nurse sneeze into her hand while serving a meal.' (w16/780) 
'Given the concern over hygiene, I was surprised to see nurses and doctors not cleaning hands between dealing with patients. One doctor actually did wash his hands, but then dried them on this trouser backside!!!' (w21/1008) 'However, I had been cleaned once (after using a bedpan) by a lady with no gloves or apron.' (w21/1022)

'...couldn't believe it when a soiled hospital nightdress was thrown on the floor at the foot of a patient's bed...it was followed by the sheets. After the patient was changed, the sheets were scooped up and carried down the ward and along the corridor.' (w21/1022)

\section{Personal Hygiene}

The lack of attention and support with maintaining personal hygiene needs was an issue for only two patients, from two different wards.

'Lack of care with personal hygiene. Not offered a wash or wet wipes after using a bed pan or commode.' (w12/595)

'It was disappointing when I had been told by the morning staff that they would help me have a shower (bag on leg) and wash my hair. Afternoon staff said “Oh no, you couldn't do that" (shower with bag on leg).' (w21/1022)

\section{Diet and Nutrition (Food)}

A comparable number of patients offered positive (seven) and negative (nine) comments regarding the presentation, choice and taste of the food served on the wards. The positive comments suggested the food was 'pleasant' and the portions 'adequate.' Two patients went further and said it was 'excellent' and that there was a good choice of menu. However, those patients who did not like the food suggested it 'could be improved,', 'it left a lot to be desired' and for one patient it was 'inedible'. Some patients complained that they did not receive the food they had ordered, although the presentation and temperature of the food served was a problem for others. 
'When it arrived on the ward it was cold and most of it ended up in the bin as most people couldn't eat it.' (w11/511)

'It was not appealing or presented nice.' (w16/790)

\section{Nurses' Bedside Manner}

Eighty patients $(39 \%)$ provided positive comments describing the behaviour and bedside manner of the nurses delivering the patient care on the study wards. This was the highest number of comments $(35.7 \%)$ relating to one specific theme. To capture the patients' descriptions of the nurse's approach to their care, key words were grouped and counted to clearly represent the majority perspective. This resulted in 11 key words or groups of words being isolated (table 5.6).

Table 5.6: Positive Key Words Used to Describe Nurses Bedside Manner

\begin{tabular}{|l|c|}
\hline Key words & $\begin{array}{c}\text { No. of times word occurred in } \\
\text { different comments }\end{array}$ \\
\hline Friendly / approachable & 26 \\
\hline Caring and considerate & 14 \\
\hline Helpful & 14 \\
\hline Kind & 11 \\
\hline Efficient/attentive & 10 \\
\hline Polite / respectful & 6 \\
\hline Professional & 6 \\
\hline Understanding & 4 \\
\hline Available /on hand/ around & 3 \\
\hline Welcoming & 2 \\
\hline Made to feel comfortable & 2 \\
\hline Other & 4 \\
\hline
\end{tabular}

The key words emerged from comments and phrases such as:

'They were understanding of my situation, so therefore were sympathetic, friendly, helpful and always on hand.' (w13/648) 
'They were all pleasant and understanding. The bit I liked best was they were all friendly.' (w13/617)

'The nurses were very kind, caring and efficient. They were approachable and very friendly.' (w14/652)

'The staff were very reassuring, courteous and efficient during my 4 day stay, and made my time acceptable.' (w23/1126)

'On the whole, they were pleasant and professional' (w4/167)

There were four 'other' positive comments or parts of comments, which described the nursing care but did not contain specific descriptive key words. These patient comments highlighted that the care they had received was brilliant the nurse had inspired confidence, made the patient feel relaxed, and their stay pleasant. One patient, whose own experience of working in customer service, felt the nurses' had delivered a level of care beyond their 'normal' duty.

'The nursing care was brilliant, even when they were short-staffed.' (w21/1014)

She [the nurse] gave me confidence for my short stay in the ward... as she was relaxing.' (w2/76)

'The nursing staff did everything they could to make my stay as pleasant as possible.' (w20/965)

'Above all, they seemed to go beyond their 'normal' duty. I work in Customer Service so I really do think people-skills are important. They were all great.' $(w 13 / 613)$

There was only one ward (ward 10) where respondents chose not to offer any positive comment regarding the nurses' bedside manner.

In the main questionnaire patients were asked if they agreed or disagreed with the statement 'I felt that the nurses liked me.' The majority of patients (138) who responded to the questionnaire strongly agreed /agreed with the statement, $67.4 \%$. Despite this $24.9 \%$ (51) of patients were unsure or did not feel the nurses did like them. This could have been a difficult question to answer for some patients who may have formed a better relationship with one nurse than another. This was demonstrated 
by seven comments although praising the nursing staff patients indicated that they felt that some nurses were better than others.

'Some nurses understood and were very good, others not so good.' (w13/622)

'Some of the nurses were more helpful than others, but in the main I just waited my turn to be treated and have no complaints overall.' (w18/888)

'The nursing care differed with nurses. Like anything, some were more approachable than others, but mostly good'. (w23/1129)

One patient found student nurses more attentive than the qualified staff.

'I found that the student nurses, both male and female, had more time for me than staff nurses. Let's hope they keep this bedside manner up when they qualify.' (w16/757)

Another patient reasoned why some patients get on well with some nurses and not others, suggesting it to be a part of 'human nature'.

'Human nature being what it is, your reaction to some nurses, as theirs is to you, sometimes a lovely rapport, others friendly, efficient only.' (w21/1020)

Although the majority of respondents (80) clearly were happy with the nurses bedside manner, 27 negative comments were provided which described experiences patients' had with nurses who lacked interest (11), were rude (10), disrespectful (3) and at times ignorant (2).

Eleven patients described a lack of interest from the nurses in comments suggesting they didn't care and weren't very happy in their work. These patients were cared for across eight different wards, two patients each from wards 3, 16 and 20 did not like the nurse's manner. One patient felt that the young staff 'gave a feeling of cheer' whereas the 'mid-age (nurses) not very caring'. 
'One nurse seemed to dismiss the fact that I was ill and seemed to ignore the fact that I struggled to walk because of the pain, and just concentrated on moving me to another ward. This made me feel very uncomfortable and upset.' (w13/606)

'...they seemed to just lose interest in me. They seemed to act that the patients were just a bother.' (w20/985)

Ten negative comments illustrated the patients' experiences of rudeness from nurses in seven different wards. Two patients in two different wards singled out the ward sister as the person who was 'abrupt' in her manner.

'One male nurse on nights asked me to clean my own stoma up and change myself.' (w20/996)

'One ward sister was far too regimental. The whole ward and nurses were different on the day she was in charge. She was abrupt and quite ignorant of my feelings. She spoke down to me and spoke to another nurse about me as though I wasn't there. I found that pretty rude but didn't complain because I was already feeling very down and upset.' (w13/622)

'The ward staff nurse was arrogant and derogatory, i.e. she told a nurse that we did not matter. The staff nurse went to change my venflon, got it wrong, and blamed me and a student nurse.' (w19/906)

Ward 20 was the only ward to receive two comments from two different patients and it was one of these patients who explained why it was important to patients for nurses to have a pleasant bedside manner.

'The care was OK, but the nurses especially one, had a bad attitude to all the patients. I would tell the nurses that there is no excuse not to be pleasant, that's what their job is. They need to understand that being in hospital can be a distressing time, so you need some support, not to be told off.' (w20/985)

For three patients being treated in a disrespectful manner was not the behaviour they expected from a nurse. 
'Over-lavish use of my first name. Made me feel like a demented geriatric.' $(w 2 / 56)$

'She treated me as though I would not understand as I am an older lady aged

74. She called me 'sweetheart' in a patronising way and, when my drip 'needle' (cannula) became dislodged during sleep, she seemed cross.' (w19/912)

\section{Treated as an Individual}

Of the patients $59.2 \%$ (121) felt that their preferences for care were addressed and that they had formed a partnership with the nursing staff $(57.6 \%, 118)$. Overall, the majority of patients felt treated as an individual by the nursing staff whilst in hospital $(69.2 \%, 142)$ (table 5.7).

Table 5.7: Treated as an Individual /Care Preferences

\begin{tabular}{|l|c|c|c|}
\hline & Strongly Agree/Agree & Unsure & $\begin{array}{c}\text { Disagree/ } \\
\text { Strongly Disagree }\end{array}$ \\
\hline $\begin{array}{l}\text { I felt that I was treated as an } \\
\text { individual }\end{array}$ & 142 & 25 & 26 \\
\hline $\begin{array}{l}\text { My preferences for care were } \\
\text { addressed }\end{array}$ & $69.2 \%$ & $12.2 \%$ & $12.7 \%$ \\
\hline $\begin{array}{l}\text { I felt as if the nurses formed a } \\
\text { partnership with me }\end{array}$ & $59.2 \%$ & 49 & 16 \\
\hline
\end{tabular}

Six patients from five different wards (two from ward 3), commented that they liked being 'treated as an individual', made to feel 'special' and 'not just part of a routine'.

'They had no special ones, as every patient seemed special to them.' (w3/123)

'Capable professionals worked as a team, treated me as an individual and were most attentive.' (w3/140)

'Felt like I was treated with respect, as an individual.' (w16/773)

'Being treated as an individual by holistic team, from consultant and rest of the team, whatever their status.' (w17/802) 
A further six patients liked the fact that the nurses responded to their particular needs and concerns, providing care when they needed it, and saw them as more than just a medical condition but as a person with individual needs. Indeed $140(68.3 \%)$ patients disagreed or strongly disagreed with the statement 'I felt that my concerns about my health were dismissed as unimportant.'

'The staff listened to my concerns about my own body and took relevant steps to make me comfortable.' (w13/646)

'Care was given to me when I wanted it, not when it fitted in as part of the ward routine.' (w16/787)

'Seeing and feeling how hard the nurses were looking after me and them being understanding of my needs.' (w18/899)

\section{Time Taken to Care Versus Waiting for Care}

Twenty positive responses from patients cared for in 11 different wards, indicated that some nurses took time to care, and made patients feel that they could ask for help. Indeed 30\% (6) of responses included the phrase 'nothing was too much trouble'. Some responses went further to explain how some nurses' demonstrated that they really cared for the patients and always had time for each individual.

'The staff had me in mind and wanted me to get better, and not only doing a job.' (w3/123)

'The nurses were very good and had time for you.' (w5/245)

'The attitude that they cared.' (w7/326)

'It felt they really cared.' $(w 7 / 328)$

'The nurses always had time for me.' (w21/1014)

'They seemed to go beyond their 'normal' duty.' (w13/613)

In particular Ward 18 received the highest number of comments $(25 \%)$ in this theme where patients clearly noted the time taken by the nurses on the ward and the empathy shown towards the patients. 
'The nurses could not do enough for me.' (w18/852)

'They always had time for me and everybody on the ward.' (w18/855)

'If I ever needed a nurse there was always one there, and they took good care of me.' (w18/857)

'They always showed concern about me and helped me in any way they could.' (w18/894)

'In some instances the nurses were caring, despite a lack of staff. Most times things, e.g. care, was carried out with great care and devotion to me.' $(w 18 / 861)$

When patients were asked to agree or disagree with the statements that they had to sometimes 'wait for nursing care' or that nurses were 'too busy' to care for them the majority disagreed or strongly disagreed (table 5.8). However, 33.7\% (51) of respondents reported that they sometimes had to wait for nursing care and $25.9 \%$ (53) felt that the nurses were sometimes too busy.

Table 5.8: Waiting for Care - Too busy

\begin{tabular}{|l|c|c|c|}
\hline & $\begin{array}{l}\text { Strongly } \\
\text { Agree/Agree }\end{array}$ & Unsure & $\begin{array}{c}\text { Disagree/ } \\
\text { Strongly } \\
\text { Disagree }\end{array}$ \\
\hline $\begin{array}{l}\text { Sometimes I had to wait for } \\
\text { nursing care }\end{array}$ & 51 & 15 & 112 \\
\hline $\begin{array}{l}\text { Sometimes I felt that the nurses } \\
\text { were too busy to deal with me }\end{array}$ & $53.7 \%$ & $7.3 \%$ & $54.6 \%$ \\
\hline
\end{tabular}

A small number of patients (9) went onto provide examples of their experiences of waiting for care. Five of the nine negative comments were concerned with waiting for assistance off a bedpan or to go to use the toilet, and the disposal of a used bedpan.

'I had to ask on numerous occasions for my bedpan to be taken away from my bedside cabinet. On one occasion I asked four times in one and a half hours, until another patient took it away for me.' (w2/51) 
'Some staff ignored "call bells" and on many occasions, when asked for a bottle or toilet help, said be back in a short time, and on many occasions it was too late, causing disasters and requiring the bed to be changed or my clothes.' $(w 11 / 529)$

'Once I waited 15-20 minutes to be taken off the bedpan. Often I felt people had to wait too long for a bedpan.' (w21/1022)

'No-one seemed in a hurry to help me to the toilet when I needed it.' (w23/1108)

A lack of urgency to answer alarm calls as well as a shortage of staff, were identified by patients as reasons for delays in their nursing care and treatment.

'Buzzer being off-ignoring me.' (w16/778)

'A lack of (or what did seem to be) urgency by senior nursing staff to emergency cord alarms.' (w19/948)

'On occasions an acute shortage of nurses led to delay in treatment.' (w12/595)

\section{Knowledge and Expertise}

Only four patients, from two different wards, chose to positively comment on the knowledge level and skills of the nurses providing the care. Two patients from ward 17, one patient liked the fact that nurses were 'capable of discussing ailments', the other commented on the 'thorough way' staff carried out procedures. Two patients from ward 8, one described the nurses as 'proficient in high tech procedures' another explained how the nurses 'helped us to cope with my dialysis [technical procedure] on the ward.'

One patient from ward 19 felt reassured when they observed junior nurse training at the patient's bedside. Similarly a patient from ward 2 liked the fact that there was a senior nurse and staff nurse available to care for them.

'Senior nurses delivering training to junior nurses were professional, which ultimately gives the patient confidence in their clinical care.' (w19/948)

'The fact that a nurse and ward sister were in attendance.' (w2/51) 
In contrast, seven patients raised some concerns over some nurses' lack of knowledge and experience of their medical problems and post-operative care. This was a particular issue for patients who were out-lying on wards that were not their specialty.

'I should have been on a stroke ward but, because of a shortage of beds, I had to stay where I was. I definitely felt vulnerable because I was on a medical ward and, although the nurses did their job well, I felt unsafe... It isn't very good in my opinion. Should be better care.' (w14/684)

'I was only put on the ward as there wasn't a bed for me on the ward I should have been on. I don't feel that they fully understood my operation.' (w14/697)

'Due to the ward being predominantly General Surgery, I felt they were unsure of post-op procedures for a gynaecological operation.' (w19/945)

'Some nurses understand my medical condition, but most of them don't, e.g., about my medication or when would I see the doctor.' (w4/190).

Two patients suggested that the 'basic nursing skills were lacking,' new staff needed a mentor and 'seemed to have been thrown in at the deep end'. Another patient felt that bank nurses did not follow care plans.

\section{Communication and Information}

Patients were positive about the information they received as part of their nursing care. $71.2 \%$ (146) of respondents felt they could get information when they wanted it. However, one in five patients felt they sometimes got conflicting information from the nurses (table 5.9).

Additional comments, provided by patients regarding the provision of information and the communication of nurses, were evenly matched with 18 positive comments and 17 negative comments. 
Table 5.9: Patient Perception of Delivery of Information

\begin{tabular}{|l|c|c|c|}
\hline & $\begin{array}{c}\text { Strongly } \\
\text { Agree/Agree }\end{array}$ & Unsure & $\begin{array}{c}\text { Disagree/ } \\
\text { Strongly Disagree }\end{array}$ \\
\hline My relatives were kept fully informed & 138 & 15 & 40 \\
of my progress (with my consent) & $67.3 \%$ & $7.3 \%$ & $19.5 \%$ \\
\hline Sometimes I got conflicting information & 44 & 26 & 123 \\
from the nurses & $21.5 \%$ & $12.7 \%$ & $60 \%$ \\
\hline I could always get information about & 146 & 22 & 31 \\
my care & $71.2 \%$ & $10.7 \%$ & $15.2 \%$ \\
\hline Sometimes the nurse looking after me & 44 & 36 & 113 \\
didn't seem to know much about me & $21.5 \%$ & $17.6 \%$ & $55.1 \%$ \\
\hline
\end{tabular}

Seventeen patients, from 13 wards, chose to positively comment (18 comments) on the fact that they were always kept informed of their condition, their progress and the procedures being performed.

'Especially liked information when I asked why, where, etc, information readily supplied if you asked for it.' (w6/265)

'Could answer all my questions and even said I could ring after I was discharged if I needed to.' (w13/648)

'Being informed of each procedure and why it was being done.' (w17/842)

'They did not talk over me but involved me in discussion.' (w21/1005)

Conversely, four patients reported episodes where information was either not shared with or passed onto them or they were provided with conflicting information from different staff members.

'Sharing information is the problem. Keep patients informed of delays, process and realistic expectations.' (w1/46)

'Conflicting information - before admission I was told I would be in and out in one day. After admission I was told by a nurse that I would definitely be in overnight, and therefore had to inform my wife. However I was told (by the surgeon during the operation) that I would go home. Back on the ward and this was not (at first) believed. I was discharged at 8.30 pm!' (w4/171) 
They were quite often so busy that you were not sure what was happening regards your treatment, and staff were not always passed on the correct information.'(w20/98)

Two patients experienced problems understanding the nurse as a result of a language barrier. One patient reported that the poor communication of their named nurse led to delays in them receiving investigations and the time wasting of other staff members (porters). Other instances of poor communication between staff included a patient moved to a ward and left for an hour, 'until someone noticed me', as staff had not communicated their transfer. Another patient felt that nurses were not aware of their illness or that they had been in hospital before.

Overall, the majority of patients $67.3 \%$ (138) felt that their relatives were kept fully informed throughout their stay on the ward. Two patients (from Wards 3 and 8) added positive comments to reinforce this aspect as being good.

'They kept myself and my wife well informed on my condition.' (w8/364)

'I was kept fully informed on my treatment and progress, which I could pass on to my relatives.' (w3/129)

However, three patients perceived that their families could have been better informed of the changes in their condition, during their stay.

'I got out of bed to go to the toilet and fell and broke my hip. My family were not informed. I think I could have had better care.' (w1/2)

'I have no complaints... apart from one nurse in charge one weekend who was loathe to inform my family of my condition.' (w12/597)

'My family had to always ask to see the doctor from the stroke ward, and my notes weren't on the ward with me...Should be better care.' (w14/684)

Three of the 18 positive comments were from patients from the same ward (Ward 3). In particular one patient described how the good communication between the nurses facilitated effective patient care. 
'They each knew the medical history of their assigned patients...this gave continuity and total confidence. They all knew though each patient, as assigned patients moved to different nurses as days changed.' (w3/129)

Two patients who chose to provide negative comments took the opportunity to express their dissatisfaction with the doctors' lack of communication with the patient. One patient described how they felt 'invisible to the doctors' another being 'left for days without seeing a doctor despite the nursing staff trying their best to help.'

\section{Organisation of Nursing Care}

The overall consensus of opinion by patients was that the nursing care was well organised. Respondents who chose to provide additional comments offered a more negative perception on how their care was organised compared with how it was delivered. Indeed, 124 comments relating to the organisation of nursing care were received, 86 of which were negative and 38 positive. The issue most raised by patients was the concern with the wards being understaffed and nurses having excessive workloads. Ward 17 received the highest number of positive comments (6) about how the care was organised compared with ward 21 which received the highest number of negative comments (16) regarding the ward organisation.

Seven key themes were identified:

- General organisation

- Routine

- Clerical work

- Response to needs

- Continuity of Care

- Inappropriate wards / moving wards

- Staffing levels and skill mix / workload 


\section{General Organisation}

Thirteen patients, from nine different wards, provided general positive comments regarding the general organisation of the nursing care. Seven of these comments encompassed phrases such as 'well ran' and 'well organised'. The other comments implied that the nursing care on these particular wards was efficient, professional and ran smoothly.

'A very dedicated, professional care system delivered in my case.' (w17/812)

'The service was relaxed but very efficient.' (w2/85).

'Nurses seemed to be organised and knew what they were doing. This made me feel safer.' (w13/606)

'Well-supervised ward.' (w14/684)

'Good service throughout.' (w16/780)

'Everything ran smoothly.' (w17/830)

The opinion that the wards were well organised was reinforced by the majority of the patient sample. When asked to agree or disagree as to whether the specific ward was well organised, $162(79.1 \%)$ patients agreed. However, patients were not as sure about who was in charge of the ward, although $92(44 \%)$ respondents agreed that they knew, $110(53.7 \%)$ were either unsure or didn't know who was in charge of their ward (table 5.10).

Table 5.10: Well organised/In-charge

\begin{tabular}{|l|c|c|c|}
\hline & $\begin{array}{c}\text { Strongly } \\
\text { Agree/Agree }\end{array}$ & Unsure & $\begin{array}{c}\text { Disagree/ } \\
\text { Strongly Disagree }\end{array}$ \\
\hline I always knew who was in & 92 & 47 & 63 \\
charge of the ward & $44.9 \%$ & $22.9 \%$ & $30.8 \%$ \\
\hline The ward was well organised & 162 & 11 & 27 \\
& $79.1 \%$ & $5.4 \%$ & $13.2 \%$ \\
\hline
\end{tabular}


Despite the overall positive opinion that wards were well organised 13 patients from 7 different wards described problems with some general aspects of how care was organised that they had experienced. General comments included:

'Nursing care on the ward was nothing short of chaos.' (w19/929)

'On the ward it was disorganised.' (w20/956)

'Organisation was rubbish.' (w21/1011)

One problem highlighted included a patient's experience of being sent home only to return with the same problem and left them feeling they should have been admitted in the first place. Another patient commented on the disappearance of nurses after afternoon visiting which left patients' waiting to get help.

'One shift in particular (afternoons) seemed to put on a caring show for the visitors and then we did not see them again until tea time. If I wanted anything during this time, it took ages to get it, e.g. trip to the loo.' (w22/1085)

One patient on ward 21 had two separate experiences of disorganised care, which highlighted first the poor organisation of inter-agency care (physiotherapy) and second, the misplacement of an important dressing, delaying care.

'I was told on Wednesday morning that someone had rung for Physio for me to do bed exercises on Friday. I said nobody had been, so she said she would look into it. On Saturday when the patient in the next bed was having Physio before she left, I beckoned her over. She said all she could do was apologise and pass it on for Monday (the day I should get out of bed).' (w21/1022)

'Dr said I would go on compression (bandage) on Monday. The dressing was by my bedside since last week. When my "big day" arrived it was gone... when I asked about the dressing (compression) they said there was no record of it, so would leave a note for the Dr for Tuesday.' (w21/1022)

A further 5 patients describe individual experiences of having to wait for different investigations. The impact for four patients was an extended stay in hospital, blocking a bed because other departments could not accommodate them for the specific tests, 
or the doctors were not available. These problems directly impact on the organisation of nursing care.

'I got out of bed to go to the toilet and fell and broke my hip... and I waited 12 hours to be X-rayed. I think I could have had better care.' (w1/2)

'The acuteness of the problem for which I was admitted had resolved itself within twelve hours but an endoscopy test was needed. This was not available for a further five days but I was advised that if I returned home in the meantime it could be several months before I could have the test. Consequently I was occupying a bed for five days, which could have been occupied by a patient with more acute problems. I could easily have returned at any time for and endoscopy.' (w19/917)

'It was the waiting for scans, X-rays, that was not good. One lady had to go 5 days without a meal because of cancellations. '(w20/987)

'I had a chicken bone fast in my throat and there wasn't one doctor able to do a simple job like that. They said I would be done when they come back from holiday...then one man lost my notes. I could not be done until Thursday, 4 days with a bone in my throat.' (w18/896)

\section{Routine}

The majority of patients who responded to the main questionnaire perceived that the ward routine was not considered more important than anything else, 121 patients (59\%). Seven positive comments, from patients on six different wards (two from ward 17) highlighted that keeping to a routine was what the patients liked.

'Coming round with our medication and taking patients to the bathroom who couldn't walk very well.' (w16/796)

'My medication was given at the right times.' (w17/814)

'The nurses kept to a strict routine - administering drugs and serving meals.' (w23/1118)

'A good routine was maintained.' (w18/886) 
In contrast, 12 negative comments raised a number of issues which patients found a problem with the ward routine. Two related problems were the waking of patients when asleep to perform nursing care and waking of patients in the morning to have breakfast, even when the patient would have preferred sleep a little longer. This was particularly an issue for 3 patient's cared for on 3 different wards.

'They bother you all the time, especially when you need sleep at night time.' $(w 8 / 374)$

'To give breakfasts before the night staff leaves... a patient can have a very bad night like difficult to get to sleep or could not sleep till the early hours but just to clear breakfast duty you just had to get up. No matter when you have slept or how well you slept.' (w13/644)

'The strict routines of meals, especially breakfast, when I was trying to recover from an operation and needed as much rest as possible (w20/961)

A further problem, which upset six patients from six different wards, was the poor routine for administering medication, with medication arriving late and not at the time they were prescribed or not receiving them at all. Only one patient commented on being kept waiting till early evening for a discharge prescription.

'I had to have sleeping pills and I never got them till really late at night. One night it was $12.45 \mathrm{am} . '($ w6/288)

'The very late hour that $10.00 \mathrm{pm}$ medication was administered, i.e. 12 midnight.' (w17/802)

'The only thing I did not like was giving me my injection at different times and sometimes missing altogether.' (w9/419)

'In all my time in hospital I did not receive an injection in my shoulder or knee for my arthritis. I was promised these repeatedly.' (w11/511)

Two patients, from two wards (3 and 15) liked the fact that when staff changed over you 'always knew who was looking after you', each member of staff was fully aware of the 'medical history of their assigned patients' because 'handovers were effectively and efficiently carried out at each shift change.' However two other patients from two different wards (12 and 21) indicated their dissatisfaction with staff 'change-over' 
with staff taking a lot of time to discuss patients fully 'leaving the patients waiting for attention' and sometimes 'incoming people seemed unclear' about the patients condition.

\section{Clerical Work}

A small number of respondents (six patients from five wards) commented on the 'burden' of paperwork already 'overworked' nurses had to shoulder. The consequence of increased administrative work was that 'staff did not have time to nurse properly' because 'the nurses' time was taken up with too much paperwork' as a result 'they didn't have much time to talk.' One patient noted that nurses stayed late 'often past their shift' to ensure the paperwork was completed and suggested they could ' $d o$ with more help.' Another objected to having to repeat personal information ' 4 or 5 times.'

\section{Response to Needs}

The majority of patients that completed the questionnaire demonstrated an overall positive perception of care with 145 respondents (70.8\%) agreeing with the statement that nurses always had time for them and 125 respondents (61\%) felt involved in care decisions (table 5.11). This is consistent with the category 'Time taken to Care' related to the delivery of nursing care.

Table 5.11: Time for me /Involved in decisions

\begin{tabular}{|l|c|c|c|}
\hline & $\begin{array}{c}\text { Strongly } \\
\text { Agree/Agree }\end{array}$ & Unsure & $\begin{array}{c}\text { Disagree/ } \\
\text { Strongly Disagree }\end{array}$ \\
\hline I felt that I was involved in & 125 & 24 & 50 \\
decisions about my care & $61 \%$ & $11.7 \%$ & $24.4 \%$ \\
\hline The nurses always had time & 145 & 19 & 33 \\
for me & $70.8 \%$ & $9.3 \%$ & $16.1 \%$ \\
\hline
\end{tabular}


Although nine comments positively reinforced the majority perspective a further 12 negative comments highlighted some degree of dissatisfaction with the promptness that nurses responded to their needs indicating that care could have been organised better to ensure their needs were addressed.

However, the nine positive comments, from patients cared for in seven different wards (two each from wards 16 and 23), praised the nurses' organisation of care and highlighted that they liked that fact that their needs were not just fitted round the ward routine but nurses were available promptly, whenever they needed them.

'Whatever was asked of the nurses was carried out promptly.' (w12/562)

'If I needed more help, I was given it.' (w17/814)

'The fact that I could buzz them if needed and someone came as soon as possible.' (w23/1129)

'Care was given to me when I wanted it, not when it fitted in as part of the ward routine.' (w16/787)

In complete contrast, three patients in three different wards had the opposite experience. They reported being 'left for long periods,' one patient when moved to a different ward was 'left for about one hour until someone noticed' without any explanation. Another patient felt 'forgotten' but understood that 'to be able to deal with every patient at once was not really possible.'

'As soon as I rang my bell the nurse was there and gave me a good explanation of why I had just been overlooked for a little while. I was able to relax and appreciate what the nurses had to keep up with.' (w16/796)

Two comments reflected an understanding by the patients' that sometimes other peoples' needs would come before their own, in particular if other patients were perceived to be more 'poorly'. 


\section{Continuity of Care}

The majority of patients, $70.2 \%$ (144 unsure, disagreeing or strongly disagreeing) indicated a degree of confusion both in terms of who was responsible for their care throughout their stay and also who was looking after them on a daily basis (134 $65.3 \%$ strongly agreeing, agreeing or unsure) (table 5.12).

Table 5.12: Responsible/Looking after

\begin{tabular}{|l|c|c|c|}
\hline & $\begin{array}{c}\text { Strongly } \\
\text { Agree/Agree }\end{array}$ & Unsure & $\begin{array}{c}\text { Disagree/ } \\
\text { Strongly Disagree }\end{array}$ \\
\hline $\begin{array}{l}\text { One nurse was responsible for my } \\
\text { care throughout my hospital stay }\end{array}$ & 56 & 47 & 97 \\
\hline I was not always certain which & $101.4 \%$ & $22.9 \%$ & $47.3 \%$ \\
nurse was looking after me & $49.2 \%$ & 33 & 63 \\
\hline
\end{tabular}

The uncertainty of which nurse was looking after which patient and how nursing care was organised was reinforced by seven negative comments from patients cared for in five different wards. Two comments were from patients on the same ward (13) indicating that they were unsure who their named nurse was.

'Having to deal with too many different nurses.' (w13/610)

'I could not talk to the named nurse who was looking after me, as I did not know who that was.' (w13/617)

Other patients indicated that there were members of staff they didn't know and frequent change over. For one patient the night staff members were always different.

'There was little continuity of nurses. It was nearly always a different nurse who gave out the pills.' (w9/434)

'I didn't know two of them.' (w14/679)

'Not always continuity with so many changes of staff.' (w21/1020) 
'The lack of continuity of nursing staff especially on the night shift. On three consecutive nights a different nursing team were on duty to just do the job.' (w23/1118)

\section{Inappropriate Wards - Moving Around}

Twelve patients described experiences of moving wards or being admitted and housed on inappropriate wards for their medical/surgical condition. Three patients out of the 12 perceived the movement both within and on to ward 15 as a problem, commenting on 'patients changing constantly' and 'none of the staff was concerned.'

Two patients (wards 15 and 23) identified that it wasn't so much the moving to another ward that was the problem but the fact that there was ineffective communication after the move between the nurses and doctors.

'I was moved to a ward with no-one informed and left for about one hour until someone noticed me there.' (w15/730)

'I was boarded out to various wards and left for days without seeing a doctor/consultant despite the nursing staff trying their best to help.' (w23/1106)

The moving of patients from ward to ward but also the moving of patients inside of wards and bays was perceived to be excessive at times.

'I was on the Medical Assessment Ward in a bay for four people and the patients were changing constantly.' (w15/724)

'I was fussed around over 3 different wards, and none of the staff was concerned.' (w15/745)

'Having to move beds 3 times in 4 days.' (w17/848)

'In the 3 days in hospital, I was moved 3 times.' (w21/1008)

'I was passed from pillar to post.' (w7/326)

Patients perceived that a shortage of beds resulted in them being placed on inappropriate wards where the nurses were not experienced to nurse their particular 
medical condition. This for some patients added to the stress of their hospital admission but was an external influence for which the nurses had little or no control.

'Due to the bed shortage, I feel the way patients are left in 'LIMBO' waiting for a bed is a horrible and stressful situation to be in. Luckily after 1 day of waiting I was fortunate to gain a bed, although not on a gynae ward. I feel that... specialities should stay within specialities.' (w19/945)

'Having to wait for a bed, owing to it being an ordeal going into hospital, and the uncertainty of it being cancelled.' (w17/842)

\section{Staffing Levels, Skill Mix and Workload}

One third of patients $(30 \%)$, who offered comments about aspects of the nursing care that they did not like, perceived there to be a shortage of nurses on the wards and an excessive workload for nurses to manage. Key phrases which captured this opinion included: not enough nurses; understaffed; always seemed to be a staff shortage; overworked; too busy. The patients' words have been summarised in table 5.13, alongside a summary of the key comments, which describe the patients' feelings about the staff shortage and the impact on the care they received.

The impression was clear, patients felt that their care was rushed and at times and they had to wait because there were not enough nurses available to care for the number and level of dependent patients on the wards. The highest number of comments (8) regarding under-staffing came from patients on ward 21 closely followed by three patients from each of the wards 15, 17, 18 and 19. The shortage of staff directly influences how nursing care is organised and delivered. It was felt that nurses 'did their best' although 'under heavy workloads' and it was generally 'not the nurses' fault' but 'they could not deliver the best care' and there was 'not enough time to give to the individual.'

There was no mention of staff shortages by patients cared for on wards 7, 9, 10, 13, 14,20 and 23. 


\begin{tabular}{|c|c|}
\hline Problems & ents \\
\hline 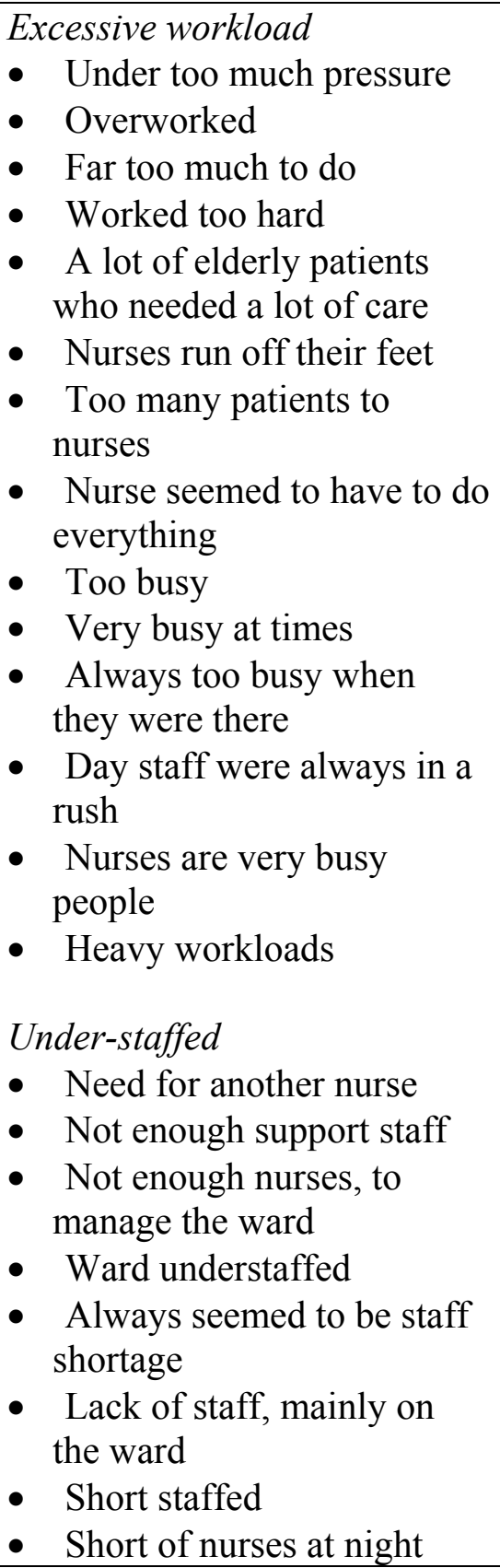 & 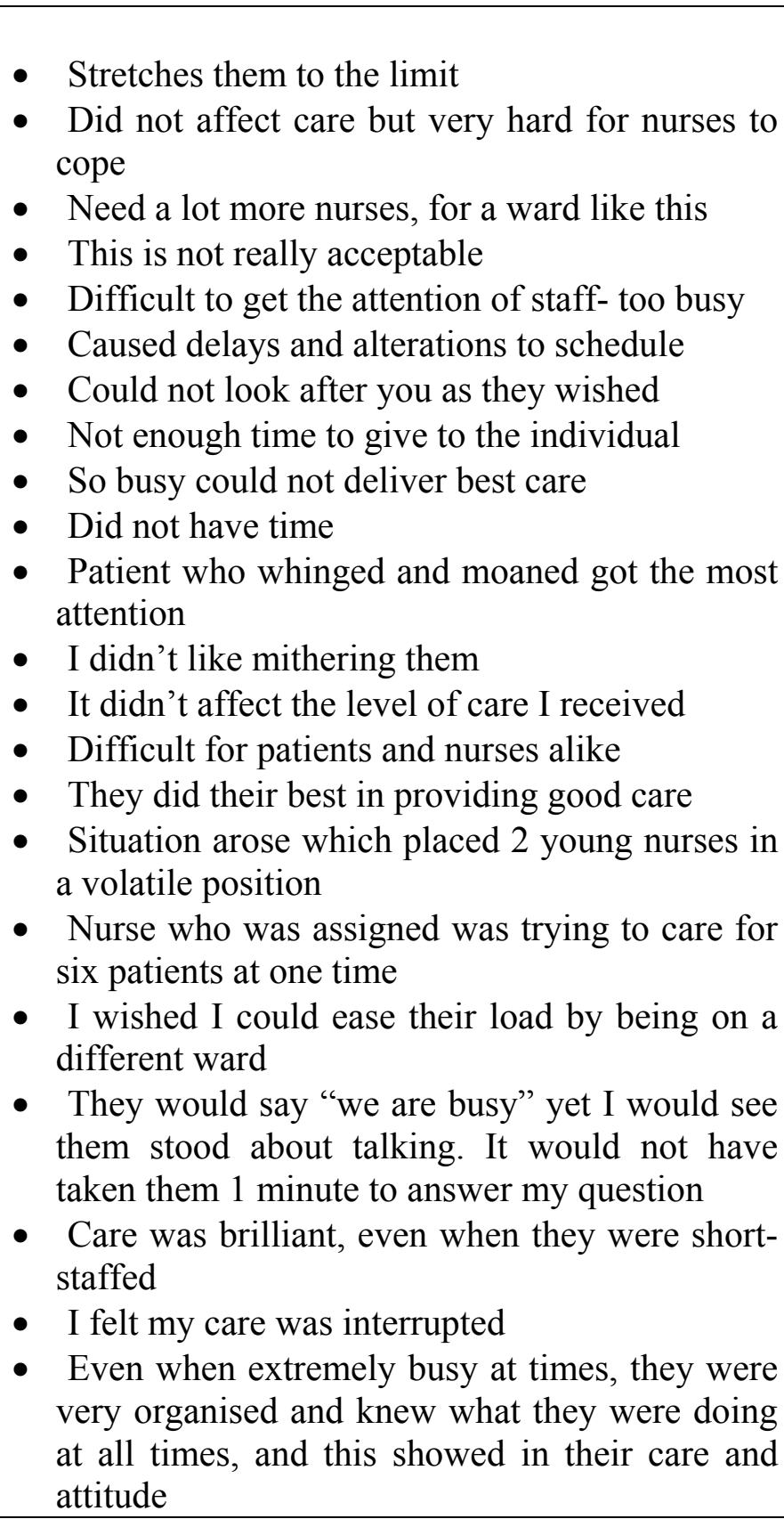 \\
\hline
\end{tabular}

The use of bank/agency staff was not an issue for patients. Only two patients' mentioned the use of agency/bank staff, one in the context of being admitted to a ward during a holiday weekend and the 'nursing staff were all agency-workers.' Another (from ward 21) suggested they had a lack of knowledge as the: 
'Bank nurses asked patients frequently as to which medication they were on, and more or less gave them what they wanted, and not what was in their notes. Also, any problems seemed to be blamed on bank nurses.' (w21/1044)

Although 30 patients highlighted the problem of staff shortages only one patient (from ward 21) described a time when they heard the nurses complaining and dissatisfied with the staffing situation.

'Many times I heard staff complaining. One said the job was frustrating, not enough people pulling their weight, and she was hoping for a transfer - said it's not like this on other wards.' (w21/1022)

\section{Other Ward Aspects}

The final category was concerned with 'Other Ward Aspects,' which included comments regarding the ward environment, the cleanliness of the ward and the visiting hours. Small groups of patients from different wards offered a balance of positive and negative comments reporting contrasting opinions and experiences of individual patients.

Nine patients offered positive comments about the ward environment, five of which described their wards as 'friendly' either referring to the atmosphere in general or the staff and patients. One patient valued the visit by the 'WRVS trolley' and two others enjoyed the personal televisions at the bedside. In comparison, nine patients also chose to negatively comment (11) on their ward environment. Descriptors of some ward environments included:

'Ward was very depressing, dark and horrible.'(w11/534)

'Victorian squalid conditions... The smell was appalling.' (w17/848)

'Too warm.' (w5/201)

Two patients struggled sleeping because of the 'noise at night' sometimes caused by equipment 'bleeping' although this was thought to be 'necessary, but a bit loud 
particularly at night.' One patient didn't like the fact that only a percentage of the overhead televisions were working, and another described a toilet being out of order and inadequate supplies of toilet paper. Two patients, from different wards described similar feelings regarding the older age group of patients on wards.

I was a relatively young woman and they had a lot of elderly patients who needed a lot of care and, even though I need to be on this kind of ward...I felt there were too many elderly on one ward.' (w5/214).

'Despite my age (70), I felt company of so many people probably no older than I was depressing. I felt much younger than they were, but equally I would have felt ill at ease in a ward of 20 year olds (w6/265)

Twelve patients' chose to raise the issue of the cleanliness of the ward. Seven patients felt their ward was 'very clean' and 'comfortable.' Whereas five patients disagreed and identified experiences such as 'beds were not cleaned after a patient went home,' and 'areas of the floor were missed and wiping down the beds was a joke!' Two apposing perspectives are shown in table 5.14 where patients' experiences were different on the same ward.

Table 5.14: Ward Cleanliness - Opposing Perspectives

\begin{tabular}{|l|l|}
\hline \multicolumn{1}{|c|}{ Ward 16 } & \multicolumn{1}{|c|}{ Ward 21 } \\
\hline $\begin{array}{l}\text { 'It was good to see the cleaners } \\
\text { on the ward starting their round } \\
\text { early and doing a good job.' }\end{array}$ & $\begin{array}{l}\text { 'I was truly amazed with the care I got, and the } \\
\text { cleanliness was magic.' }\end{array}$ \\
\hline 'The ward was dirty.' & $\begin{array}{l}\text { 'At no point has my bed been pulled forward to } \\
\text { clean behind, neither has the chair to my right } \\
\text { or the locker to my left...I have only seen the } \\
\text { floor buffed once and the ceiling vents cleaned.' }\end{array}$ \\
\hline
\end{tabular}

Again a handful of patients (five) commented on the visiting hours allocated on the wards. Two of the patients with positive perceptions were from ward 6 and two 
patients with negative perceptions were from ward 11. Three patients felt they were 'flexible' and 'generous, the other two described them as inflexible' and 'not adequate' particularly for visitors who worked. 


\section{CHAPTER SIX}

\section{DISCUSSION}

The aim of this chapter is to provide a discussion of the findings presented in previous chapters and to highlight any issues surrounding the methods used in the study. This discursive element will reflect the fifth stage of the soft system framework which underpins this study (Figure 6.1) and will be an integrated discussion of the responses obtained from both patients and staff. Throughout the discussion it must be remembered that the response rates from both groups were low $(24.8 \%$ for staff and $17.9 \%$ for patients) so that any conclusions derived from the study must be treated with caution.

Figure 6.1: Phase 5 Soft Systems Methodology

\section{Phase 5: Comparing conceptual models with reality}

$\Rightarrow$ Comparison used to generate debate about possible changes that can be made in order to alleviate the gap between models and reality

\section{Root Definitions}

The earlier stages of this project involved the development of a number of root definitions that captured the essence of the different approaches to the organisation of care, namely Primary, Team and Task Allocation. To recapitulate, these root definitions were as follows;

\section{Root Definition of Primary Nursing}

A system owned and operated by health care staff within a specific clinical care area with the aim of ensuring that an identifiable autonomous individual has responsibility 
for the planning, directing and delivery of high quality health care to a small group of specific patients.

\section{Root Definition of Team Nursing}

A system owned by ward managers and operated by health care staff within a specific clinical care area with aim of delivering care to a specific group of patients with responsibility devolved from the ward manager and shared across a small team of practitioners and support workers.

\section{Root Definition of Task Allocation (Functional Nursing)}

A hierarchical system owned and directed by ward managers who are responsible for the planning and direction of care for an entire specific clinical care area which is delivered to all patients in that care area by health care staff with the aim of supplying patient needs through the completion of a variety of tasks.

These root definitions were used to develop a rich picture which was a visualisation of the elements that impact upon the satisfactory organisation of nursing care. The data that was obtained from the ward and staff questionnaires and from the observations that were carried out was used to test the accuracy of these definitions.

\section{Discussion of Findings}

\section{Model of Care}

The overall model of organisation of care in the acute wards of Bolton NHS Trust is that of team nursing, with a small minority organising care by way of task allocation. Thomas and Bond (1995) noted that rarely did a ward fulfil all the criteria for one specific style of organisation and this can be seen in the results from this study, with $45 \%$ of respondents operating a weak team approach to organisation of care, implying that other organisational methods are also used. 
It was clear from the results obtained that the majority of patients were satisfied with the organisation and delivery of their care with the total number of positive comments outnumbering negative ones across most wards. There was an indication of polarisation of patient experience, with some wards being seen as efficient and effective in the delivery of their care whilst others attracted more negative comments. Of the wards for which there was data, the majority of those that achieved positive patient evaluations were categorised as using a moderate team approach. Tentatively this could then imply that the stronger the team nursing model and less task allocation the better the patient experience. A possible reason for this could be the increased direct patient care being given by the qualified nurse on the moderate team wards compared to personal cares being given by the health care assistant on the weak team (more task allocation) wards. However, there is insufficient evidence to support this hypothesis and more in-depth research is necessary to prove or disprove this supposition. There was no data available from the ward which received the highest number of negative comments from patients since that wards had not responded to the organisation of care questionnaire. Thomas (1992) suggested that although there were identifiable differences between organisational modes of care there was no difference within such modes. However, this is not supported in this study where wards appeared to obtain both negative and positive comments suggesting that patient experiences were polarised even within organisational approaches to care management.

The overall opinion of the patients who responded was that, regardless of mode of organisation, the wards were well run. Nonetheless there were a minority of patients' who felt that the organisational practices of the ward required some improvement. Coyle and Williams (2001) have noted that there is greater value in examining patient dissatisfaction as a way of evaluating quality of care, for this reason the negative experiences are discussed. They noted that the concept of personal identity threat by exposure to experiences that could be perceived as dehumanising or disempowering affected perception of both organisation and delivery of care. This was apparent in the findings in this study; those patients who expressed dissatisfaction with both organisation and/or care delivery tended to use illustrative examples which involved being ignored or diminished in some way by the nursing staff. Whilst it is acknowledged that this was only a small minority of patients, the experiences they reported obviously had made a big impact upon their overall perceptions of the 
service offered. However, the majority of the patients felt that the nursing service provided individualised care, the lack of routine in areas such as medications, particularly night sedation and pain relief was seen as an issue for some patients. The importance of routine and 'basic' care has been identified as key components in patient satisfaction (Sixma et al. 1998).

\section{Patient Medication}

Clearly the medicines issue is one that is most important to patients since it featured so prominently in the negative comments received. It must be stressed that instances of good practice were also noted. For example, ward 16 used the co-ordinator effectively by ensuring that they were available to check all IV's each morning to avoid encroaching on the time of other qualified staff that had their own team of patients to care for. The same ward was also trialling single nurse administration of one particular medicine (Oromorph) which although not a controlled drug is treated as one by the Trust and so requires two nurses to check and administer. The trialled method of administration by one qualified nurse rather than two is commendable as an effective and efficient use of nursing time.

Other examples of good practice were the use of medication lockers by the bedside. However there is a clear requirement for better stocking procedures and for the pharmacy to improve the service they provide at weekends. There was a lot of time wasted by the ward staff on Mondays searching for drugs. Kelly (1994) suggests that self-medication approaches can help to promote patient independence and satisfaction. Self-medication, for carefully assessed and selected independent patients may be a strategy that the Trust may wish to consider both for the beneficial effects this will have upon patient morale and the impact it may have on reducing the time that the nursing staff spend upon medicine rounds. 


\section{Staffing Levels}

On the whole nursing care was positively appraised and patients found the majority of staff to be helpful kind and caring. However, reports of poor levels of basic care, in some cases, were directly attributable to staff having to prioritise care as a result of staff shortages. Linked to this point is negative staff manners towards patients which were reported by the patient questionnaire but were not actually not observed on any of the wards. Abrupt or rude behaviour can also be a result of excessive pressure of workload for staff, nevertheless such behaviour is inexcusable.

Both patients and staff acknowledged that the issue which has the biggest impact upon both the organisation and delivery of care is staffing levels. The patients perceived the wards as short staffed and often cited night time as an area of particular concern. The staff on the other hand emphasised the difficulties that attended the organisation of care when the ward co-ordinator has to carry a case load as well as an administrative role. The lack of qualified staff upon the ward was seen as a particular problem by the more junior nurses (D and E grades) and is probably reflective of their inexperience. Makinen et al. (2003a) have noted that job stress and the feeling of overload can be attenuated by possessing autonomy and job control, elements which may be difficult for the junior staff to achieve. The Trust is implementing different initiatives in attempt to address nurse staffing levels and skill mix but this study highlights that it is still an ongoing problem.

There appears a vicious cycle of increased patient workload causing work related stress causing staff sickness and absence which then reduces the skill mix of the team which then increases the patients workload thus resulting in the need for bank/agency staff to assist with patient care. This in turn brings a different set of problems. Indeed every part of the cycle impacts directly on the organisation, delivery and quality of patient care.

Patients and nurses spoke of the use of bank/agency staff as a barrier to the provision of good care since such staff were seen as transitory in nature and disadvantaged in that they did not know the ward or the patients in the way that the permanent staff did. Manias et al. (2003) have noted that improved communication between agency 
providers and hospital employers facilitates both the quality of care provided by and the job satisfaction of agency staff. Action is being taken by the Trust to reduce the unacceptable levels of sickness and absence which is considered to be the main reason for the increased use of temporary staff (Bolton Royal Hospitals NHS Trust, 2004).

However, for a Trust that uses bank staff, that is existing permanent staff working extra hours, it is hard to understand why nurses already orientated to the working of the hospital are viewed in such a transitory nature. A reason for this could be that they are used inappropriately on wards that are unfamiliar or of a different speciality. It must be noted that one ward within the Trust had 'recruited' an agency nurse who always worked for them when agency input was required. This guaranteed familiarity with the ward team, the patient group and the working of the wider multi-disciplinary team enhancing their contribution to the team. Although this model, for the deployment of bank or agency, is followed as rule by the Trust the evidence suggests it is not the experience of the staff on the wards.

\section{Leadership}

The Trust, have invested in different approaches over the last two years to improve the leadership skills of the nurses on the wards (University of Leeds, 2006). There was evidence on a small number of wards, both from staff comments and through the observation that effective leadership was occurring within the co-ordinator role. Indeed it was perceived that clinical leadership and knowledge on the shop floor enhanced the quality of care provided. However, on those wards where the coordinator role was compromised through reduced staffing levels the leadership was limited and often reduced to 'fire-fighting' ward problems or consumed by administrative duties. Staff and patients identified different ways that senior experienced staff could improve the quality of care on the ward by both providing and advising on patient care. The co-ordinator role could be used as an effective way of providing clinical leadership at the point of care providing the role is not reduced to a managerial and administrative role. There needs to be sufficient levels of staff and the ward leader needs to work independently of the staff team to enable this to happen. 
The leadership from nursing staff needs to be more visible when it comes to the organisation of doctors' ward rounds. It was observed that many ward rounds currently take place when activity on the ward is excessive and the nurses have other priorities. Birtwistle et al. (2000) noted that whilst doctors see ward rounds as playing a valuable part of good care, nurses did not view them as constructive use of their time. Birtwistle et al. (2000) further speculate that the dissatisfaction of the nursing staff around this issue is detrimental to the professional relationship. Nurses highlighted that the arrival of doctors to perform a ward round at unscheduled times had a negative impact on the nurses' time and delayed patient care. Nurses need to use their leadership and organisational skills to negotiate the ground rules for doctors' ward rounds that best suit the doctors, the ward nurses and the patients. In addition, an excessive number of doctors accompanying the ward round were observed on one particular busy ward. Despite none of the patients or nurses raising this as a problem the ward was very overcrowded, indeed unsafe. This again could be reflected upon by the leader of the ward and discussed with the wider multi-disciplinary team.

\section{Protected Meal Times}

Good practice was witnessed on wards that instigated 'protected' meal times for patients where visitors and medics were not allowed on the ward or to disturb patients, or patient tests were not performed. This allowed time for nurses and HCAs to feed dependent patients without being interrupted and also allowed for respite for the staff from institutional and collegial demands upon their time. This seemed to be a new initiative introduced by a few wards so it was not a surprise that there were no patient comments reflecting the good practice. However, the Trust may wish to consider sharing this good practice to other wards throughout the hospital.

\section{Bed Meetings}

There were barriers to the provision of care that were recognised by the nurses but which did not appear obvious to the patients. Those that most obviously lend 
themselves to resolution are those of phone calls, paperwork and bed meetings. Our observations showed that bed meetings, which featured as disruptive tasks in both the qualitative and quantitative data were a draw on co-ordinators time (or staff nurses) to leave the ward and meet to hand over bed status ( 8.30 and 1.30 observed times) when they could be doing more on the ward to help with patient care. Bed availability needs to be communicated another way without impeding on the time of the qualified staff since it is important that the nurses are on the ward directing care and not attending meetings. During our observation periods it was noted that many co-ordinators couldn't attend anyway as they were too busy.

\section{Telephone Calls / Paperwork}

Dealing with telephone calls was the most disruptive task identified by the quantitative data. However this problem could be dealt with by more effective use of ward clerks to answer the telephone and sort out queries without disturbing staff particularly in the morning when much of the personal patient care is performed. Another area of dissatisfaction which could be alleviated by more effective use of the ward clerk is that of excessive paperwork. Patient comments supported the repetitive nature of the paperwork and that nurses' time could be used more effectively.

The Trust computer system causes delays in obtaining patient information. Much of the information is collected many times which leads to unnecessary repetition of work and documentation. This was observed on most of the wards; either difficulties accessing the system or repeating paper based information onto the computer system. The Department of Health highlighted unnecessary paperwork as a cause for concern in 1996. Indeed the computer programme 'Teamwork' used for measuring and monitoring staffing activity, was identified from the initial staff focus group, as a hindrance rather than a useful tool to plan and organise care. There appeared no ownership for this computer program and comments suggested a lack of understanding on the information it produced, and how it was used. For this method of measuring staff activity to be successful, staff training needs to be reviewed and revisited. Alternatively, if staff members are unclear about its value and use in the 
workplace, the Trust may wish to consider reviewing the future value of using Teamwork workload methodology.

Furthermore the referral processes to other agencies could be improved in the short term by the use of existing paperwork instead of copying information and by using the ward clerk to follow up and check whether the referral paperwork has been received rather than nurse. Chasing up and checking referrals to other agencies was a feature of the observation periods and was a significant draw on nurses' time. In attempt to address this problem the Trust, in some areas, has introduced a multi-disciplinary collaborative patient document in an attempt to concentrate all patient information in one place and reduce repetition. However, whether this is the method of choice or another, the negative impact of excessive paperwork and computer based systems on the nurse's time remains a problem which needs to be addressed.

\section{Communication}

Information and communication strategies would benefit from further investigation. Our observations indicated that taped handover appeared less effective than verbal handover for facilitating discussion and allowing clarification of patient progress and care. Taped handover was not observed to save any time and the research suggests that verbal handover could be a more effective communication tool. Kerr (2002) has suggested that handover interaction is a complex phenomenon which can be complemented but not necessarily replaced by taped information. Nurses need to be aware of how long a handover takes as some patients did hint that at times they were too long.

The use of the printed patient communication sheets (providing a summary of each patient) were good practice and were seen to be used by all the MDT. Although these are a good communication tool they are only effective when they are kept up to date and portray useful information. Keeping these up to date was again the role of the nurse but did not necessarily have to be and maybe with direction could be taken on by the ward clerk or a HCA. On wards where patient turnover is excessive the use of a printed patient sheet is limited as keeping the information up to date requires too 
much time. For other wards which have not yet implemented this idea they could found it useful.

\section{Inappropriate Wards}

Another significant impact upon the organisation and delivery of care as perceived by the nursing staff was the practice of admitting patients to wards which were either not staffed for or skilled in the care of such patients. Ward staff noted their concern and worried that the quality of care they were able to offer such patients was not of a suitable standard. Patients commented on a 'bed shortage' and this along with determining which patients were admitted to which ward was not within the control of the nursing team. However there was also an element that saw such 'outliers' as forming a barrier to the provision of care for the 'legitimate' patients on the ward. This reflects the work of Stockwell (1972) who suggested that patients nursed upon wards for which they were not intended were in danger of unpopularity. Although this was not strongly reflected in the qualitative data from this study, a small number of patients were not happy to be nursed on 'inappropriate' wards and described feeling unsafe at times. There was no overt evidence that these patients were unpopular; there was a clear indication by the nurses that they were seen as adding to the overall workload of the nursing staff.

\section{Inadequate Stock}

There was clear evidence of a borrowing and lending culture across the wards. From the comments provided by the nurses and the patients, reinforced by the observation of activity there were problems with the lack of stock items, such as drugs, dressings and linen items (theatre gowns, blankets, linen bags). The result of not having available items led to heightened dissatisfaction, time wasting trying to locate an item on a different ward and stress due to the delays placed on the delivery of patient care. The working between different agencies within the hospital needs to be reviewed to reduce the amount of nursing time wasted. The stocking of drugs with pharmacy and the appropriate delivery and the correct amount of linen to meet the demands of the 
ward need to be appraised and current working arrangements changed and monitored. In addition to supplies, a small number of nurses highlighted the lack of equipment which hinders the provision of patient care. Again all these small issues impact directly upon the nurses time and effectiveness in delivering the patient care. Ward managers may wish to address these issues directly with the support services involved and agree more appropriate stock levels.

\section{Discussion of Root Definitions}

\section{Organisation of care was defined as;}

'A system owned and operated by health care staff which aims to provide high quality care to patients and is impacted upon by collegial and institutional pressures, patient experiences and expectations and which can affect the autonomy, professional growth and relationships and job satisfaction of nurses.'

It is apparent from the responses of the ward's staff that the amount of ownership that the staff have upon the organisation of the care they provide is strongly affected by the demands of other health care professionals and the administrative demands both of the ward environment and the overall organisation. For example, the attendance at bed meetings was perceived by a significant number of staff as affecting both the organisation and delivery of care. It was also clear that the staff felt that they were autonomous in their practice, however it appears that this autonomy is restricted to their clinical decision making rather than their managerial role. This tension between the managerial and clinical elements of the ward co-ordinator role reflect the work of Wilmott (1998) who found that attendance at meetings that impacted upon the administrative rather than the service delivery facets of the modern nursing role were seen as additional but not contributing to quality of care.

The root definitions that were developed for the different modalities of organisation of care tended more or less accurately reflect the nature and focus of care organisation. There was no evidence of primary nursing, based upon the Bowman and Thompson 'organisation of care' questionnaire (1995), within the wards sampled. The majority of wards appeared to be using team approaches of varying degrees to organise and 
deliver their care. The teams that operated a weaker version of team nursing as described by Bowman and Thompson (1995) did not reflect the root definition in that devolution of responsibility for care was not always apparent. This was often because staff shortages meant that the ward leader was also carrying a care case load.

The insight into the clinical reality of the acute care staff can be contrasted with the rich picture that was developed to represent the concepts of the organisation and delivery of care (table 6.1).

Table 6.1: Mapping of Findings to Theoretical Concepts

\begin{tabular}{|c|c|c|}
\hline \multicolumn{2}{|l|}{ Nursing Care } & \multirow[b]{2}{*}{ Nursing Perspective } \\
\hline $\begin{array}{l}\text { Rich picture } \\
\text { concept }\end{array}$ & Patient Perspective & \\
\hline Autonomy & $\begin{array}{l}\text { - Not commented upon by } \\
\text { patients }\end{array}$ & $\begin{array}{l}\text { - Staff generally felt supported and } \\
\text { autonomous in their practice }\end{array}$ \\
\hline $\begin{array}{l}\text { Collaborative } \\
\text { working }\end{array}$ & $\begin{array}{l}\text { No sense of } \\
\text { collaborative working } \\
\text { between or within } \\
\text { disciplines }\end{array}$ & $\begin{array}{l}\text { - Strong supportive nursing team } \\
\text { - Demands of other health care professionals } \\
\text { impacted upon how care was organised } \\
\text { - Other agency referral processes time } \\
\text { consuming }\end{array}$ \\
\hline Staff Resources & $\begin{array}{l}\text { Levels of staffing } \\
\text { perceived as insufficient }\end{array}$ & $\begin{array}{l}\text { - Reduced staffing levels impact upon patient } \\
\text { care } \\
\text { - High sickness rates on some ward and } \\
\text { increased use of bank staff }\end{array}$ \\
\hline $\begin{array}{l}\text { Institutional } \\
\text { pressures }\end{array}$ & $\begin{array}{l}\text { - Cleanliness seen as an } \\
\text { issue }\end{array}$ & $\begin{array}{l}\text { - Teamwork systems not seen to be useful for } \\
\text { - organising and measuring workload. } \\
\text { - Dependency levels seen as a 'paper exercise' } \\
\text { - Early Warning paperwork takes priority } \\
\text { - Early discharge pressures } \\
\text { - Bed shortages and pressures }\end{array}$ \\
\hline $\begin{array}{l}\text { Collegial } \\
\text { pressures }\end{array}$ & $\begin{array}{l}\text { - Not commented upon by } \\
\text { patients }\end{array}$ & $\begin{array}{l}\text { - Covering sickness and working extra shifts } \\
\text { affects staff retention } \\
\text { - Reflection on poor practice only no time to } \\
\text { praise good work }\end{array}$ \\
\hline $\begin{array}{l}\text { Systems of } \\
\text { organising work }\end{array}$ & $\begin{array}{l}\text { - General satisfaction } \\
\text { with care }\end{array}$ & $\begin{array}{l}\text { - Patient records time consuming } \\
\text { - Referral paperwork for patients excessive } \\
\text { - Computer systems slow and time consuming } \\
\text { to use } \\
\text { - Lack of stock items delay patient care and } \\
\text { waste nurses time }\end{array}$ \\
\hline $\begin{array}{l}\text { Work related } \\
\text { stress }\end{array}$ & $\begin{array}{l}\text { - Staff seen as over } \\
\text { worked }\end{array}$ & $\begin{array}{l}\text { - Staffing levels } \\
\text { - Increased patient dependency } \\
\text { - Increased workload } \\
\end{array}$ \\
\hline Job Satisfaction & - Not commented upon by & - There was little perceived opportunity for \\
\hline
\end{tabular}




\begin{tabular}{|c|c|c|}
\hline & patients & $\begin{array}{l}\text { team building or clinical supervision } \\
\text { - Nurses doing too many jobs that could be } \\
\text { done by others }\end{array}$ \\
\hline \multicolumn{3}{|l|}{ Patients } \\
\hline Family & $\begin{array}{l}\text { - Generally satisfied with } \\
\text { family involvement }\end{array}$ & $\begin{array}{l}\text { - Not perceived as sufficiently engaged in } \\
\text { patient care }\end{array}$ \\
\hline Expectations & $\begin{array}{l}\text { - Patient care good and } \\
\text { praise for nursing team } \\
\text { although basic care not } \\
\text { always fulfilled } \\
\end{array}$ & $\begin{array}{l}\text { - Patients do not expect to get involved in their } \\
\text { own care }\end{array}$ \\
\hline $\begin{array}{l}\text { Previous } \\
\text { experiences }\end{array}$ & $\begin{array}{l}\text { - Previous experience } \\
\text { serves as measure of } \\
\text { satisfaction with care }\end{array}$ & $\begin{array}{l}\text { - } \text { More dependent } \\
\text { - Nursed on inappropriate wards at times }\end{array}$ \\
\hline Fears & $\begin{array}{l}\text { - Patients do not always } \\
\text { feel supported in their } \\
\text { concerns }\end{array}$ & - Not commented upon by nurses \\
\hline
\end{tabular}

To further facilitate this comparison, the 'reality' of the organisation of care suggested by this study has been mapped onto the concepts presented in the theoretical model produced in chapter three, see figure 6.2.

When comparing the reality of organisation and delivery of care within Bolton NHS Trust with the rich picture that was developed at the beginning of the study, it was clear that some of the elements played a bigger part in the management of acute care than others. For example, staffing issues were at the forefront of both the staff and patients perspectives. Institutional directives added to the pressure on the nursing staff to realise the organisational agenda alongside delivering quality patient care. There was no real sense of collaborative working noted within the data obtained. There was a dichotomy between the clinical autonomy of the staff which they acknowledged and the apparent lack of managerial autonomy. Ward rounds need to be organised when it is appropriate for the nurses and the medical staff and promoting a more collaborative working environment. 
Figure 6.2: Rich Picture - Influences on the Organisation of Care Concepts (The Reality)

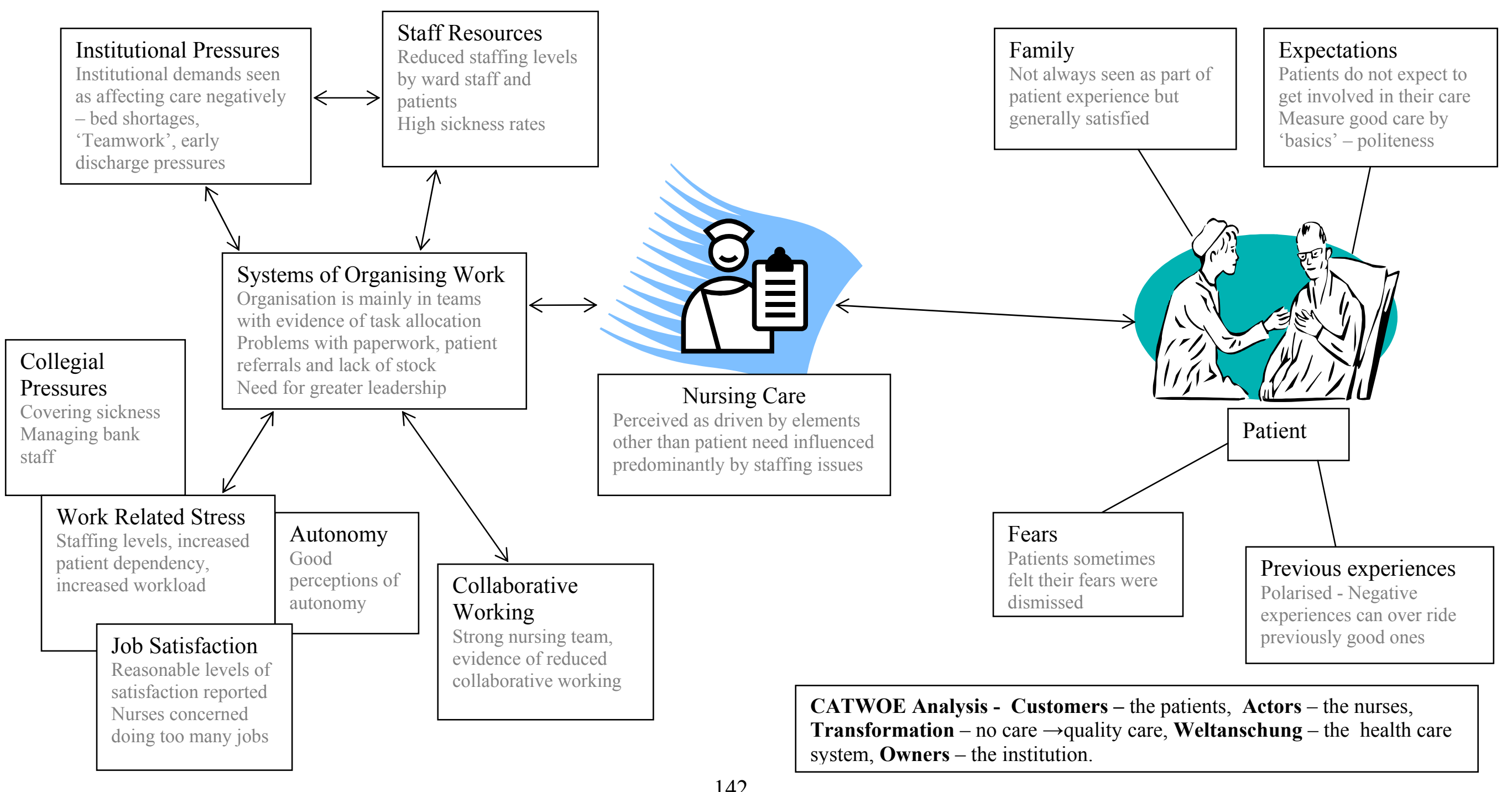




\section{Issues within the Methodology}

The data collection in this study was informed by a number of methods. In the first instance, efforts were made to obtain in-depth data from both staff and patients by holding two focus groups at the beginning of the study. Unfortunately response was limited. No patients managed to attend the focus group that was set up to seek their views and opinions and only a restricted number of Trust staff members were able to participate in the staff focus group. This was unfortunate since the opinions that may have obtained would have both informed the development of the questionnaires and would have provided greater insights into the perceived strengths and weaknesses of the organisation and delivery of care across the acute wards of the Trust. It must be emphasised, however, that the data obtained from the staff focus group was extremely useful and contributed to root definition development and questionnaire design.

Response rates to the questionnaires were low both for staff and for patients. Bowling (2002) notes that response rates for questionnaires are often lower than for other data collection methods, nonetheless the extremely low response rate obtained in this study was disappointing. Since a majority of both patients and staff are unrepresented the potential for bias must be acknowledged.

The observational element of the study was seen as contributing concept validity in that it allowed for the experiences and opinions reported by staff and patients to be corroborated in the clinical environment. This provided more in-depth understanding of the issues identified and also allowed for the context of the organisation and delivery of care to be incorporated into the subsequent discussion and recommendations of the study. The observation was carried out by one member of the research team which could potentially imply a degree of bias in terms of incidents observed. However the use of observation, triangulated with the other methods used helped to reduce that threat.

The underpinning framework for analysis which supported these data collection methods was Soft Systems Methodology as described by Checkland and Scholes, (1992). This approach proved to be useful in terms of focussing the problem, defining 
what different approaches to organising nursing care mean and developing an overview of the elements and impacting factors that make up organisation and delivery of care. A weaker element of SSM as a theoretical framework was, however, that it proved limited on offering structure to the delivery of nursing care.

Nonetheless, the methods and methodology used achieved the stated aims of the study. They were appropriate in terms of meeting the demands of the study. For the future, this work could be built upon by the use of a rigorous time and motion study to provide insights into exactly what nurses do, for who and for how long. The conclusions and key messages attendant upon the findings of this study are presented in the next chapter. 


\section{CHAPTER SEVEN CONCLUSIONS AND KEY MESSAGES}

A number of key messages are apparent from this study. Generally, patients are satisfied with the nursing care offered by the Trust and the staff employed by the Trust show reasonable levels of job satisfaction. Care within the Trust is organised and delivered across all three of the defined methods of care organisation reactively to the situation on the wards, with team nursing dominating. Most of the acute wards in the Trust believe that they are using a team approach to care.

The main points that came out of the study focussed upon staffing levels and the number of qualified staff available to organise and deliver care. Both patients and staff agree regarding the effect that staffing levels have upon the organisation and delivery of care. Bank staff were perceived to impact upon the delivery of care, generally in a less than positive manner because they are not regular members of ward teams and may require extra information or support. Junior staff in particular found low numbers of qualified staff a cause of stress.

Some of the difficulties reported by ward co-ordinators could be addressed by better use of ward clerks, telephone answering and referral checking for example, as could a review of time-consuming activities which do not contribute directly to the organisation and delivery of care such as twice daily attendance at bed meetings.

Whilst patient responses were favourable on the whole, some patients felt that elements of their care could have been significantly improved. Issues that are a threat to personal integrity, such as slow delivery of hygiene related care or late delivery of care were the main cause of patient dissatisfaction. Concerns expressed by a minority of patients regarding the attitudes of staff maybe allied to the pressures of work; however we have no observed evidence to support this hypothesis.

We saw very little evidence of collaborative working. Ward rounds appeared to be scheduled for the benefit of medical personnel and the referral system to other 
agencies is perceived as cumbersome. It is suggested that efforts should be made to review how collaborative working operates across the Trust

There were a number of areas of good practice observed including:

- The ward which developed a relationship with a particular bank nurse

- The use of single nurse checking for non-controlled drugs

- The use of 'protected time' for patient meals which allowed the nurses to concentrate their energies on the patients

- The use of printed sheets as a communication tool

In conclusion, although the majority of users of the Trust services are satisfied with the care they receive and staff morale is generally good there are areas for improvement, notably amongst experienced staffing levels.

\section{Implications for Future Research}

This study has completed 5 out of the 7 elements of soft systems methodology. There is an opportunity for the Trust to continue the work that this study has begun by completing the last two stages which involves implementing changes which are feasible, based upon the comparisons made in the earlier stages of the process and then evaluating those changes. This reflects the action research and cyclical nature of the SSM approach.

The Trust may also wish to instigate a rigorous time and motion study which would add to the findings of this one as it would provide more in-depth data on what nurses do for whom and how often. The data provided by this study would also be expanded upon if a series of focus groups for patients were held in order to fully explore the areas of satisfaction and dissatisfaction reported upon in this study. 


\section{REFERENCES}

Adams A, Bond S (1997) Clinical Speciality and organizational features of acute hospital wards. Journal of Advanced Nursing 26 1158-1167

Adams A, Bond S (2003a) Staffing in acute hospital wards: part 1. The relationship between number of nurses and ward organizational environment. Journal of Nursing Management 11 287- 292

Adams A, Bond S (2003b) Staffing in acute hospital wards: part 2. The relationships between grade mix, staff stability and features of ward organizational environment. Journal of Nursing Management 11 287- 292

Aharony L, Stasser S (1993) Patient satisfaction; what we know about and what we still need to explore. Medical Care Review 50(1) 49-79

Audit Commission (2001) Acute Hospital Portfolio. Ward Staffing No 3. Audit Commission Publications Wetherby

Birtwistle L, Houghton J, Rostill H (2000) A review of surgical ward round in a large paediatric hospital: does it achieve its aims? Medical Education 34 398-403

Bolton Hospitals Trust (2004) Implementation of New Deal for Nurses. Paper submitted to Trust Board 22 March 2004.

Bolton Hospitals NHS Trust (2005a). Fit for the Future. Paper submitted and approved by Trust Board 25 April 2005

Bolton Hospitals NHS Trust (2005b). Best possible care - now and into the future. A vision and strategy for Bolton Hospitals NHS Trust to 2010. Bolton Hospitals NHS Trust Internal Report

Bolton Hospitals Website http://www.boltonhospitals.nhs.uk [Accessed 18/08/05] 
Boumans NPG, Landeweerd JA (1999) Nurses' well-being in a primary nursing care setting in the Netherlands. Scandinavian Journal of Caring Sciences 13 116-122

Bowling A (2002) Research Methods in Health. Investigating health and health services. Second Edition. OU Press. Buckingham

Bowman GS, Thompson DR, Webster RA (1995) The development of a classification system for nurses' work methods in Bowman GS Thompson DR [Eds] A Classification System for Nurses' Work Methods Report No. 9 National Institute for Nursing. Oxford

Chang AM (1995) Role Determination in nursing, implications for service provision. Journal of Nursing Management 3 25-34

Checkland P, Scholes J (1992) Soft Systems Methodology in Action. John Wiley \& Sons. Chichester

Commission for Healthcare Audit and Inspection (2005) Acute hospital portfolio review Ward Staffing, June. Commission for Healthcare Audit and Inspection. London.

Commission for Health Improvement website http://www.chi.nhs.uk/Ratings/Reports/AcuteTrustDetail.asp?TrustCode=RMC [Accessed 18/08/05]

Coyle J, Williams B (2001) Valuing people as individuals; development of an instrument through a survey of person centeredness in secondary care. Journal of Advanced Nursing 36(3)450-459

Department of Health (1996) Seeing the wood, sparing the trees: efficiency scrutiny into the burdens of paperwork in NHS Trusts and Health Authorities. HMSO 
Department of Health (2006a) NHS in England the Operating Framework for 2006/2007 DoH, London

Department of Health (2006b) Payment by Results. www.dh.gov.uk/paymentbyresults [Accessed 1.02.06]

Department of Health (2006c) Agenda For Change.

http://www.dh.gov.uk/PolicyAndGuidance/HumanResourcesAndTraining/Modernisin gPay/AgendaForChange [Accessed 1.02.06]

Jinks AM, Hope P (2000) What do nurses do? An observational survey of the activities of nurses on acute surgical and rehabilitation wards. Journal of Nursing Management 8 273-279

Johansson I, Larssson G, Hamrin E (1994) Changes of Nursing organization in a surgical department: effects on work satisfaction and quality of care. Journal of Advanced Nursing 3: 169-175

Kelly JM (1994) Implementing a patient self medication programme. Rehabilitation Nursing 19(2) 87-90

Kerr MP (2002) A qualitative study of shift handover practice and function from a socio-technical perspective. Journal of Advanced Nursing 37 (2) 125-137

Larsson BW (1999) Patients views of quality of care; do they merely reflect their sense of coherence. Journal of Advanced Nursing 30(1) 33-39

Mäkinen A, Kivimäki M, Elvainio M, Virtanen M (2003a) Organization of nursing care and stressful work characteristics. Journal of Advanced Nursing 43(2) 197-205

Mäkinen A, Kivimäki M, Elvainio M, Virtanen M, Bond S (2003b) Organization of nursing care as a determinant of job satisfaction among hospital nurses. Journal of Nursing Management 11 299-306 
Manias E, Aitken R, Peerson A, Parker J, Wong K (2003) Agency nursing work in acute care settings; perceptions of hospital nurse managers and agency nurse providers. Journal of Clinical Nursing 12 457- 466

McClosky JC, Bulechek GM, Moorhead S, Daly J (1996) Nurse' use and delegation of indirect care. Intervention Nursing Economics 14 22-33

Melchior M, Halfens RJG, Abu-saad HH, van den Berg AA, Gasman P (1999) The effects of primary nursing on work-related factors. Journal of Advanced Nursing 2(1) $88-96$

McKenna HP (1995) Nursing skill mix substitutions and quality of care: an exploration of three assumptions from the research literature. Journal of Advanced Nursing 21 (3) 452-459

National Audit Office (2004) Improving patient care by reducing the risk of hospital acquired infection. HMSO. London

Sixma, HJ, Kerssen JJ, van Campen, C, Peters L (1998) Quality of care from the patients' perspective: from theoretical concept to a new measuring instrument. Health Expectations 1 (2) 82

Spilsbury K, Meyer J (2001) Defining the nursing contribution to patient outcome: lessons from a review of the literature examining nursing outcomes, skill mix and changing roles. Journal of Clinical Nursing 10 3-14

Staniszewska S, Ahmed L (1999) The concepts of expectation and satisfaction; do they capture the way patients evaluate their care? Journal of Advanced Nursing 29(2) 364-372

Stockwell F (1972) The unpopular patient: Royal College of Nursing research project. London: Royal College of Nursing. 
Thomas LH (1992) Qualified Nurses and Nursing auxiliary perceptions of their work environment in primary, team and functional nursing wards. Journal of Advanced Nursing 17 373-382

Thomas LH, Bond S (1990) Towards defining the organization of nursing care in hospital wards: an empirical study. Journal of Advanced Nursing 15 1106-112

University of Leeds (2006) Leading an Empowered Organisation - LEO. http://www.cdhpp.leeds.ac.uk/services/leo.php [accessed 1.02.06]

Wilmott M (1998) The new ward manager; an evaluation if the changing role of the staff nurse. Journal of Advanced Nursing 28 (2) 418-427 


\section{Appendix 1}

\section{Bowman \& Thompson - Classification System Checklist}

Complete Questionnaire and Scoring System:

\begin{tabular}{|l|l|l|}
\hline 1. & What is the nurses' assessment of patients based on?: (Tick appropriate box) \\
\hline 1a & A nursing perspective & 3 \\
\hline 1b & A medical perspective & 2 \\
\hline 1c & A mixture of nursing and medical perspective & 1 \\
\hline
\end{tabular}

\begin{tabular}{|l|l|l|}
\hline 2. & Who is responsible for completing the nursing record from assessment to \\
evaluation?: (Tick appropriate box)
\end{tabular}

\begin{tabular}{|l|l|l|l|}
\hline 3. & $\begin{array}{l}\text { How much of the nurse's role is taken up with administrative duties?: (Tick } \\
\text { appropriate box) }\end{array}$ & 4 \\
\hline 3a & None & & 3 \\
\hline 3b & Very little & 2 \\
\hline 3c & Some & & 1 \\
\hline 3d & A lot & \\
\hline
\end{tabular}

\begin{tabular}{|l|l|l|}
\hline 4. & Who is accountable for the patients nursing care?: (Tick appropriate box) \\
\hline $4 \mathrm{a}$ & A named registered nurse all of the time & 4 \\
\hline $4 \mathrm{~b}$ & More than one registered nurse & 3 \\
\hline $4 \mathrm{c}$ & A registered nurse when on duty & 2 \\
\hline $4 \mathrm{~d}$ & The senior nurse & 1 \\
\hline
\end{tabular}

\begin{tabular}{|l|l|l|}
\hline 5. & Who is responsible for the patients' nursing care?: (Tick appropriate box) \\
\hline $5 \mathrm{a}$ & A named registered nurse all of the time & 4 \\
\hline $5 \mathrm{~b}$ & More than one registered nurse & 3 \\
\hline $5 \mathrm{c}$ & A registered nurse when on duty & 2 \\
\hline $5 \mathrm{~d}$ & The senior nurse & 1 \\
\hline
\end{tabular}

\begin{tabular}{|c|c|c|}
\hline 6. & \multicolumn{2}{|c|}{$\begin{array}{l}\text { Who has the authority for prescribing the patients nursing care?: (Tick } \\
\text { appropriate box) }\end{array}$} \\
\hline $6 a$ & A named registered nurse all of the time & 4 \\
\hline $6 \mathrm{~b}$ & More than one registered nurse & 3 \\
\hline $6 \mathrm{c}$ & A registered nurse when on duty & 2 \\
\hline $6 \mathrm{~d}$ & The senior nurse & 1 \\
\hline
\end{tabular}




\begin{tabular}{|l|l|l|l|}
\hline 7. & $\begin{array}{l}\text { What is the senior nurse's role in making decisions about nursing care?: (Tick } \\
\text { appropriate box) }\end{array}$ \\
\hline $7 \mathrm{a}$ & Central & 3 \\
\hline $7 \mathrm{~b}$ & Advisory & 2 \\
\hline $7 \mathrm{c}$ & A mixture & 1 \\
\hline
\end{tabular}

\begin{tabular}{|l|l|l|}
\hline 8. & Who generally discusses the patient's nursing care with medical and \\
paramedical staff?: (Tick appropriate box)
\end{tabular}

\begin{tabular}{|l|l|l|}
\hline 9. & How are patients allocated to nurses on admission?: (Tick appropriate box) \\
\hline 9a & $\begin{array}{l}\text { By the senior nurse or nurse in charge regardless of work } \\
\text { activity }\end{array}$ & 1 \\
\hline 9b & $\begin{array}{l}\text { By the senior nurse or nurse in charge according to work } \\
\text { activity }\end{array}$ & 2 \\
\hline 9c & $\begin{array}{l}\text { By the senior nurse or nurse in charge after negotiating work } \\
\text { activity }\end{array}$ & 3 \\
\hline
\end{tabular}

\begin{tabular}{|l|l|l|l|}
\hline 10. & How does leadership operate on the ward?: (Tick appropriate box) \\
\hline $10 \mathrm{a}$ & By the senior nurse independently making decisions & 1 \\
\hline $10 \mathrm{~b}$ & By staff being involved in decision-making of key issues & & 2 \\
\hline $10 \mathrm{c}$ & A mixture & & 3 \\
\hline
\end{tabular}

\begin{tabular}{|l|l|l|}
\hline 11. & $\begin{array}{l}\text { Which nurse is responsible for communicating with patient's relatives?: } \\
\text { (Tick appropriate box) }\end{array}$ & 1 \\
\hline $11 \mathrm{a}$ & The senior nurse or nurse in charge & 2 \\
\hline $11 \mathrm{~b}$ & The nurse allocated to the patient for a series of shifts & 3 \\
\hline $11 \mathrm{c}$ & The nurse allocated to the patient for a shift & 4 \\
\hline $11 \mathrm{~d}$ & A named registered nurse from admission to discharge & \\
\hline
\end{tabular}

\begin{tabular}{|l|l|l|}
\hline 12. & \multicolumn{2}{|l|}{$\begin{array}{l}\text { (To be asked to the patient) Which nurse is mainly responsible for the } \\
\text { patient while in hospital?: (Tick appropriate box) }\end{array}$} \\
\hline $12 \mathrm{a}$ & The nurses share it & 1 \\
\hline $12 \mathrm{~b}$ & Two or three main nurses & 2 \\
\hline $12 \mathrm{c}$ & One named nurse in particular & 3 \\
\hline
\end{tabular}

\begin{tabular}{|l|l|l|l|}
\hline 13. & $\begin{array}{l}\text { (To be asked to the patient) How often is the patient involved in the decisions } \\
\text { related to nursing care?: (Tick appropriate box) }\end{array}$ \\
\hline $13 \mathrm{a}$ & Nearly always & 4 \\
\hline $13 \mathrm{~b}$ & Frequently & 3 \\
\hline $13 \mathrm{c}$ & Rarely & 2 \\
\hline $13 \mathrm{~d}$ & never & 1 \\
\hline
\end{tabular}




\section{Scoring Interpretation:}

Primary Style

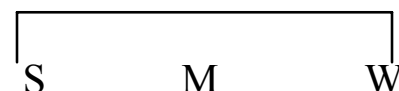

Team Style

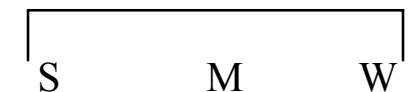

Task Style

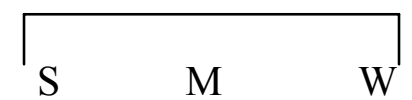

46454443424140393837363534333231302928272625242322212019181716151413

High

Low

Attachment

Attachment

Facilitated

Facilitated

$\mathrm{S}=$ Strong attachment facilitated within organisational style

$\mathrm{M}=$ Moderate attachment facilitated within organisational style

$\mathrm{W}=$ Weak attachment facilitated within organisational style

\section{Scores fall into three groups:}

\section{A LOW SCORE (13-23) = Task Nursing}

The patient is loosely attached to all staff members equally. Any staff-patient attachment is random.

\section{A MIDDLE SCORE (24-34) = Team Nursing}

The patient may attach to any one of a group of nurses who form a sub-group of the total ward nursing staff. The registered nurse has the opportunity equal to other staff in the group for patient-nurse attachment.

\section{A HIGH SCORE (35-46) = Primary Nursing}

The patient is more likely to attach to a registered nurse than any other staff member. The registered nurse's job is designed to be patient orientated and offers the best opportunity for companionship attachment. 


\section{Appendix 2 Staff Questionnaire - Results}

\begin{tabular}{|c|c|c|c|c|c|}
\hline & $\begin{array}{c}\text { Alway } \\
\mathbf{s}\end{array}$ & Often & Occasionally & Rarely & Never \\
\hline $\begin{array}{l}\text { 1. Care is organised in teams on } \\
\text { my ward }\end{array}$ & $\begin{array}{c}56 \\
58.9 \% \\
\end{array}$ & $\begin{array}{c}23 \\
24.2 \% \\
\end{array}$ & $\begin{array}{c}2 \\
2.1 \% \\
\end{array}$ & $\begin{array}{c}2 \\
2.1 \% \\
\end{array}$ & $\begin{array}{c}11 \\
11.6 \% \\
\end{array}$ \\
\hline $\begin{array}{l}\text { 2. We use primary nursing to } \\
\text { organise patient care }\end{array}$ & $\begin{array}{c}33 \\
34.7 \% \\
\end{array}$ & $\begin{array}{c}30 \\
31.6 \% \\
\end{array}$ & $\begin{array}{c}4 \\
4.2 \% \\
\end{array}$ & $\begin{array}{c}9 \\
9.5 \% \\
\end{array}$ & $\begin{array}{c}13 \\
13.7 \% \\
\end{array}$ \\
\hline $\begin{array}{l}\text { 3. I work in a task orientated } \\
\text { environment }\end{array}$ & $\begin{array}{c}18 \\
18.9 \% \\
\end{array}$ & $\begin{array}{c}19 \\
20.0 \% \\
\end{array}$ & $\begin{array}{c}23 \\
24.2 \% \\
\end{array}$ & $\begin{array}{c}23 \\
24.2 \% \\
\end{array}$ & $\begin{array}{c}12 \\
12.6 \% \\
\end{array}$ \\
\hline $\begin{array}{l}\text { 4. Ward routine is seen to be } \\
\text { more important than patient } \\
\text { care }\end{array}$ & $\begin{array}{c}18 \\
18.9 \%\end{array}$ & $\begin{array}{c}13 \\
13.7 \%\end{array}$ & $\begin{array}{c}16 \\
16.8 \%\end{array}$ & $\begin{array}{c}32 \\
33.7 \%\end{array}$ & $\begin{array}{c}30 \\
31.6 \%\end{array}$ \\
\hline $\begin{array}{l}\text { 5. I can work autonomously and } \\
\text { have the authority to direct } \\
\text { patient care }\end{array}$ & $\begin{array}{c}53 \\
55.8 \%\end{array}$ & $\begin{array}{c}32 \\
33.7 \%\end{array}$ & $\begin{array}{c}9 \\
9.5 \%\end{array}$ & $\begin{array}{c}1 \\
1.1 \%\end{array}$ & $\begin{array}{c}0 \\
0 \%\end{array}$ \\
\hline $\begin{array}{l}\text { 6. I feel accountable for the care } \\
\text { I give to my patients }\end{array}$ & $\begin{array}{c}93 \\
97.9 \% \\
\end{array}$ & $\begin{array}{c}2 \\
2.1 \% \\
\end{array}$ & $\begin{array}{c}0 \\
0 \% \\
\end{array}$ & $\begin{array}{c}0 \\
0 \% \\
\end{array}$ & $\begin{array}{c}0 \\
0 \% \\
\end{array}$ \\
\hline $\begin{array}{l}\text { 7. I feel supported in my } \\
\text { professional learning }\end{array}$ & $\begin{array}{c}23 \\
24.2 \% \\
\end{array}$ & $\begin{array}{c}28 \\
29.5 \% \\
\end{array}$ & $\begin{array}{c}32 \\
33.7 \% \\
\end{array}$ & $\begin{array}{c}9 \\
9.5 \% \\
\end{array}$ & $\begin{array}{c}3 \\
3.2 \% \\
\end{array}$ \\
\hline $\begin{array}{l}\text { 8. The level of patient } \\
\text { dependency impacts on how } \\
\text { care is organised }\end{array}$ & $\begin{array}{c}37 \\
38.9 \%\end{array}$ & $\begin{array}{c}43 \\
45.3 \%\end{array}$ & $\begin{array}{c}9 \\
9.5 \%\end{array}$ & $\begin{array}{c}4 \\
4.2 \%\end{array}$ & $\begin{array}{c}1 \\
1.1 \%\end{array}$ \\
\hline $\begin{array}{l}\text { 9. The more a patient becomes } \\
\text { involved in their care the } \\
\text { easier it is to organise }\end{array}$ & $\begin{array}{c}25 \\
26.3 \%\end{array}$ & $\begin{array}{c}43 \\
45.3 \%\end{array}$ & $\begin{array}{c}22 \\
23.2 \%\end{array}$ & $\begin{array}{c}4 \\
4.2 \%\end{array}$ & $\begin{array}{c}0 \\
0 \%\end{array}$ \\
\hline $\begin{array}{l}\text { 10. Care is hard to organise when } \\
\text { a patient is demanding or } \\
\text { requires a lot of attention }\end{array}$ & $\begin{array}{c}12 \\
12.6 \%\end{array}$ & $\begin{array}{c}41 \\
43.2 \%\end{array}$ & $\begin{array}{c}36 \\
37.9 \%\end{array}$ & $\begin{array}{c}5 \\
5.3 \%\end{array}$ & $\begin{array}{c}1 \\
1.1 \%\end{array}$ \\
\hline $\begin{array}{l}\text { 11. Patient care is organised } \\
\text { around the needs of the } \\
\text { individual patient }\end{array}$ & $\begin{array}{c}53 \\
55.8 \%\end{array}$ & $\begin{array}{c}35 \\
36.8 \%\end{array}$ & $\begin{array}{c}4 \\
4.2 \%\end{array}$ & $\begin{array}{c}1 \\
1.1 \&\end{array}$ & $\begin{array}{c}1 \\
1.1 \%\end{array}$ \\
\hline $\begin{array}{l}\text { 12. Patients who shout loudest } \\
\text { get the most attention and the } \\
\text { best care }\end{array}$ & $\begin{array}{c}6 \\
6.3 \%\end{array}$ & $\begin{array}{c}15 \\
15.8 \%\end{array}$ & $\begin{array}{c}33 \\
34.7 \%\end{array}$ & $\begin{array}{c}20 \\
21.1 \%\end{array}$ & $\begin{array}{c}20 \\
21.1 \%\end{array}$ \\
\hline $\begin{array}{l}\text { 13. Patient care on the ward is } \\
\text { well organised and of a high } \\
\text { quality }\end{array}$ & $\begin{array}{c}41 \\
43.2 \%\end{array}$ & $\begin{array}{c}41 \\
43.2 \%\end{array}$ & $\begin{array}{c}11 \\
11.6 \%\end{array}$ & $\begin{array}{c}1 \\
1.1 \%\end{array}$ & $\begin{array}{c}1 \\
1.1 \%\end{array}$ \\
\hline $\begin{array}{l}\text { 14. Staffing levels directly } \\
\text { influence how much care you } \\
\text { can provide for the patients }\end{array}$ & $\begin{array}{c}54 \\
56.8 \%\end{array}$ & $\begin{array}{c}27 \\
28.4 \%\end{array}$ & $\begin{array}{c}14 \\
14.7 \%\end{array}$ & $\begin{array}{c}0 \\
0 \%\end{array}$ & $\begin{array}{c}0 \\
0 \%\end{array}$ \\
\hline 15. Working with inexperienced & 30 & 36 & 19 & 7 & 3 \\
\hline
\end{tabular}




\begin{tabular}{|c|c|c|c|c|c|}
\hline $\begin{array}{l}\text { staff changes the way you } \\
\text { organise your patient care }\end{array}$ & $31.6 \%$ & $37.9 \%$ & $20.0 \%$ & $7.4 \%$ & $3.2 \%$ \\
\hline $\begin{array}{l}\text { 16. The skill mix within the team is } \\
\text { sufficient to provide a high } \\
\text { quality of patient care }\end{array}$ & $\begin{array}{c}13 \\
13.7 \%\end{array}$ & $\begin{array}{c}55 \\
57.9 \%\end{array}$ & $\begin{array}{c}20 \\
21.1 \%\end{array}$ & $\begin{array}{c}5 \\
5.3 \%\end{array}$ & $\begin{array}{c}2 \\
2.1 \%\end{array}$ \\
\hline $\begin{array}{l}\text { 17. The roles and responsibilities } \\
\text { of others in the team are clear }\end{array}$ & $\begin{array}{c}38 \\
40.0 \% \\
\end{array}$ & $\begin{array}{c}43 \\
45.3 \% \\
\end{array}$ & $\begin{array}{c}6 \\
6.3 \% \\
\end{array}$ & $\begin{array}{c}5 \\
5.3 \% \\
\end{array}$ & $\begin{array}{c}3 \\
3.2 \% \\
\end{array}$ \\
\hline $\begin{array}{l}\text { 18. I have more responsibility } \\
\text { than I can cope with }\end{array}$ & $\begin{array}{c}10 \\
10.5 \% \\
\end{array}$ & $\begin{array}{c}19 \\
20.0 \% \\
\end{array}$ & $\begin{array}{c}38 \\
40.0 \% \\
\end{array}$ & $\begin{array}{c}22 \\
23.2 \% \\
\end{array}$ & $\begin{array}{c}6 \\
6.3 \% \\
\end{array}$ \\
\hline $\begin{array}{l}\text { 19. I am listened to and get a lot } \\
\text { of support from my colleagues }\end{array}$ & $\begin{array}{c}21 \\
22.1 \% \\
\end{array}$ & $\begin{array}{c}48 \\
50.5 \% \\
\end{array}$ & $\begin{array}{c}18 \\
18.9 \% \\
\end{array}$ & $\begin{array}{c}7 \\
7.4 \% \\
\end{array}$ & $\begin{array}{c}1 \\
1.1 \% \\
\end{array}$ \\
\hline $\begin{array}{l}\text { 20. I feel that I use all my } \\
\text { professional skills at work }\end{array}$ & $\begin{array}{c}44 \\
46.3 \% \\
\end{array}$ & $\begin{array}{c}38 \\
40.0 \% \\
\end{array}$ & $\begin{array}{c}9 \\
9.5 \% \\
\end{array}$ & $\begin{array}{c}4 \\
4.2 \% \\
\end{array}$ & $\begin{array}{c}0 \\
0 \% \\
\end{array}$ \\
\hline $\begin{array}{l}\text { 21. Staff sickness causes patient } \\
\text { care to be compromised }\end{array}$ & $\begin{array}{c}15 \\
15.8 \% \\
\end{array}$ & $\begin{array}{c}34 \\
35.8 \% \\
\end{array}$ & $\begin{array}{c}36 \\
37.9 \% \\
\end{array}$ & $\begin{array}{c}6 \\
6.3 \% \\
\end{array}$ & $\begin{array}{c}4 \\
4.2 \% \\
\end{array}$ \\
\hline $\begin{array}{l}\text { 22. Inexperienced staff within the } \\
\text { team result in patient care } \\
\text { becoming task orientated }\end{array}$ & $\begin{array}{c}9 \\
9.5 \%\end{array}$ & $\begin{array}{c}21 \\
2.1 \%\end{array}$ & $\begin{array}{c}37 \\
38.9 \%\end{array}$ & $\begin{array}{c}21 \\
22.1 \%\end{array}$ & $\begin{array}{c}7 \\
7.4 \%\end{array}$ \\
\hline $\begin{array}{l}\text { 23. Poor communication between } \\
\text { nursing team members } \\
\text { causes a breakdown in patient } \\
\text { care }\end{array}$ & $\begin{array}{c}9 \\
9.5 \%\end{array}$ & $\begin{array}{c}22 \\
23.2 \%\end{array}$ & $\begin{array}{c}40 \\
42.1 \%\end{array}$ & $\begin{array}{c}21 \\
22.1 \%\end{array}$ & $\begin{array}{c}3 \\
3.2 \%\end{array}$ \\
\hline $\begin{array}{l}\text { 24. Poor communication between } \\
\text { multi-disciplinary team } \\
\text { members regarding patient } \\
\text { investigations/ inhibits the } \\
\text { organisation of nursing care }\end{array}$ & $\begin{array}{c}11 \\
11.6 \%\end{array}$ & $\begin{array}{c}29 \\
30.5 \%\end{array}$ & $\begin{array}{c}38 \\
40.0 \%\end{array}$ & $\begin{array}{c}12 \\
12.6 \%\end{array}$ & $\begin{array}{c}5 \\
5.3 \%\end{array}$ \\
\hline $\begin{array}{l}\text { 25. Negative personalities or } \\
\text { specific people on the ward } \\
\text { interfere with how you } \\
\text { organise your patient care }\end{array}$ & $\begin{array}{c}3 \\
3.2 \%\end{array}$ & $\begin{array}{c}18 \\
18.9 \%\end{array}$ & $\begin{array}{c}38 \\
40.0 \%\end{array}$ & $\begin{array}{c}25 \\
26.3 \%\end{array}$ & $\begin{array}{c}11 \\
11.6 \%\end{array}$ \\
\hline $\begin{array}{l}\text { 26. Team relationships enhance } \\
\text { the way you organise your } \\
\text { care }\end{array}$ & $\begin{array}{c}25 \\
26.3 \%\end{array}$ & $\begin{array}{c}38 \\
40.0 \%\end{array}$ & $\begin{array}{c}16 \\
16.8 \%\end{array}$ & $\begin{array}{c}8 \\
8.4 \%\end{array}$ & $\begin{array}{c}5 \\
5.3 \%\end{array}$ \\
\hline $\begin{array}{l}\text { 27. Shift managers/team leaders } \\
\text { cause nursing care to become } \\
\text { disorganised }\end{array}$ & $\begin{array}{c}3 \\
3.2 \%\end{array}$ & $\begin{array}{c}7 \\
7.4 \%\end{array}$ & $\begin{array}{c}38 \\
40.0 \%\end{array}$ & $\begin{array}{c}32 \\
33.7 \%\end{array}$ & $\begin{array}{c}14 \\
14.7 \%\end{array}$ \\
\hline $\begin{array}{l}\text { 28. Shift managers/team leader } \\
\text { positively influence how } \\
\text { nursing care is organised }\end{array}$ & $\begin{array}{c}22 \\
23.2 \%\end{array}$ & $\begin{array}{c}39 \\
41.1 \%\end{array}$ & $\begin{array}{c}27 \\
28.4 \%\end{array}$ & $\begin{array}{c}5 \\
5.3 \%\end{array}$ & $\begin{array}{c}1 \\
1.1 \%\end{array}$ \\
\hline $\begin{array}{l}\text { 29. My manager treats me as an } \\
\text { individual }\end{array}$ & $\begin{array}{c}43 \\
45.3 \%\end{array}$ & $\begin{array}{c}28 \\
29.5 \%\end{array}$ & $\begin{array}{c}7 \\
7.4 \%\end{array}$ & $\begin{array}{c}2 \\
2.1 \%\end{array}$ & $\begin{array}{c}1 \\
1.1 \%\end{array}$ \\
\hline $\begin{array}{l}\text { 30. Members of the multi } \\
\text { professional team interrupt }\end{array}$ & $\begin{array}{c}7 \\
7.4 \% \\
\end{array}$ & $\begin{array}{c}13 \\
13.7 \%\end{array}$ & $\begin{array}{c}44 \\
46.4 \%\end{array}$ & $\begin{array}{c}25 \\
26.3 \%\end{array}$ & $\begin{array}{c}5 \\
5.3 \% \\
\end{array}$ \\
\hline
\end{tabular}




\begin{tabular}{|c|c|c|c|c|c|}
\hline $\begin{array}{l}\text { patient care and disturb the } \\
\text { planned nursing care }\end{array}$ & & & & & \\
\hline $\begin{array}{l}\text { 31. Multi-professional team } \\
\text { members respect the nursing } \\
\text { care and integrate their care } \\
\text { well }\end{array}$ & $\begin{array}{c}15 \\
15.8 \%\end{array}$ & $\begin{array}{c}44 \\
46.3 \%\end{array}$ & $\begin{array}{c}30 \\
31.6 \%\end{array}$ & $\begin{array}{c}5 \\
5.3 \%\end{array}$ & $\begin{array}{c}1 \\
1.1 \%\end{array}$ \\
\hline $\begin{array}{l}\text { 32. Nurses work separately to the } \\
\text { rest of the multi-professional } \\
\text { team }\end{array}$ & $\begin{array}{c}0 \\
0 \%\end{array}$ & $\begin{array}{c}17 \\
17.9 \%\end{array}$ & $\begin{array}{c}25 \\
26.3 \%\end{array}$ & $\begin{array}{c}34 \\
35.8 \%\end{array}$ & $\begin{array}{c}15 \\
15.8 \%\end{array}$ \\
\hline 33. Staff morale is high & $\begin{array}{c}5 \\
5.3 \%\end{array}$ & $\begin{array}{c}22 \\
23.2 \%\end{array}$ & $\begin{array}{c}34 \\
35.8 \%\end{array}$ & $\begin{array}{c}25 \\
26.3 \%\end{array}$ & $\begin{array}{c}6 \\
6.3 \%\end{array}$ \\
\hline $\begin{array}{l}\text { 34. Nurses are tired and } \\
\text { overworked }\end{array}$ & $\begin{array}{c}35 \\
36.8 \%\end{array}$ & $\begin{array}{c}37 \\
38.9 \%\end{array}$ & $\begin{array}{c}20 \\
21.2 \%\end{array}$ & $\begin{array}{c}3 \\
3.2 \&\end{array}$ & $\begin{array}{c}0 \\
0 \%\end{array}$ \\
\hline $\begin{array}{l}\text { 35. The are a sufficient number of } \\
\text { nurses available to provide } \\
\text { adequate care for patients }\end{array}$ & $\begin{array}{c}4 \\
4.2 \%\end{array}$ & $\begin{array}{c}29 \\
30.5 \%\end{array}$ & $\begin{array}{c}26 \\
27.4 \%\end{array}$ & $\begin{array}{c}26 \\
27.4 \%\end{array}$ & $\begin{array}{c}9 \\
9.5 \%\end{array}$ \\
\hline $\begin{array}{l}\text { 36. To achieve the patient care } \\
\text { expected nurses need to } \\
\text { delegate many tasks to less } \\
\text { qualified staff }\end{array}$ & $\begin{array}{c}14 \\
14.7 \%\end{array}$ & $\begin{array}{c}43 \\
45.3 \%\end{array}$ & $\begin{array}{c}30 \\
31.6 \%\end{array}$ & $\begin{array}{c}5 \\
5.3 \%\end{array}$ & $\begin{array}{c}2 \\
2.1 \%\end{array}$ \\
\hline $\begin{array}{l}\text { 37. Delegating tasks to } \\
\text { inexperienced staff reduces } \\
\text { the quality of the patient care }\end{array}$ & $\begin{array}{c}7 \\
7.4 \%\end{array}$ & $\begin{array}{c}18 \\
18.9 \%\end{array}$ & $\begin{array}{c}44 \\
46.3 \%\end{array}$ & $\begin{array}{c}17 \\
17.9 \%\end{array}$ & $\begin{array}{c}8 \\
8.4 \%\end{array}$ \\
\hline $\begin{array}{l}\text { 38. Writing patient documentation } \\
\text { is time consuming and } \\
\text { reduces the time available to } \\
\text { nurses to provide patient care }\end{array}$ & $\begin{array}{c}33 \\
34.7 \%\end{array}$ & $\begin{array}{c}35 \\
35.8 \%\end{array}$ & $\begin{array}{c}19 \\
20.0 \%\end{array}$ & $\begin{array}{c}5 \\
5.3 \%\end{array}$ & $\begin{array}{c}2 \\
2.1 \%\end{array}$ \\
\hline $\begin{array}{l}\text { 39. Other duties take the nurse } \\
\text { away from providing direct } \\
\text { patient care (See table) }\end{array}$ & $\begin{array}{c}29 \\
30.5\end{array}$ & $\begin{array}{c}36 \\
37.9\end{array}$ & $\begin{array}{c}11 \\
11.6 \%\end{array}$ & $\begin{array}{c}3 \\
3.2 \%\end{array}$ & $\begin{array}{c}2 \\
2.1 \%\end{array}$ \\
\hline $\begin{array}{l}\text { 40. Planned admissions enable } \\
\text { the nurse to organise and } \\
\text { deliver patient care easier }\end{array}$ & $\begin{array}{c}23 \\
24.2 \%\end{array}$ & $\begin{array}{c}24 \\
25.3 \%\end{array}$ & $\begin{array}{c}24 \\
25.3 \%\end{array}$ & $\begin{array}{c}10 \\
10.5 \%\end{array}$ & $\begin{array}{c}2 \\
2.1 \%\end{array}$ \\
\hline $\begin{array}{l}\text { 41. Unplanned admissions } \\
\text { interrupt the nurses organised } \\
\text { care and reduce the level of } \\
\text { patient care achieved in the } \\
\text { shift }\end{array}$ & $\begin{array}{c}9 \\
9.5 \%\end{array}$ & $\begin{array}{c}20 \\
21.1 \%\end{array}$ & $\begin{array}{c}41 \\
43.2 \%\end{array}$ & $\begin{array}{c}14 \\
14.7 \%\end{array}$ & $\begin{array}{c}5 \\
5.3 \%\end{array}$ \\
\hline $\begin{array}{l}\text { 42. A patients relatives can help } \\
\text { organise and deliver the care } \\
\text { required by the patient } \\
\text { reducing the pressure on the } \\
\text { nurses }\end{array}$ & $\begin{array}{c}3 \\
3.2 \%\end{array}$ & $\begin{array}{c}13 \\
13.7 \%\end{array}$ & $\begin{array}{c}50 \\
52.6 \%\end{array}$ & $\begin{array}{c}23 \\
24.2 \%\end{array}$ & $\begin{array}{c}4 \\
4.2 \%\end{array}$ \\
\hline
\end{tabular}




\begin{tabular}{|c|c|c|c|c|c|}
\hline $\begin{array}{c}\text { 43. Visitors and relatives increase } \\
\text { the workload of the nurse and } \\
\text { interrupt how patient care is } \\
\text { organised }\end{array}$ & $\begin{array}{c}12 \\
12.6 \%\end{array}$ & $\begin{array}{c}40 \\
42.1 \%\end{array}$ & $\begin{array}{c}34 \\
35.8 \%\end{array}$ & $\begin{array}{c}7 \\
7.4 \%\end{array}$ & $2.1 \%$ \\
\hline $\begin{array}{c}\text { 44. The layout of the ward } \\
\text { positively influences how } \\
\text { patient care is organised }\end{array}$ & $21.1 \%$ & $38.9 \%$ & $24.2 \%$ & $10.5 \%$ & $3.2 \%$ \\
\hline $\begin{array}{c}\text { 45. Working in geographical areas } \\
\text { in the ward enhances how } \\
\text { nursing care is organised and } \\
\text { delivered }\end{array}$ & 16 & 37 & 21 & 14 & 5 \\
\hline
\end{tabular}

\begin{tabular}{|l|l|}
\hline Free Text answers to Question 39 & No. of Responses \\
\hline Phones & 27 \\
\hline MDT & 15 \\
\hline Bed meetings/managers & 14 \\
\hline Paper work & 12 \\
\hline Meetings & 9 \\
\hline Computer work & 9 \\
\hline Relatives/Visitors & 8 \\
\hline Discharge & 7 \\
\hline Ward rounds & 5 \\
\hline Sickness/off duty & 5 \\
\hline Looking for things (inc Drs.) & 5 \\
\hline Complaints & 5 \\
\hline Clerk duties & 4 \\
\hline bleep & 4 \\
\hline Study days & 3 \\
\hline Staff shortage & 3 \\
\hline Referrals & 3 \\
\hline Management & 3 \\
\hline Visiting hours & 2 \\
\hline Taking blood/ ECG & 2 \\
\hline Patients & 2 \\
\hline
\end{tabular}




\begin{tabular}{|l|l|}
\hline Ordering & 2 \\
\hline Mentoring \& assessing & 2 \\
\hline Drugs check & 2 \\
\hline Appraisals & 2 \\
\hline Tidying up & 1 \\
\hline Teaching & 1 \\
\hline Own caseload & 1 \\
\hline Notes & 1 \\
\hline Independent nursing care & 1 \\
\hline General queries & 1 \\
\hline Communication & 1 \\
\hline
\end{tabular}




\begin{tabular}{|c|c|c|}
\hline $\begin{array}{c}\text { Qualified staff } \\
\text { Ward } 16\end{array}$ & $\begin{array}{c}\text { Qualified staff } \\
\text { Ward } 6\end{array}$ & $\begin{array}{l}\text { Health Care worker } \\
\text { (HCW) Ward } 6\end{array}$ \\
\hline $\begin{array}{l}\text { Direct Patient Care } \\
\text { Medicine administration } \\
\text { Patient menus } \\
\text { Sit up patient / in chair ++ } \\
\text { Re-dress cannula site } \\
\text { Discuss care with team ++ } \\
\text { Get commode for patient +++ } \\
\text { Remove venflon } \\
\text { Remove IVI ++ } \\
\text { Advise patient about fluid } \\
\text { balance } \\
\text { Help patient out of bed } \\
\text { Assist patient taking medication } \\
++++ \\
\text { Assist patient to eat breakfast } \\
\text { Provide bowl for patient } \\
\text { Remove nasal oxygen } \\
\text { Sort out patients clothes } \\
\text { Give patient personal cares } \\
\text { (washes) (x4 10-15 minutes a } \\
\text { patient) } \\
\text { Administer nebuliser }++ \\
\text { Turn patient on opposite site } \\
\text { (pressure area care) } \\
\text { Record patients observations } \\
\text { Answer patient buzzer } \\
\text { Weigh patient } \\
\text { Give patient a drink } \\
\text { Assist co-ordinator with patient } \\
\text { wash in side ward } \\
\text { Lift patient } \\
\text { Assist patients to eat dinner } \\
\text { Encourage patient to feed self } \\
\text { Administer controlled drug }\end{array}$ & 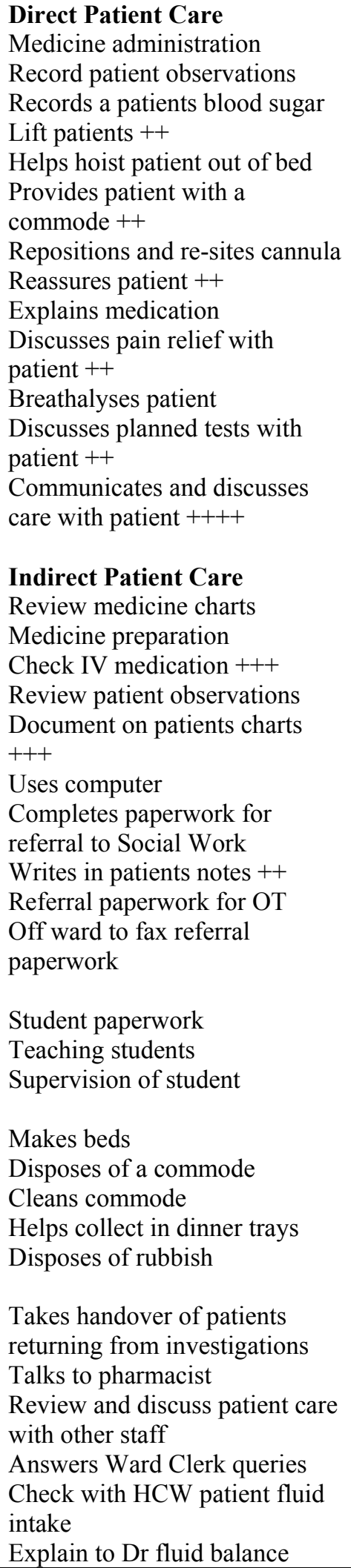 & $\begin{array}{l}\text { Direct Patient Care } \\
\text { Give out patients breakfasts } \\
\text { Help patient on and off } \\
\text { commode / bedpan }++++++ \\
\text { Help patients to eat } \\
\text { Help patients to drink } \\
\text { Give out bowls for washes } \\
\text { Help patients with washes } \\
\text { Two HCWs do all immobile } \\
\text { /dependent patients personal } \\
\text { washes and cares and lift } \\
\text { patients out of bed (x4) } \\
\text { Help patients walking back from } \\
\text { toilet } \\
\text { Give out patient lunches } \\
\text { Empty catheter bag } \\
\text { Lift patients } \\
\text { Indirect Patient Care } \\
\text { Collect in breakfast trays } \\
\text { Dispose of used bowls } \\
\text { Make beds ++++ } \\
\text { Clean chair between moving to } \\
\text { different patient area } \\
\text { Clean bed areas/beds after } \\
\text { discharge } \\
\text { Put pressure relieving mattress } \\
\text { on patients' bed } \\
\text { Find patients notes } \\
\text { Give out trays for lunch } \\
\text { Make drinks for patients } \\
\text { Record urine volume } \\
\text { investigation) } \\
\text { Record fluid intake } \\
\text { Record food intake } \\
\text { Answer phone query and find } \\
\text { answer } \\
\text { Ask Student Nurse to review } \\
\text { patients Pressure area care } \\
\text { during personal cares } \\
\end{array}$ \\
\hline
\end{tabular}




\begin{tabular}{|l|l|l|}
\hline after wash & record \\
Write on patient charts & $\begin{array}{l}\text { Discuss patients IVI } \\
\text { prescription with Dr }\end{array}$ & \\
Paperwork - continuing care & Discussed care of patient with & \\
forms & TVN & \\
Read and write in patients notes & Communicates changes to care \\
++ & of patients advised by TVN to & \\
Files X-rays from patient & Drs \\
returning from investigation & Takes handover of ward round \\
Takes handover of patients & changes from co-ordinator \\
Handover patients to late staff & Sorts out inadequate completed & \\
& blood form by Dr \\
Observes student measuring & Discusses off duty with Sister \\
patients blood sugar & Telephones for pressure \\
Show student how to send off & relieving mattress \\
specimen & Answers phone \\
& Takes call of relatives \\
Hands over patients to physio & Telephones OT to confirm \\
Discuss care with doctors & receipt of referral paperwork \\
Discuss care with district nurse & Speaks to relatives \\
Call relative to inform re & & \\
visiting times & & \\
\end{tabular}

(+++ indicates activity performed on numerous occasions) 
Task Identified

Phone calls

Multi-Disciplinary Team meetings

Bed meetings/managers

Paper work

Meetings (other than bed meetings)

Computer work

Dealing with relatives/visitors

Discharges

Ward rounds

Sickness/off duty

Looking for things (inc Drs.)

dealing with complaints

Carrying out clerk duties

Being the bleep holder

Attending study days

Staff shortages

Making referrals

General management issues

Visiting hours

Carrying out physiological measurement (ECG's etc)

Patients demands

Ordering

Mentoring \& assessing students

Checking drugs

Doing staff appraisals

Tidying up the clinical area

Teaching

Dealing with own caseload

Chasing patient notes

Independent nursing care

dealing with general queries

Communication
No. of Responses

28

15

14

12

9

9

8

7

5

5

5

5

4

4

3

3

3

3

2

2

2

2

2

2

2

1

1

1

1

1

1

1 


\section{Appendix 5 Patient Satisfaction Questionnaire - Results}

\begin{tabular}{|c|c|c|c|c|c|}
\hline & $\begin{array}{l}\text { Strongly } \\
\text { Agree }\end{array}$ & Agree & Unsure & Disagree & $\begin{array}{l}\text { Strongly } \\
\text { Disagree }\end{array}$ \\
\hline \multirow{2}{*}{$\begin{array}{l}\text { 1. One nurse was responsible for my } \\
\text { care throughout my hospital stay }\end{array}$} & 20 & 36 & 47 & 66 & 31 \\
\hline & $9.8 \%$ & $17.6 \%$ & $22.9 \%$ & $32.2 \%$ & $15.1 \%$ \\
\hline \multirow{2}{*}{$\begin{array}{l}\text { 2. I felt that I was involved in decisions } \\
\text { about my care }\end{array}$} & 41 & 84 & 24 & 40 & 10 \\
\hline & $20 \%$ & $41.0 \%$ & $11.7 \%$ & $19.5 \%$ & $4.9 \%$ \\
\hline \multirow{2}{*}{$\begin{array}{l}\text { 3. Sometimes I had to wait for nursing } \\
\text { care }\end{array}$} & 2 & 49 & 15 & 80 & 32 \\
\hline & $9.8 \%$ & $23.9 \%$ & $7.3 \%$ & $39 \%$ & $15.6 \%$ \\
\hline \multirow{2}{*}{$\begin{array}{l}\text { 4. I felt that the nurses always listened } \\
\text { to me }\end{array}$} & 70 & 89 & 13 & 21 & 5 \\
\hline & $34.1 \%$ & $43.4 \%$ & $6.3 \%$ & $10.2 \%$ & $2.4 \%$ \\
\hline \multirow{2}{*}{$\begin{array}{l}\text { 5. Nothing was ever too much trouble } \\
\text { for the nurses }\end{array}$} & 90 & 75 & 16 & 18 & 3 \\
\hline & $43.9 \%$ & $36.6 \%$ & $7.8 \%$ & $8.8 \%$ & $1.5 \%$ \\
\hline \multirow{2}{*}{$\begin{array}{l}\text { 6. I was not always certain which nurse } \\
\text { was looking after me }\end{array}$} & 30 & 71 & 33 & 49 & 14 \\
\hline & $14.6 \%$ & $34.6 \%$ & $16.1 \%$ & $23.9 \%$ & $6.8 \%$ \\
\hline \multirow{2}{*}{$\begin{array}{l}\text { 7. My relatives were kept fully informed } \\
\text { of my progress (with my consent) }\end{array}$} & 58 & 80 & 15 & 26 & 14 \\
\hline & $28.3 \%$ & $39 \%$ & $7.3 \%$ & $12.7 \%$ & $6.8 \%$ \\
\hline \multirow{2}{*}{$\begin{array}{l}\text { 8. I always knew who was in charge of } \\
\text { the ward }\end{array}$} & 35 & 57 & 47 & 44 & 19 \\
\hline & $17.1 \%$ & $27.8 \%$ & $22.9 \%$ & $21.5 \%$ & $9.3 \%$ \\
\hline \multirow[t]{2}{*}{ 9. Sometimes I felt I was invisible } & 12 & 29 & 9 & 97 & 51 \\
\hline & $5.9 \%$ & $14.1 \%$ & $4.4 \%$ & $47.3 \%$ & $24.9 \%$ \\
\hline \multirow{2}{*}{$\begin{array}{l}\text { 10. Ward routine seemed more } \\
\text { important than anything else }\end{array}$} & 14 & 31 & 30 & 92 & 29 \\
\hline & $6.8 \%$ & $15.1 \%$ & $14.6 \%$ & $44.9 \%$ & $14.1 \%$ \\
\hline \multirow{2}{*}{$\begin{array}{l}\text { 11. I was satisfied with the care I } \\
\text { received }\end{array}$} & 91 & 80 & 8 & 16 & 5 \\
\hline & $44.4 \%$ & $39.0 \%$ & $3.9 \%$ & $7.8 \%$ & $2.4 \%$ \\
\hline \multirow{2}{*}{$\begin{array}{l}\text { 12. I could always get information about } \\
\text { my care }\end{array}$} & 66 & 80 & 22 & 28 & 3 \\
\hline & $32.2 \%$ & $39.0 \%$ & $10.7 \%$ & $13.7 \%$ & $1.5 \%$ \\
\hline \multirow[t]{2}{*}{ 13. The ward was well organised } & 61 & 101 & 11 & 24 & 3 \\
\hline & $29.8 \%$ & $49.3 \%$ & $5.4 \%$ & $11.7 \%$ & $1.5 \%$ \\
\hline \multirow{2}{*}{$\begin{array}{l}\text { 14. Sometimes I felt that the nurses } \\
\text { were too busy to deal with me }\end{array}$} & 12 & 41 & 20 & 88 & 36 \\
\hline & $5.9 \%$ & $20 \%$ & $9.8 \%$ & $42.9 \%$ & $17.6 \%$ \\
\hline \multirow{2}{*}{$\begin{array}{l}\text { 15. My preferences for care were } \\
\text { addressed }\end{array}$} & 30 & 91 & 49 & 15 & 1 \\
\hline & $14.6 \%$ & $44.4 \%$ & $23.9 \%$ & $7.3 \%$ & $0.5 \%$ \\
\hline
\end{tabular}




\begin{tabular}{|c|c|c|c|c|c|}
\hline 16. The nurses always had time for me & $\begin{array}{c}50 \\
24.5 \% \\
\end{array}$ & $\begin{array}{c}95 \\
46.3 \% \\
\end{array}$ & $\begin{array}{c}19 \\
9.3 \% \\
\end{array}$ & $\begin{array}{c}28 \\
13.7 \% \\
\end{array}$ & $\begin{array}{c}5 \\
2.4 \% \\
\end{array}$ \\
\hline $\begin{array}{l}\text { 17. I felt as if the nurses formed a } \\
\text { partnership with me }\end{array}$ & $\begin{array}{c}36 \\
17.6 \% \\
\end{array}$ & $\begin{array}{c}82 \\
40.0 \% \\
\end{array}$ & $\begin{array}{c}35 \\
17.1 \% \\
\end{array}$ & $\begin{array}{c}36 \\
17.6 \% \\
\end{array}$ & $\begin{array}{c}5 \\
2.4 \% \\
\end{array}$ \\
\hline $\begin{array}{l}\text { 18. I felt that my concerns about my } \\
\text { health were dismissed as } \\
\text { unimportant }\end{array}$ & $\begin{array}{c}7 \\
3.4 \%\end{array}$ & $\begin{array}{c}20 \\
9.8 \%\end{array}$ & $\begin{array}{c}26 \\
12.7 \%\end{array}$ & $\begin{array}{c}89 \\
43.4 \%\end{array}$ & $\begin{array}{c}51 \\
24.9 \%\end{array}$ \\
\hline $\begin{array}{l}\text { 19. Sometimes the nurses talked about } \\
\text { me but not to me }\end{array}$ & $\begin{array}{c}5 \\
2.4 \% \\
\end{array}$ & $\begin{array}{c}21 \\
10.2 \% \\
\end{array}$ & $\begin{array}{c}36 \\
17.6 \% \\
\end{array}$ & $\begin{array}{c}87 \\
42.4 \% \\
\end{array}$ & $\begin{array}{c}45 \\
22.0 \% \\
\end{array}$ \\
\hline 20. I felt that the nurses liked me & $\begin{array}{c}36 \\
17.6 \% \\
\end{array}$ & $\begin{array}{c}102 \\
49.8 \% \\
\end{array}$ & $\begin{array}{c}43 \\
21.0 \% \\
\end{array}$ & $\begin{array}{c}5 \\
2.4 \% \\
\end{array}$ & $\begin{array}{c}3 \\
1.5 \% \\
\end{array}$ \\
\hline $\begin{array}{l}\text { 21. Sometimes the nurse looking after } \\
\text { me didn't seem to know much } \\
\text { about me }\end{array}$ & $\begin{array}{c}11 \\
5.4 \%\end{array}$ & $\begin{array}{c}33 \\
16.1 \%\end{array}$ & $\begin{array}{c}36 \\
17.6 \%\end{array}$ & $\begin{array}{c}89 \\
43.4 \%\end{array}$ & $\begin{array}{c}24 \\
11.7 \%\end{array}$ \\
\hline $\begin{array}{l}\text { 22. Sometimes I got conflicting } \\
\text { information from the nurses }\end{array}$ & $\begin{array}{r}12 \\
5.9 \% \\
\end{array}$ & $\begin{array}{r}32 \\
15.6 \% \\
\end{array}$ & $\begin{array}{c}26 \\
12.7 \% \\
\end{array}$ & $\begin{array}{c}96 \\
46.8 \% \\
\end{array}$ & $\begin{array}{c}27 \\
13.2 \% \\
\end{array}$ \\
\hline $\begin{array}{l}\text { 23. I felt that I was treated as an } \\
\text { individual }\end{array}$ & $\begin{array}{c}55 \\
26.8 \%\end{array}$ & $\begin{array}{c}87 \\
42.4 \%\end{array}$ & $\begin{array}{c}25 \\
12.2 \%\end{array}$ & $\begin{array}{c}20 \\
9.8 \%\end{array}$ & $\begin{array}{c}6 \\
2.9 \%\end{array}$ \\
\hline
\end{tabular}

24. What did you like best about how the nursing care was organised and delivered to you on the ward? (Free text)

25. What did you not like about how the nursing care was organised and delivered on the ward? (Free text)

26. If you could change an aspect of you nursing care for the better what would it be and why? (Free text)

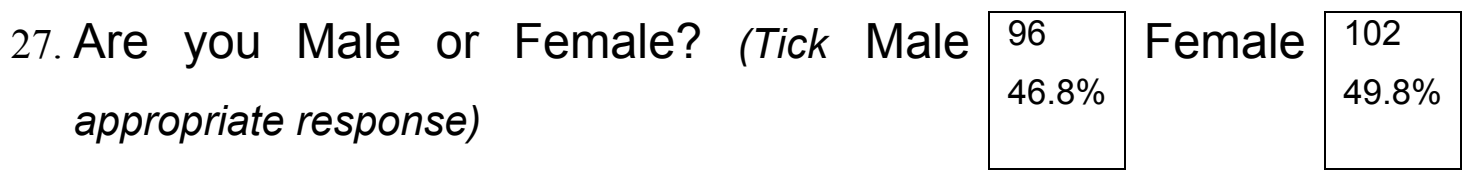

28. How many wards were you nursed on?

29. How long were you in hospital?

days 


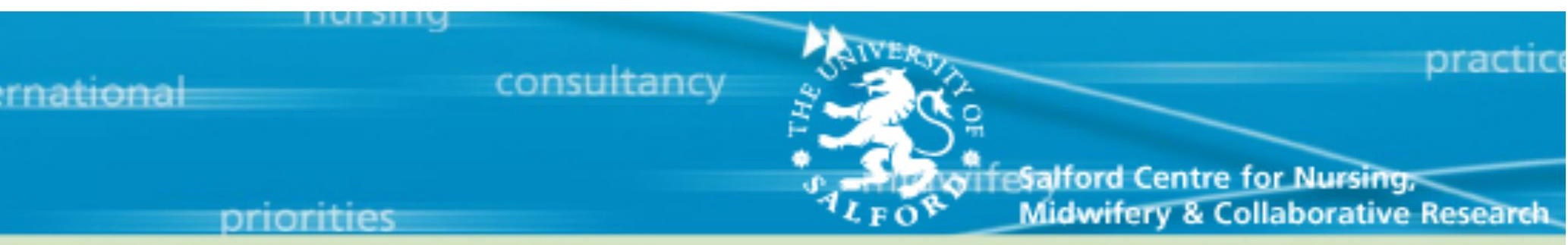

Salford Centre for Nursing, Midwifery and Collaborative Research IHSCR, University of Salford

$7^{\text {th }}$ Floor Allerton Building

Insert ISBN Number here

Frederick Road, Salford

M6 6PU

$\mathrm{T}+44(0) 1612952768$

w.e.moran@salford.ac.uk

www.research.salford.ac.uk/scnmcr/SCNMCR 